\title{
Molecular Thermodynamic Modeling of Fluctuation Solution Theory Properties
}

\author{
O’Connell, John P.; Abildskov, Jens
}

Published in:

Fluctuation Theory of Solutions

Publication date:

2013

Link back to DTU Orbit

Citation (APA):

O'Connell, J.P., \& Abildskov, J. (2013). Molecular Thermodynamic Modeling of Fluctuation Solution Theory Properties. In E. Matteoli, J. P. O'Connell, \& P. E. Smith (Eds.), Fluctuation Theory of Solutions: Applications in Chemistry, Chemical Engineering and Biophysics CRC Press.

\section{General rights}

Copyright and moral rights for the publications made accessible in the public portal are retained by the authors and/or other copyright owners and it is a condition of accessing publications that users recognise and abide by the legal requirements associated with these rights.

- Users may download and print one copy of any publication from the public portal for the purpose of private study or research.

- You may not further distribute the material or use it for any profit-making activity or commercial gain

- You may freely distribute the URL identifying the publication in the public portal

If you believe that this document breaches copyright please contact us providing details, and we will remove access to the work immediately and investigate your claim 


\title{
9. Molecular Thermodynamic Modeling of Fluctuation Solution Theory Properties
}

\author{
John P. O’Connell ${ }^{1}$ and Jens Abildskov ${ }^{2}$ \\ ${ }^{1}$ Department of Chemical Engineering, University of Virginia \\ Charlottesville, VA 22904-4741 USA \\ ${ }^{2}$ CAPEC, Department of Chemical and Biochemical Engineering Building 229, \\ Technical University of Denmark, 2800 Kgs. Lyngby, DK
}




\begin{abstract}
Fluctuation Solution Theory provides relationships between integrals of the molecular pair total and direct correlation functions and the pressure derivative of solution density, partial molar volumes, and composition derivatives of activity coefficients. For dense fluids, the integrals follow a relatively simple corresponding-states behavior even for complex systems, show welldefined relationships for infinite dilution properties in complex and near-critical systems, allow estimation of mixed-solvent solubilities of gases and pharmaceuticals, and can be expressed by simple perturbation models for densities and gas solubilities, including ionic liquids and complex mixtures such as coal liquids. The approach is especially useful in systems with strong nonidealities. This chapter describes successful application of such modeling to a wide variety of systems treated over several decades and suggests how to test Equation of State mixing rules.
\end{abstract}




\subsection{Introduction}

Among the many thermodynamic properties that can be treated by Fluctuation Solution Theory, those for mixtures have had the longest history. Chapter 1 develops the relations from fluctuations in the grand ensemble for partial derivatives of the mole numbers with chemical potentials at fixed temperature, volume, and other chemical potentials in terms of integrals of pair total correlation functions. Matrix inversions and thermodynamic manipulations connect these integrals to partial derivatives of the pressure with respect to mole numbers which are related to the partial molar volume, and derivatives with respect to density, that are related to the isothermal compressibility. Expansions of these properties about infinitely dilute solution were the focus of the seminal paper of Kirkwood and Buff (Kirkwood and Buff 1951), and further works by Buff and coworkers where partial molar energies and heat capacities (Buff and Brout 1955), as well as perturbation theory for corresponding states (Buff and Schindler 1958), were developed. Pearson and Rushbrooke (Pearson and Rushbrooke 1957) further extended the relations by involving the direct correlation function to provide closure relations for correlation function integrals.

After some time, the basic formulation for activities and compressibilities was redone for the whole range of concentrations and for expressions that avoided matrix complexities by involving integrals of direct correlation functions (O’Connell 1971b). It was noted much later that for molecular systems, these relations depended on the applicability of the "weak approximation" for angle-dependent intermolecular forces (Gray and Gubbins 1984; O'Connell 1994). In the absence of molecular simulations, this justified the successful applications of early works that used molecular theory (Gubbins and O'Connell 1974) and practical (Brelvi and O'Connell 1972, 
1975b, 1975a; Brelvi and O'Connell 1975c) perspectives, mainly via corresponding states. This FST approach was extended to correlate densities and activities of supercritical components in liquids and liquid mixtures (Mathias and O’Connell 1979; Mathias and O'Connell 1981; O'Connell 1981; Perry and O'Connell 1984) and of aqueous electrolyte solutions (Cabezas and O’Connell 1986; Cooney and O'Connell 1987; Perry, Cabezas, and O'Connell 1988; O'Connell, $\mathrm{Hu}$, and Marshall 1999). Properties of near- and supercritical systems were also well-described (Campanella, Mathias, and O’Connell 1987; O’Connell, Sharygin, and Wood 1996; Liu and O'Connell 1998; O'connell and Liu 1998; Plyasunov, O'Connell, and Wood 2000; Plyasunov et al. 2000; Sedlbauer, O’Connell, and Wood 2000; Plyasunov et al. 2001; Plyasunov, Shock, and O'Connell 2006). In recent years extensions have been made to ionic liquid systems and to solubilities of solids, such as pharmaceuticals, in mixed solvents (Abildskov, Ellegaard, and O’Connell 2009; Ellegaard, Abildskov, and O'Connell 2009; Abildskov, Ellegaard, and O’Connell 2010a, 2010b; Ellegaard 2011).

The purpose of this chapter is to review these applications of FST methodology for correlating and predicting properties of a wide variety of systems and as a basis for validating equation of state models. Some of the material is already in the previous review monograph (O'Connell 1990), though little of that discussion is repeated here. Since that time, advances have been made in several directions; these are the present focus. Section 9.2 describes applications to pure component and mixture densities, Section 9.3 treats phase equilibria with a focus on dilute solutions, and Section 9.4 describes the use of FST formulations to test EOS models and mixing rules against data for binary TCFIs and DCFIs. 


\subsection{FST Modeling of Pure Component and Mixture Density Dependences on Pressure and}

\section{Composition}

Relations of the integrals of total correlation functions (TCFI) to derivatives for the variations of molar density to pressure can be written for systems of any number of components, as in Section 1.1.6. These involve matrix inverses with all of the pair TCFIs of the system. Section 1.2 gives the full relations for applications to pure, binary and ternary systems. As shown in Section 1.2.3, there is also a set of relations for the derivatives in terms of the DCFI which are somewhat simpler and more direct. There are two modeling objectives with these relations. One is to obtain a solution density at elevated pressures; the other is to obtain the component partial molar volumes for the solution density variations with composition. The next section describes approaches that have been used for both objectives in a wide variety of pure and binary systems.

\subsubsection{Compressibilities}

FST gives relations for the reduced bulk modulus and the partial molar volume of component $i$ to integrals of the total and direct correlation functions (TCFIs and DCFIs) (Section 1.2). The greatest use of this relationship has been for compressed liquids where the TCFI and DCFI show simple corresponding states dependence on density with weak temperature dependence (Brelvi and O'Connell 1972, 1975b, 1975a; Mathias and O'Connell 1979; Mathias and O'Connell 1981; Campanella, Mathias, and O'Connell 1987; Huang and O'Connell 1987; Abildskov, Ellegaard, and O'Connell 2010a). In terms of DCFIs, the expression is,

$$
\left(\frac{\partial \beta p}{\partial \rho}\right)_{T,\{x\}}=\sum_{i=1}^{n_{c}} x_{i} \sum_{j=1}^{n_{c}} x_{j}\left[1-C_{i j}(T,\{\rho\})\right]
$$

The general expression for TCFIs involves matrix inverses. For pure components, Equation 9.1 
becomes Equation 1.65 of Section 1.3.1, which is simple for TCFIs,

$$
1 / \rho \kappa_{T} k_{B} T=1-C=1 /(1+\rho G)
$$

Following the initial approach of Brelvi (Brelvi and O'Connell 1972) for $(1-C)$, the most comprehensive corresponding states correlation was by Huang (Huang and O'Connell 1987) where $C$, scaled by a characteristic parameter $C^{*}$, is correlated by polynomials in $\rho$, scaled by $V^{*}$, and $T$, scaled by $T^{*}$,

$$
C=C * \sum_{i=0}^{3} \sum_{j=0}^{2} a_{i j}\left(\rho V^{*}\right)^{i}(\tau)^{j}
$$

where $\tau=T / T^{*}$, which is always less than unity. The parameters $C^{*}, V^{*}$, and $T^{*}$ are given for many substances by Huang (Huang and O’Connell 1987) and Poling, et al. (Poling, Praunitz, and O'Connell 2000) as well as for ionic liquids by Abildskov, et al. (Abildskov, Ellegaard, and O'Connell 2010a). The correlation has been applied to mixtures by employing mixing rules for $V^{*}$ and $T^{*}$. An atomic group contribution method was also established (Huang and O'Connell 1987). Figure 9.1 shows the behavior of the scaled DCFI. Note that there is essentially no temperature dependence of $C / C^{*}$ when $\rho V^{*}$ is less than 1.0 , about 2.5 times the critical density. Close inspection shows there is a crossover of the isotherms near $\rho V^{*}=0.93$ (Huang and O’Connell 1987).

[Inert Figure 9.1]

An alternative corresponding states model for DCFI formulates a perturbation about hard spheres, with an added term linear in density. This approach has been used successfully for organic substances (Mathias and O'Connell 1981; Campanella, Mathias, and O'Connell 1987) and also for ionic liquids (Abildskov, Ellegaard, and O'Connell 2010a), 


$$
1-C_{i j}=\left(1-C_{i j}\right)^{h s}+\rho\left\{2 V_{i j}^{*} \tilde{b}\left(T / T_{i j} *\right)-\left[V_{i i}^{*} \tilde{b}^{h s}\left(T / T_{i i} *\right)+V_{j j}^{*} \tilde{b}^{h s}\left(T / T_{j j}\right)\right]\right\}
$$

The reduced covolumes, $\tilde{b}$ and $\tilde{b}^{\text {hs }}$, are generalized functions of reduced temperature and multiplied by a characteristic volume, $V^{*}$. Expressions for the hard-sphere DCFI of Equation 9.4 are given by Mathias (O’Connell 1981) and Campanella, et al. (Campanella, Mathias, and O’Connell 1987). Abildskov, et al. (Abildskov, Ellegaard, and O'Connell 2010a) give the most recent correlations for the hard-sphere diameters and linear-density coefficients as functions of reduced temperature. Ionic liquid characteristic parameters for Equations 9.3 and 9.4 are listed in along with group contribution characteristics for ILs (Abildskov, Ellegaard, and O'Connell 2010a).

Comparisons of these correlations with experiment are given in the next section. "Experimental" compressibilities are typically values manipulated from densities measured at discrete pressures, so direct comparisons of densities of compressed fluids are more reliable than compressibilities.

\subsubsection{Pure component and solution densities}

The pressure dependence of liquid densities can be obtained by isothermal integration of Equation 9.1 over a change in density from a reference state, $\rho^{0}, p^{0}, T$, and $\{x\}$, such as ambient or saturated, to the desired state, $p, T$, and $\{x\}$. In terms of the DCFIs, for which most applications have been made,

$$
\frac{p(T, \rho,\{x\})-p\left(T, \rho^{0},\{x\}\right)}{k_{B} T}=\int_{x_{i} \rho^{0}}^{x_{i} \rho} \sum_{i=1}^{n_{c}} x_{i} \frac{\overline{V_{i}}}{k_{B} T \kappa_{T}} d \rho_{i}=\int_{x_{i} \rho^{0}}^{x_{i} \rho} \sum_{i=1}^{n_{c}} x_{i}\left(\left.\sum_{j=1}^{n_{c}} x_{j}\left[1-C_{i j}\left(T, \rho_{i}\right)\right]\right|_{T,\{x\}}\right) d \rho_{i} 9.5
$$

A general integration procedure for these relations is described by O'Connell (O'Connell 1981; 
O'Connell 1994; O'Connell 1995), though for models of the forms 9.3 and 9.4, analytic relations exist. The equations below are given by Abildskov, et al. (Abildskov, Ellegaard, and O'Connell 2009).

For Equation 9.3, the pressure difference can be solved iteratively to obtain $\rho$,

$$
\begin{aligned}
& \frac{p(T, \rho)-p^{0}\left(T, \rho^{0}\right)}{R T}=\left[1-C^{*} b_{1}(\tilde{T})\right]\left(\rho-\rho^{0}\right) \\
& -C *\left[b_{2}(\tilde{T}) V * \frac{\rho^{2}-\left(\rho^{0}\right)^{2}}{2}+b_{3}(\tilde{T}) V *^{2} \frac{\rho^{3}-\left(\rho^{0}\right)^{3}}{3}+b_{4}(\tilde{T}) V^{* 3} \frac{\rho^{4}-\left(\rho^{0}\right)^{4}}{4}\right]
\end{aligned}
$$

where the coefficients $b_{i}(\tilde{T})$ are combinations of those in Equation 9.3 and are listed by Abildskov, et al. (Abildskov, Ellegaard, and O'Connell 2009). It should be noted that predictions of pressure/density differences, such as done here, are much more accurate than those that attempt to obtain high-pressure densities directly, since errors in estimation of the reference density, $\rho^{0}$, a quantity that is normally easy to measure, are eliminated.

A worked example of this correlation is described in Section 4-12 of (Poling, Praunitz, and O’Connell 2000). Parameters for many substances are given by O'Connell (O’Connell 1990; O’Connell 1995) and Huang (Huang and O'Connell 1987). For densities greater than twice the critical density, the accuracy is extremely good for a wide variety of substances.

Figure 9.2 shows pressures computed at measured densities at different temperatures for the ionic liquid $\left[\mathrm{C}_{1} \mathrm{C}_{2} \operatorname{Im}\right]\left[\mathrm{Tf}_{2} \mathrm{~N}\right]$ using the correlation of Equation 9.6 (Abildskov, Ellegaard, and O'Connell 2010a). The agreement is normally better than comparable methods (Paduszynski and Domanska 2012). Figure 9.2 shows that the measurements by different workers (Gardas et 
al. 2007; Jacquemin et al. 2007) are different for both the reference densities and compressibilities, since the low pressure intercepts and the slopes of the lines are not the same. While the correlation cannot distinguish which reference density might be correct, the lines associated with the calculations suggest that the compression data of Gardas, et al. (Gardas et al. 2007) may be more reliable at lower temperatures, though they are between the slopes from the data at higher $T$.

[Insert Figure 9.2]

The relations based on Equation 9.4 from (Abildskov, Ellegaard, and O'Connell 2010a) are,

$$
\frac{p-p^{0}}{k_{B} T}=\left(\frac{p^{h s}}{k_{B} T}\right)-\left(\frac{p^{h s}}{k_{B} T}\right)^{0}+\sum_{i=1}^{n_{c}} \sum_{j=1}^{n_{c}}\left(x_{j} x_{i} \rho^{2}-x_{i}^{0} x_{j}^{0} \rho^{02}\right)\left(b_{i j}-b_{i j}^{h s}\right)
$$

For pure components, this becomes,

$$
\frac{p-p^{0}}{k_{B} T}=\left(\frac{p^{h s}}{k_{B} T}\right)-\left(\frac{p^{h s}}{k_{B} T}\right)^{0}+\left(\rho^{2}-\rho^{02}\right)\left(b_{i i}-b_{i i}^{h s}\right)
$$

where the $h s$ expressions are given below. The elements of the $n_{c} \times n_{c}$ matrix $\boldsymbol{b}$ are calculated

using,

$$
b_{i j}=\tilde{b}_{i j} V_{i j}^{*}
$$

with,

$$
\tilde{b}_{i j}=c_{1}+\frac{c_{2}}{\tilde{T}_{i j}}+\frac{c_{3}}{\tilde{T}_{i j}^{2}}+\frac{c_{4}}{\tilde{T}_{i j}^{3}}+\frac{c_{5}}{\tilde{T}_{i j}^{8}}
$$

and the set of $\{c\}$ values is,

$$
c^{T}=\left\{\begin{array}{llllll}
0.3625065 & -0.7140666 & -1.7543882 & 0.47075 & -0.0041793
\end{array}\right\}
$$

The characteristic $V_{i j}{ }^{*}$ of Equation 9.9 is, 


$$
V_{i j}^{*}=\frac{\left(\sqrt[3]{V_{i}^{*}}+\sqrt[3]{V_{j}^{*}}\right)^{3}}{8}
$$

while the characteristic $\tilde{T}_{i i}$ for Equation 9.10 when $i \neq j$ is,

$$
\tilde{T}_{i j}=\frac{T}{\left(1-k_{i j}\right) \sqrt{T_{i i}^{*} T_{j j}^{*}}}
$$

The hard-sphere terms are,

$$
\left(\frac{p^{h s}}{R T}\right)=\frac{6}{\pi}\left(\frac{\xi_{0}}{1-\xi_{3}}+\frac{3 \xi_{1} \xi_{2}}{\left(1-\xi_{3}\right)^{2}}+\frac{\left(\xi_{2}\right)^{3}\left(3-\xi_{3}\right)}{\left(1-\xi_{3}\right)^{3}}\right)
$$

The hard-sphere quantities are,

$$
\begin{array}{rlrl}
\xi_{q} & =\frac{\pi}{6} \sum_{j=1}^{n_{c}} \rho_{j} \sigma_{j}^{q}=\frac{\pi}{6} \rho \sum_{j=1}^{n_{c}} x_{j} \sigma_{j}^{q} \quad ; & q & =0,1,2,3 \\
\xi_{q}^{0}=\frac{\pi}{6} \sum_{j=1}^{n_{c}} \rho_{j}^{0} \sigma_{j}^{q}=\frac{\pi}{6} \rho^{0} \sum_{j=1}^{n_{c}} x_{j}^{0} \sigma_{j}^{q} & ; & q=0,1,2,3
\end{array}
$$

where,

$$
\sigma_{i}=\sqrt[3]{\frac{3}{2 \pi} b_{i i}^{h s}}
$$

For a pure component, 9.14 becomes,

$$
\left(\frac{p^{h s}}{R T}\right)=\frac{6}{\pi}\left(\frac{\xi}{1-\xi}+\frac{3 \xi}{(1-\xi)^{2}}+\frac{(\xi)^{2}(3-\xi)}{(1-\xi)^{3}}\right)
$$

and Equation 9.15 plus Equation 9.16 give,

$$
\xi=\frac{1}{2} b_{i i}^{h s}
$$

The elements of the $n_{c} \times n_{c}$ matrix $\boldsymbol{b}^{h s}$ in Equation 9.7 are calculated with the following equations, 


$$
\begin{gathered}
b_{i j}^{h s}=\frac{b_{i i}^{h s}+b_{j j}^{h s}}{2} \\
b_{i i}^{h s}=V_{i}^{*} \tilde{b}_{i i}^{h s} \quad, \quad \tilde{b}_{i i}^{h s}=\left\{\begin{array}{cc}
\frac{\alpha_{1}}{\tilde{T}_{i}^{\alpha_{2}}} & \tilde{T}_{i}=\frac{T}{T_{i}^{*}}>0.73 \\
\beta_{1} e^{\beta_{2} \tilde{T}_{i}} & \tilde{T}_{i}=\frac{T}{T_{i}^{*}}<0.73
\end{array}\right.
\end{gathered}
$$

where the sets of constants $\{\alpha\}$ and $\{\beta\}$ are,

$$
\alpha=\left\{\begin{array}{l}
0.65386227 \\
0.16067976
\end{array}\right\} \quad, \quad \beta=\left\{\begin{array}{l}
0.807662393 \\
-0.22010926
\end{array}\right\}
$$

Though the forms of all the other equations are the same, the values used in Equation 9.11 and 9.21 by Mathias and O’Connell (Mathias and O'Connell 1981) and Campanella, et al. (Campanella, Mathias, and O’Connell 1987) differ somewhat from those developed by Abildskov, et al. (Abildskov, Ellegaard, and O’Connell 2009) and Ellegaard, et al. (Ellegaard, Abildskov, and O'Connell 2011) which were revised to more successfully correlate the properties of ionic liquids. Those given here are from Campanella (Campanella, Mathias, and O’Connell 1987). As in Equation 9.6, the pressure difference is analytic in reduced density and temperature, providing a solution for $\rho$ at a specified $p$ or for $p$ at a specified $\rho$.

\subsubsection{Partial Molar Volumes}

There is a direct FST connection of partial molar volumes of components in solution to DCFI,

$$
\left(\frac{\partial \beta p V}{\partial N_{i}}\right)_{T, V, N_{j \neq i}}=\frac{\overline{V_{i}}}{k_{B} T \kappa_{T}}=\sum_{j=1}^{n_{c}} x_{j}\left[1-C_{i j}(T,\{\rho\})\right]
$$

This relation has a number of aspects that lead to successful correlations, including in the near- 
critical region where $\bar{V}_{i}^{\infty}$ may diverge (O’Connell 1994; O'Connell and Liu 1998; Plyasunov, O'Connell, and Wood 2000; Plyasunov et al. 2000; Sedlbauer, O'Connell, and Wood 2000; Plyasunov et al. 2001; Plyasunov, Shock, and O’Connell 2006). It also gives a correction about a misinterpretation of the pressure dependence of gas solubility (Mathias and O'Connell 1979; Mathias and O'Connell 1981; O'Connell 1981), and notes errors in the values of partial molar volumes of gases from supercritical fluid chromatography (Liu and O'Connell 1998). The practical range of dilute solution compositions where a property is independent of the component's concentration, or is effectively at infinite dilution, depends on the property and the desired accuracy. Composition sensitivity is greater for activity coefficients than for partial molar volumes and enthalpies. This section describes several aspects of partial molar volume modeling, focusing on infinitely dilute solutions and the near-critical region.

\subsubsection{Partial Molar Volumes at Infinite Dilution}

For dilute solutions, the volume of a dilute binary solution might be approximated as,

$$
V_{m}\left(T, p, x_{1}\right) \approx\left(1-x_{2}\right) \bar{V}_{1}^{o}+x_{2} \bar{V}_{2}^{\infty} \quad x_{2}<0.1
$$

Under this assumption, Equation 9.22 for a binary becomes,

$$
\lim _{N_{2} \rightarrow 0}\left(\frac{\partial \beta p V}{\partial N_{2}}\right)_{T, V, N_{1}}=\frac{\bar{V}_{2}^{\infty}}{k_{B} T \kappa_{T, 1}^{o}} \equiv A_{K r}=1-C_{12}^{\infty}\left(T, \rho_{1}^{o}\right)
$$

The ratio of properties in 9.24 is called the Krichevskii function, $A_{K r}$, and identified at the solvent critical point as the Krichevskii parameter (Levelt Sengers 1991). The first FST correlation for partial molar volumes of gases in liquids was done by Brelvi (Brelvi and O’Connell 1975c), using characteristic properties for his correlation of the reduced bulk modulus (Brelvi and O’Connell 1972). Recent work (Ellegaard, Abildskov, and O'Connell 2011) has used the form 
of Equation 9.4 for partial molar volumes of gases in ILs. The comparisons with data for these systems seem not to be as successful as for their compressibilities and phase equilibria, for reasons that are not apparent.

For systems far from the critical point of component 1 , the value of $\bar{V}_{2}^{\infty}$ is relatively small and positive. However, Cooney and O'Connell (Cooney and O'Connell 1987) noted that the variation with pressure of $\bar{V}_{i}^{\infty}$ for aqueous salts, even at conditions approaching the critical where $\bar{V}_{2}^{\infty}$ is negative, could be successfully correlated with water density and requiring temperature dependence only below $100{ }^{\circ} \mathrm{C}$. This was followed by recognizing from data as well as theory, that $A_{K r}$ for aqueous nonelectrolytes is well-behaved from ambient conditions through the critical region, even though as $T \rightarrow T_{c 1}, \bar{V}_{2}^{\infty}$ diverges strongly (Levelt Sengers 1991). Typically, if $T_{c 1}>T_{c 2}$, such as for volatile nonelectrolytes (Hnědkovský, Majer, and Wood 1995), $\bar{V}_{2}^{\infty} \rightarrow \infty$, while for $T_{c 1}<T_{c 2}$, such as for inorganics (Hnědkovský, Wood, and Majer 1996) and salts (Sedlbauer, O'Connell, and Wood 2000), $\bar{V}_{2}^{\infty} \rightarrow-\infty$. The heat capacity at infinite dilution, $\bar{C}_{p}^{\infty}$, also diverges for all systems (see Figure 9.8 below). However, since $A_{K r}$ is only very weakly divergent (Levelt Sengers 1991), $1-C_{12}^{\infty}$ is well-behaved over essentially all experimentally accessible conditions. In fact, data over wide ranges of density show that $A_{K r}$, like pure component DCFI, is virtually independent of temperature for both nonelectrolytes and electrolytes (O’Connell 1995; O'Connell, Sharygin, and Wood 1996). For example, Figure 9.3 shows the variation of $A_{K r}$ from experiment for several small solutes in water for wide ranges of temperature and density along with the correlation,

$$
A_{K r}=1+a_{1} \rho+a_{2}[\exp (c \rho)-1]
$$


where $a_{1}$ and $a_{2}$ are solute-dependent parameters and $c$ is a universal constant ( $\mathrm{O}^{\prime}$ Connell, Sharygin, and Wood 1996).

[Insert Figure 9.3]

Further investigations have shown the generality of this behavior. Both Plyasunov (Plyasunov et al. 2001; Plyasunov 2011) and Majer, et al. (Majer, Sedlbauer, and Bergin 2008) have studied volumetric and phase behavior of many aqueous systems and developed group contribution methods for a large variety of nonelectrolytes in water at extreme conditions. This behavior has led to extensive models for thermodynamic properties and phase behavior of dilute aqueous systems (Plyasunov, O'Connell, and Wood 2000; Plyasunov et al. 2000; Sedlbauer, O'Connell, and Wood 2000; Plyasunov et al. 2001; Plyasunov, Shock, and O’Connell 2006; Majer, Sedlbauer, and Bergin 2008; Plyasunov 2011). Details of these models are described below.

\subsubsection{Partial molar volumes at finite concentrations}

One issue associated with the above systems is defining the mole fraction of solute where infinite dilution is no longer a satisfactory assumption. Liu (Liu and O'Connell 1998; O'connell and Liu 1998) investigated this in the context of supercritical chromatography measurements for partial molar volumes. Expanding the DCFI in solute mole fraction about infinite dilution shows that first-order terms can be significant even at mole fractions of the order of $10^{-3}$. This suggests that common conditions and literature treatments of data could be unreliable. The analysis was extended to solubilities in supercritical fluids, noting that at least one set of data did not display the required thermodynamic consistency for phase equilibria and volumetric behavior. 


\subsection{FST Modeling of Phase Equilibria Involving Dilute Solutions}

Issues in dilute solution modeling have been discussed extensively (Cabezas and O'Connell 1993). The application of FST to these systems provides a powerful method for both solution nonidealities and densities as shown in the above sections, by integrating the FST partial derivatives of chemical potential from a reference state to a solution state. The most successful cases have been for solutions with strong nonidealities such as for supercritical gas components (Mathias and O'Connell 1981; Campanella, Mathias, and O'Connell 1987; O'connell and Liu 1998; Plyasunov, O’Connell, and Wood 2000; Plyasunov et al. 2000; Sedlbauer, O'Connell, and Wood 2000; Plyasunov et al. 2001; Plyasunov, Shock, and O’Connell 2006) and for solids in liquids (Ellegaard, Abildskov, and O'Connell 2009; Abildskov, Ellegaard, and O'Connell 2010a, 2010b; Ellegaard 2011). Also, FST formulations give the basis for correlations used for supercritical extraction of solids into near-critical solvents (Liu and O'Connell 1998; O'connell and Liu 1998). The usual form is done with fugacities rather than chemical potentials since complexities of the latter at infinite dilution are eliminated (see Section 1.1.4).

\subsubsection{Models based on activity coefficients}

The thermodynamic formulation of the fugacities in a binary appropriate for dilute solutions is,

$$
\begin{aligned}
& f_{1}=\left(1-x_{2}\right) \gamma_{1} f_{1}^{0} \\
& f_{2}=x_{2} \gamma_{2}^{*} H_{21}
\end{aligned}
$$

where $\lim _{x_{1} \rightarrow 1} \gamma_{1}=1$ and $\lim _{x_{1} \rightarrow 1} \gamma_{2}^{*}=1$ and $H_{21}$ is Henry's constant or the fugacity of the hypothetical pure component 2 in a state consistent with linear mole fraction dependence at infinite dilution, 
and $f_{1}{ }^{0}$ is the fugacity of pure component 1 in its standard state. The property $\gamma_{2}^{*}$ is the activity coefficient, related to the excess chemical potential, in the "unsymmetric convention" (Prausnitz, Lichtenthaler, and Gomes de Azevedo 1999). See below for dealing with mixed solvents.

Kirkwood and Buff (Kirkwood and Buff 1951) included expressions for $\gamma_{2}^{*}$ in single solvents from a Taylor's series expansion in solute mole fraction. The coefficients were collections of infinite-dilution (pure component 2) pair KBIs at the first order and pair and triplet KBIs at the second order. The form used for applications is,

$$
\ln \gamma_{2}^{*}=\Delta_{12}^{0}\left(-2 x_{2}+x_{2}^{2}\right)+\Delta_{112}^{0} x_{2}^{3}+\ldots
$$

The Gibbs-Duhem Equation gives,

$$
\ln \gamma_{1}=\Delta_{12}^{0} x_{2}^{2}+\ldots
$$

O'Connell (O'Connell 1971a) also gave these formulae in terms of direct correlation function integrals with,

$$
\Delta_{12}^{0}=\frac{1}{2}\left[\left(1-C_{11}^{0}\right)-\frac{\left(1-C_{12}^{0}\right)^{2}}{\left(1-C_{22}^{0}\right)}\right]
$$

and an equivalent for $\Delta_{112}^{0}$ in terms of pair and triplet DCFI. Expressions were also given for the partial molar volumes and the reduced bulk modulus to lowest order of the expansion in mole fraction. It is expected that this correlation, with an empirical value of $\Delta_{12}^{0}$, would be adequate up to solute mole fractions of $x_{2} \sim 0.1$. Brelvi (Brelvi and O'Connell 1975c) developed a correlation for $\Delta_{12}^{0}$ in the spirit of his prior work (Brelvi and O'Connell 1972).

If models for TCFIs or DCFIs are available, the complete expression for both $\ln \gamma_{1}$ and $\ln \gamma_{2}^{*}$ can 
be obtained through appropriate integration. The expression is simpler for DCFIs,

$$
\ln \gamma_{i}^{*}=\sum_{j=1}^{n_{c}} \int_{x_{j}^{0} \rho^{0}}^{x_{j} \rho} \frac{\left[1-C_{i j}\left(T, \rho_{i}\right)\right]}{\rho} d \rho_{j}
$$

If the solution state is specified by pressure rather than density, the same model for DCFI is used in both Equations 9.5 and 9.30 to obtain $\rho$ and $\gamma_{1} *$ for a specified state of $T, p$, and $\{x\}$ relative to the state $T, p^{0}, \rho^{0}$, and $\left\{x^{0}\right\}$ where $\gamma_{2} *$ is unity. The methodology for this approach is fully described by O’Connell (O’Connell 1981; O’Connell 1994; O’Connell 1995).

This method was used for gas solubility and solution densities of liquids by Mathias and O'Connell (Mathias and O'Connell 1979; O'Connell 1981) and expanded by Campanella, et al. (Campanella, Mathias, and O'Connell 1987) for a wide variety of systems including hydrocarbons, organics, and aqueous solvents. The method has recently been extended by Ellegaard et al. (Ellegaard, Abildskov, and O'Connell 2009) and Abildskov et al. (Abildskov, Ellegaard, and O'Connell 2010b) for use in IL systems. For a model of the form of Equation 9.4, this becomes,

$$
\ln \gamma_{i}\left(T, \rho,\{x\} ; \rho^{0},\{x\}^{0}\right)=\ln \gamma_{i}^{h s}\left(T, \rho,\{x\} ; \rho^{0},\{x\}^{0}\right)+2 \sum_{j=1}^{n_{c}}\left(x_{j} \rho-x_{j}^{0} \rho^{0}\right)\left(b_{i j}-b_{i j}^{h s}\right)
$$

where, 


$$
\begin{aligned}
& \ln \gamma_{i}^{h s}\left(T, \rho,\{x\} ; \rho^{0},\{x\}^{0}\right)= \\
& {\left[\begin{array}{l}
\ln \rho-\left[\ln \left(1-\xi_{3}\right)\right]\left[1-\left(\frac{\xi_{2} \sigma_{i}}{\xi_{3}}\right)^{2}\left(3-2 \frac{\xi_{2} \sigma_{i}}{\xi_{3}}\right)\right] \\
+\frac{3\left(\xi_{2} \sigma_{i}+\xi_{1} \sigma_{i}^{2}\right)-\left(\xi_{2} \sigma_{i}\right)^{3}\left(2-\xi_{3}\right) / \xi_{3}^{2}}{1-\xi_{3}}+\frac{3}{\xi_{3}}\left(\frac{\xi_{2} \sigma_{i}}{1-\xi_{3}}\right)^{2}+\frac{\pi}{6} \sigma_{i}^{3} \frac{p^{h s}}{R T}
\end{array}\right]} \\
& -\left[\begin{array}{c}
\ln \rho^{0}-\left[\ln \left(1-\xi_{3}^{0}\right)\right]\left[1-\left(\frac{\xi_{2}^{0} \sigma_{i}}{\xi_{3}^{0}}\right)^{2}\left(3-2 \frac{\xi_{2}^{0} \sigma_{i}}{\xi_{3}^{0}}\right)\right] \\
+\frac{3\left(\xi_{2}^{0} \sigma_{i}+\xi_{1}^{0} \sigma_{i}^{2}\right)-\left(\xi_{2}^{0} \sigma_{i}\right)^{3}\left(2-\xi_{3}^{0}\right) /\left(\xi_{3}^{0}\right)^{2}}{1-\xi_{3}^{0}}+\frac{3}{\xi_{3}^{0}}\left(\frac{\xi_{2}^{0} \sigma_{i}}{1-\xi_{3}^{0}}\right)^{2}+\frac{\pi}{6} \sigma_{i}^{3}\left(\frac{p^{h s}}{R T}\right)^{0}
\end{array}\right]
\end{aligned}
$$

There are two aspects of this treatment that are significant. First, one or more binary constants are used in models such as Equation 9.4, e.g., in Equation 9.13. Therefore, when Equation 9.46 (?) is taken to the limit of pure solvent 3, there is a relation between the Henry's Constants,

$$
\lim _{x_{3} \rightarrow 1} \ln \gamma_{2}^{*}=\ln \left(\frac{H_{2 R}}{H_{23}}\right)=\int_{\rho_{\text {pure } R}}^{0} \frac{\left.\left[1-C_{2 R}(T,\{\rho\})\right]\right|_{d}}{\rho}+\int_{0}^{\rho_{\text {pure } 3}} \frac{\left[1-C_{23}(T,\{\rho\})\right] \mid}{\rho} d \rho_{3}
$$

Therefore, if the binary constant, $k_{2 R}$ is set or determined from experiment, Equation 9.33 determines $k_{23}$. Second, this also means that one can predict solute solubility in a solvent $i$ from that in a convenient reference solvent, $R$,

$$
\begin{aligned}
& f_{i}=\left(1-x_{2}\right) \gamma_{i} f_{i}^{0} \\
& f_{2}=x_{2} \gamma_{2}^{+} H_{2 R}
\end{aligned}
$$

with,

$$
\lim _{x_{R} \rightarrow 1} \ln \gamma_{2}^{+}=1
$$

Here,

$$
\ln \gamma_{2}^{+}=\int_{\rho_{\text {pure } R}}^{x_{R} \rho} \frac{\left[1-C_{2 R}(T,\{\rho\})\right] \mid}{\rho} d \rho_{R}+\int_{0}^{x_{3} \rho} \frac{\left[1-C_{23}(T,\{\rho\})\right]}{\rho} d \rho_{3}
$$


Examples of using this with good success for hydrogen in different solvents, including for model coal liquids, based on a single reference solvent are given by Campanella, et al. (Campanella, Mathias, and O'Connell 1987) and O'Connell (O’Connell 1995). Treatment of complex mixed solvents, including for actual coal liquids, is also described in those references. This concept also works quite well for ILs (Abildskov, Ellegaard, and O’Connell 2009; Ellegaard, Abildskov, and O'Connell 2010).

Figure 9.4 shows predictions of pressure versus liquid mole fraction for the methane (1) and mcresol system where the Henry's Constant of Equation 9.26 was obtained from fitting data directly (solid lines) or predicted with quinolone (dashed lines) as the reference solvent in Equation 9.34. As the arrows show, the prediction is not uniformly accurate in this case. Better results have been obtained with other solutes, especially hydrogen, nitrogen, and carbon monoxide, including mixed solvents, as shown by Campanella, et al. (Campanella, Mathias, and O’Connell 1987). Figures 9.5 and 9.6 show similar results for a system containing hydrogen and an ionic liquid (Abildskov, Ellegaard, and O’Connell 2009).

[Insert Figure 9.4, 9.5 and 9.6]

\subsubsection{Models based on equations of state}

For infinitely dilute solutions, the temperature independence of $A_{K r}$ at higher densities leads to the Henry's Constant of Equation 9.26 by integrating Equation 9.24. The relations are,

$$
\ln \left(\frac{\beta \varphi_{2}^{\infty} p}{\rho_{1}^{o}}\right)=\int_{0}^{\rho_{1}^{o}}\left(A_{K r}-1\right) \frac{d \rho}{\rho}
$$

From this relation, a formulation can be made in terms of the infinite dilution properties of 
hydration for water as the solvent, such as the difference of Gibbs energies between the fluid at the designated reference pressure, $p^{0}$, and the infinitely dilute solute at $p$,

$$
\Delta_{h} G_{2}^{\infty}(T, p)=R T\left[\ln \frac{\varphi_{2}^{\infty} p}{p^{0}}\right]
$$

This yields Henry's constants via,

$$
H_{21}(T, p)=\exp \left[-\Delta_{h} G_{2}^{\infty}(T, p) / R T\right]
$$

Standard thermodynamic manipulations yield the infinite dilution enthalpy, entropy, and isobaric heat capacity of hydration (Plyasunov, O'Connell, and Wood 2000; Sedlbauer, O'Connell, and Wood 2000). For example,

$$
\Delta_{h} C_{p, 2}^{\infty}=-T^{2}\left(\frac{d^{2} \Delta_{h} G_{2}^{\infty} / T}{d T^{2}}\right)
$$

The issues are how to utilize known solution information at low temperatures and pressures that do depend on $T$ and to express the properties at conditions below the critical temperature where there is temperature dependence of $A_{K r}$. This approach need not be limited to aqueous systems, but those are the only ones which have been treated.

The first approach (Plyasunov, O'Connell, and Wood 2000) was to augment the high density function of Equation 9.25 with temperature-dependent correlations of cross $\left(B_{12}\right)$ and pure solvent $\left(B_{11}\right)$ second virial coefficients to include the low density behavior for the integral of Equation 9.37. An analytically integrable form was adopted:,

$$
\begin{gathered}
A_{K r}=\left(1-\alpha_{1}\right)+\alpha_{1}\left[\left(1-C_{11}^{0}\right)\right]+2 \rho\left\{B_{12}(T)-B_{11}(T)\right\} \exp \left(k_{1} \rho\right) \\
+\rho\left(\frac{\alpha_{2}}{T^{5}}+\alpha_{3}\right)\left[\exp \left(k_{2} \rho\right)-1\right]
\end{gathered}
$$

where values of $B_{11}$ and $B_{12}$ are obtained from the square-well potential model, $k_{1}$ and $k_{2}$ are 
universal constants, and $\alpha_{1}, \alpha_{2}$, and $\alpha_{3}$ are solute-dependent parameters. The full final relations of Equations 9.37 to 9.40 are given by Plyasunov, et al. (Plyasunov et al. 2000). These have been used to obtain infinite dilution thermodynamic properties of many organic substances in water (Plyasunov et al. 2001; Plyasunov, Shock, and O’Connell 2006). Figure 9.7 shows results for $\mathrm{H}_{2} \mathrm{~S}$ in water at various pressures and temperatures.

[Insert Figure 9.7]

The alternative route to aqueous solute properties based on FST was to use a finite pressure reference state where properties could be obtained and compute the difference in Gibbs energy between the desired state and the reference state (Sedlbauer, O'Connell, and Wood 2000). This allows calculations for electrolytes which would not have second virial coefficients that could be used at low densities as in Equation 9.41. The relation here for $A_{K r}$ is similar to Equation 9.41,

$$
\begin{aligned}
& A_{K r}=\left(1-\beta_{1}\right)+\beta_{1}\left[\left(1-C_{11}^{0}\right)\right]+ \\
& \rho\left\{\beta_{2}+\beta_{3} \exp (1500 / T)+\beta_{4} \exp \left(c_{1} \rho\right)+\delta\left[\exp \left(c_{2} \rho\right)-1\right]\right\}
\end{aligned}
$$

where values of $c_{1}$ and $c_{2}$ are universal constants and $\beta_{1}, \beta_{2}, \beta_{3}$, and $\beta_{4}$ are solute-dependent parameters. The value of $\delta$ has a specific value for the class of solute: cation, anion, nonelectrolyte.

Again, analytic expressions for $\Delta_{h} \bar{G}_{2}^{\infty}$ and $H_{21}$ are found using Equations 9.37 to 9.39 (Sedlbauer, O'Connell, and Wood 2000), though slightly differently than by Plyasunov, et al. (Plyasunov, O'Connell, and Wood 2000; Plyasunov et al. 2000). The modification to deal with temperatures below the critical is to add a temperature-dependent correction term to the heat 
capacity, which is different for nonelectrolytes and electrolytes,

$$
\begin{aligned}
\Delta_{h} \bar{C}_{p, 2}^{\infty \text { corr }} & =\beta_{5} \frac{\left(T-T_{c}\right)^{2}}{(T-228)} \quad T<T_{c 1} & & \text { Aqueous nonelectrolytes }
\end{aligned}
$$

These analytically integrable expressions are included in the evaluations for $\Delta_{h} \bar{G}_{2}^{\infty}$ and for $H_{21}$ (Sedlbauer, O’Connell, and Wood 2000). Figure 9.8 shows results for this model for aqueous $\mathrm{NaCl}$ with data for infinite dilution partial molar volumes and heat capacities at elevated temperatures. Results for Henry's Constants are also quite accurate.

[Insert Figure 9.8]

\subsubsection{Solubilities in Mixed Liquid Solvents}

While the above treatments are for solutes in single solvents, many applications of interest involve mixed solvents, especially for gases and pharmaceutical compounds. FST has been used to develop successful descriptions of such systems. Chapter 10 describes the approach of Shulgin and Ruckenstein. The focus here is on "excess solubility", $\ln x^{e x}$, the difference in solubility in a real solvent mixture and that for the solvents as an ideal solution (Prausnitz, Lichtenthaler, and Gomes de Azevedo 1999). For very dilute solutions, the solubility is the reciprocal of the Henry's constant, so typically the "excess Henry's Constant", $H_{2}{ }^{E x}$, is modeled, 


$$
\ln H_{2}^{E x} \equiv \ln H_{2 m}-\sum_{i}^{n_{s}} x_{i} \ln H_{2 i}
$$

where the sum is over all solvents. Most measurements and models have been for binary solvents where the variation of $\mathrm{H}_{2}{ }^{E x}$ can be positive or negative or both. Empirical models have been developed, especially because the variation of $H_{2}^{E x}$ with composition is similar for all solutes and is mostly determined by the substances of the solvent mixture. FST approaches have been among the most successful for both gaseous and solid solutes in mixed solvents as also described in Chapter 10.

\subsubsection{Gas Solubility in Mixed Solvents}

There have been two FST approaches to gas solubility in mixed solvents. The first (O'Connell 1971a) expressed $H_{2}^{E x}$ in terms of collections of DCFI with simple parameterization; details of the relations are given in Section 9.3.3.2. The second (Mathias and O'Connell 1979; Campanella, Mathias, and O'Connell 1987) used the DCFI model of Equation 9.4 by integrating the DCFI for the solute from one pure solvent, identified as reference solvent, $\mathrm{R}$, to the mixture composition, which for a binary is given by $x_{R}$. Then,

$$
H_{2}^{E x} \equiv\left(1-x_{R}\right) \ln \left(H_{2 R} / H_{23}\right)+\ln \gamma_{2}^{*}
$$

where $\ln \gamma_{2}^{*}$ is found from Equation 9.30 with $\rho^{0}$ being the pure reference solvent density, and the solution component densities being those for the mixed solvent, $\rho_{i}=x_{i} \rho_{m}$ for $i=R, 3$. For most systems, the mixture density used can be that for an ideal solution, though for aqueous systems, the excess volume is large enough that it must be taken into account (Campanella, Mathias, and O’Connell 1987; O’Connell 1995). Figure 9.9 shows results for $H_{2}^{E x}$ of ethylene in aqueous acetone and aqueous methanol. The complex behavior of the alcohol system is captured 
reasonably well, and quantitative agreement for the acetone system is obtained only if the solution excess volume is included. Without this contribution, the results are similar to those of the simplest model where $H_{2}^{E x}$ is set equal to the negative of the excess Gibbs energy of the solvent mixture (O'Connell and Prausnitz 1964). It should be noted that the method was applied to the solubility of ethane and ethylene in the ternary solvent water, methanol, and acetone with good success when the solvent excess volumes were estimated by binary additivity.

[Insert Figure 9.9]

\subsubsection{Solid Solubility in Mixed Solvents}

The dissolution of solids into liquids is often a dilute solution situation and, as for gases, FST modeling following the approach of O'Connell (O'Connell 1971a) has been applied (Ellegaard, Abildskov, and O'Connell 2009; Ellegaard, Abildskov, and O'Connell 2010). If the solid is pure and the solution is ideal, the solubility can be found from the properties of the pure solute. This is given in (Ellegaard, Abildskov, and O'Connell 2010) as,

$$
\ln x_{2}^{i d}=-\frac{\Delta h_{m 2}}{R}\left(\frac{1}{T}-\frac{1}{T_{m 2}}\right)+\frac{\Delta C_{p m 2}}{R}\left[\ln \left(\frac{T}{T_{m 2}}\right)-1+\frac{T_{m 2}}{T}\right]
$$

where $T_{m 2}$ is the melting temperature, $\Delta h_{m 2}$ is the enthalpy of melting, and $\Delta C_{p m 2}$ is the difference in heat capacity of the hypothetical subcooled liquid and the solid from $T_{m 2}$ to $T$.

For mixed solvent systems, it is common to define an excess solubility,

$$
x_{2}^{E x} \equiv \ln x_{2}-x_{1} \ln x_{2,1}-\left(1-x_{1}\right) \ln x_{2,3}
$$

in the limit, 


$$
\lim _{x_{2} \rightarrow 0} x_{2}^{E x}=-H_{2}^{E x}
$$

For estimations of dilute solid solubility, an expansion similar to Equation 9.27 is done for a ternary system and to the first order,

$$
H_{2}^{E x}=\lim _{x_{2} \rightarrow 0} \frac{x_{3}}{2}\left(\frac{\partial \ln \gamma_{3}}{\partial x_{3}}\right)_{T, P, N_{1}, N_{2}}+\frac{x_{1}}{2}\left(\frac{\Delta_{12}^{m}}{1+x_{1} x_{3} \Delta_{13}^{m}}-\Delta_{12}^{0}\right)+\frac{x_{3}}{2}\left(\frac{\Delta_{23}^{m}}{1+x_{1} x_{3} \Delta_{13}^{m}}-\Delta_{23}^{0}\right)
$$

where ${ }^{m}$ indicates the solvent mixture and ${ }^{0}$ indicates pure solvent. With suitable approximations (O’Connell 1971a; Ellegaard, Abildskov, and O’Connell 2009; Ellegaard, Abildskov, and O'Connell 2010), in particular that $\Delta_{1 i}^{m}=\Delta_{1 i}^{0}$, the final form becomes,

$$
H_{2}^{E x}=\lim _{x_{2} \rightarrow 0} \frac{x_{3}}{2}\left(\frac{\partial \ln \gamma_{3}}{\partial x_{3}}\right)_{T, P, N_{1}, N_{2}}\left(1+x_{1} \Delta_{12}^{0}+x_{3} \Delta_{23}^{0}\right)
$$

The partial derivative is obtained from parameters found by regressing vapor-liquid equilibrium data for the solvent mixture. The estimated solubilities are not very sensitive to these parameters. There are multiple ways to obtain the $\Delta_{1 j}^{0}$ values. One is to use data from solute solubilities in the pure solvents and regress the parameters $\Delta_{12}^{0}$ and $\Delta_{23}^{0}$ separately. Then,

$$
\Delta_{2 i}^{0}=2 \frac{\ln x_{2 i}^{i d}-\ln x_{2 i}}{\left(1-x_{2 i}\right)^{2}}
$$

This method requires values of the pure solute properties. Alternatively, if solute solubilities in mixed solvents are available, these data can be regressed for the parameters simultaneously and the pure solute properties are not needed. Note that the theory demands that parameters for a particular solute-solvent pair be the same for all systems involving the pair, regardless of the additional solvent. In (Ellegaard, Abildskov, and O'Connell 2010), those regressed from ternary 
data were assumed independent of temperature, though the obtained binary values did vary with $T$.

In (Ellegaard, Abildskov, and O'Connell 2010), data were analyzed from 9 pharmaceutical solutes in a total of 68 binary mixtures of 10 solvents, with some of the mixtures at different temperatures. The absolute average relative deviation of using parameters from binary data was $23 \%$ while that from correlation of ternary data was $11 \%$. Additional study of this method is described in (Ellegaard 2011) with more solutes and binary solvents, as well as in some ternary solvents. Figure 9.10 shows excess solubility results for representative systems.

[Insert Figure 9.10]

\subsection{FST Properties of Reactive Components and Strong Electrolyte Solutions}

The FST statistical mechanics described above are for nonelectrolyte systems. The treatment of solutions of ionizing salts, or in fact any system where speciation of the input components occurs, requires additional analysis. This section describes some elements of this area; other aspects are discussed in Chapter 8 .

There are two general situations in which the particles in a solution do not have the same identity as those that are put into the system: when a component dissociates and when components can combine to form other species. The first case is commonly identified with salts forming ions with electrostatic charges. In both cases, the reactions need not be complete, so that the solution can have the original species (components) as well as the new species. Further, the speciation 
need not lead to detectable entities. Thus, the "chemical theory of solutions" and the "solution of groups" descriptions of solution nonideality (Prausnitz, Lichtenthaler, and Gomes de Azevedo 1999) involve virtual species considered to have thermodynamic properties. The general thermodynamics of such systems was established by Perry, et al. (Perry, Telotte, and O'Connell 1981) and their FST analysis was later articulated (Perry and O’Connell 1984).

The concept is that all species considered to have thermodynamic properties will also have pair correlation functions. However, because of stoichiometry, there are constraints on both the properties and the correlation function integrals. Further, though the collection of charges on ions requires electroneutrality only as a consequence of the stoichiometry, there are long-range electrostatic correlations of the ions that affect FST modeling of electrolytes. This aspect has also been treated (Cabezas and O'Connell 1986; Perry, Cabezas, and O'Connell 1988; O'Connell 1993). The purpose of this section is to briefly outline the basis and results available.

\subsubsection{FST of Reactive Components}

The principal effect of speciation is the expansion of the composition space associated with the input components to the larger composition space of the species. The goal is to express with models the properties of the species in the larger space and then project these properties into the smaller component space that has the proper number of independent variables and properties, i.e., the number of components plus 2, to obtain measurable properties. The key mathematical entity is the projection operator, $W$, a nonsquare $\left(n \times n_{c}\right)$ matrix accounting for the stoichiometric connection between the $n_{c}$ components and the $n$ species. The full development, mathematical details and specific examples are given by Perry (Perry, Telotte, and O'Connell 1981; Perry and 
O’Connell 1984). Applications to strong electrolytes are given by Perry, et al. (Perry, Cabezas, and O'Connell 1988), O’Connell (O’Connell 1993; O’Connell, Hu, and Marshall 1999), as discussed in the next section. We provide here a simple example.

A traditional thermodynamics approach to reactions uses the set of the initial moles of species, $\left\{n_{i}^{0}\right\}$, the matrix ( $n \times \boldsymbol{R}$ ) of reaction stoichiometric coefficients, $\boldsymbol{v}$, and the set of extents of the $\boldsymbol{R}$ independent reactions, $\xi\}$, to obtain the moles of species at some point in the reaction,

$$
\left\{n_{i}\right\}=\left\{n_{i}^{0}\right\}+\boldsymbol{v}^{\mathrm{T}}\{\xi\}
$$

An example is the reaction $\mathrm{A}_{1}+\mathrm{A}_{2}=2 \mathrm{~A}_{3}$ where the components are 1 and 2 and the species are 1, 2 and 3. Equation 9.53 would give,

$$
\left\{\begin{array}{l}
n_{1} \\
n_{2} \\
n_{3}
\end{array}\right\}=\left\{\begin{array}{l}
n_{1}^{0} \\
n_{2}^{0} \\
n_{3}^{0}
\end{array}\right\}+\left\{\begin{array}{c}
-\xi \\
-\xi \\
2 \xi
\end{array}\right\}
$$

An approach that allows description of the independent thermodynamic properties of reacting systems uses a slight variation,

$$
\{n\}=W\left\{n_{o}\right\}
$$

where $\left\{n_{o}\right\}$ is the set of mole numbers of the input components. Then,

$$
W=\left[\begin{array}{cc}
1-\xi & 0 \\
-\xi & 1 \\
2 \xi & 0
\end{array}\right]
$$

where the extent of reaction has been scaled to component 1 . The importance of the latter form is that all independent partial molar properties can be related by,

$$
\boldsymbol{W}^{T}\{\bar{X}\}=\left\{\bar{X}_{o}\right\}
$$


where $X$ can be $V, H, G$, etc. In our example for partial molar volume,

$$
\left\{\begin{array}{c}
\bar{V}_{1} \\
\bar{V}_{2} \\
\bar{V}_{3}
\end{array}\right\}=\left\{\begin{array}{c}
\bar{V}_{1 o} \\
\bar{V}_{2 o} \\
\frac{1}{2}\left(\bar{V}_{1 o}+\bar{V}_{2 o}\right)
\end{array}\right\}
$$

Similar connections can be made for properties of mixing, excess properties, and activity coefficients. Using this approach on fluctuation properties is described by Perry and O'Connell (Perry and O’Connell 1984). The relations for TCFI among pairs of species are extremely complex with the extents of reactions embedded in the TCFI. However, those for DCFI are much more direct and the extents of reaction are contained in the projectors. Defining the desired matrix,

$$
\left[\boldsymbol{A}^{-1}\right]_{i j}=\left[\frac{\partial\left(\mu_{o i} / R T\right)}{\partial n_{o j}}\right]_{T, V, n_{o k \neq j}}
$$

The connection of the matrix of FST component derivatives, $\boldsymbol{A}^{-1}$, to the matrix of species DCFI, $C$, is,

$$
\boldsymbol{A}^{-1}=\boldsymbol{K}^{T}\left(\boldsymbol{x}^{-1}-\boldsymbol{C}\right) \boldsymbol{K}
$$

where the elements of the matrix $\boldsymbol{K}$ are,

$$
K_{i j}=W_{i j}+\left[\boldsymbol{v} \boldsymbol{\xi}^{\prime} \boldsymbol{n}_{o}\right]_{i j}
$$

And the elements of the matrix $\xi$ are,

$$
\left[\xi^{\prime}\right]_{i j}=\left(\frac{\partial \xi_{i}}{\partial n_{o j}}\right)_{T, V, \mu_{o k \neq j}}
$$

Ultimately obtaining the desired properties such as density differences and activity coefficients would be complicated, but feasible. This seems not to have been attempted. A much simpler 
case is for complete reactions, such as dissociation of strong electrolytes, is shown in the next section.

\subsubsection{FST of Strong Electrolyte Solutions}

Equations 9.60, 9.61, and 9.62 above can be used directly for FST properties of solutions with fully ionized salts (Perry and O'Connell 1984). In this case, the projection of the extent of reaction terms in Equation 9.62 are null and,

$$
\boldsymbol{A}^{-1}=\boldsymbol{W}^{T}\left(\boldsymbol{x}^{-1}-\boldsymbol{C}\right) W
$$

For dissociation of a salt $a_{v_{a}} b_{v_{b}}$ into ions, the FST derivatives are,

$$
\begin{aligned}
& {\left[\frac{\partial \beta \mu_{o 1}}{\partial n_{o 1}}\right]_{T, V, n_{o 2}}=x_{1}^{-1}-C_{11}} \\
& {\left[\frac{\partial \beta \mu_{o 1}}{\partial n_{o 2}}\right]_{T, V, n_{o 1}}=-v_{a} C_{1 a}=-v_{b} C_{b}=\left[\frac{\partial \beta \mu_{o 2}}{\partial n_{o 1}}\right]_{T, V, n_{o 2}}} \\
& {\left[\frac{\partial \beta \mu_{o 2}}{\partial n_{o 2}}\right]_{T, V, n_{o 1}}=\frac{v_{a}+v_{b}}{x_{2}}-\left[v_{a}^{2} C_{a a}+2 v_{a} v_{b} C_{a b}+v_{b}^{2} C_{b b}\right]}
\end{aligned}
$$

where $x_{1}=N_{o 1} /\left[N_{o 1}+\left(v_{a}+v_{b}\right) N_{o 2}\right]$ and $x_{2}=1-x_{1}$. Models for the species DCFI can be used in Equations 9.64 to obtain solution thermodynamic properties in the same manner as was done with nonelectrolytes above.

However, examination of the Debye-Hückel limiting law (Perry, Cabezas, and O'Connell 1988) shows a major complication in that the long-range electrostatic interactions lead to divergences of the ion-ion correlation functions, $c_{a a}, c_{a b}$, and $c_{b b}$ in the limit of infinite dilution. Analysis of the long-range contributions (Stell, Patey, and Høye 1981) leads to rigorous formulae for the 
Limiting Law DCFIs, while more appropriate models for the Extended Limiting Law DCFIs are found (Perry, Cabezas, and O'Connell 1988; O'Connell 1993). The short-range contributions can be modeled by $2^{\text {nd }}$ virial terms similar to those of Pitzer (Pitzer 1995); full expressions are given in (O’Connell, Hu, and Marshall 1999). The pressure and activity coefficient relations from Equations 9.5 and 9.30, are, respectively,

$$
\begin{aligned}
\frac{p-p^{0}}{k_{B} T}= & \left(\rho-\rho^{0}\right)-\left\{\frac{1}{2}\left(\rho_{o 1}^{2}-\rho_{o 1}^{02}\right) \Delta F_{11}+\rho_{o 1} \rho_{o 2} \Delta F_{12}+\rho_{o 2}^{2} \Delta F_{22}\right\} \\
& -\left\{\frac{1}{3}\left(\rho_{o 1}^{3}-\rho_{o 1}^{03}\right) \Delta \Phi_{111}+\rho_{o 1}^{2} \rho_{o 2} \Delta \Phi_{112}+\rho_{o 1} \rho_{o 2}^{2} \Delta \Phi_{112}+\rho_{o 2}^{2} \Delta \Phi_{222}\right\} \\
& +\rho_{o 1} S_{\gamma} I^{3 / 2}\left\{\frac{\partial \ln \varepsilon}{\partial \rho_{o 1}}\right\}_{T, \rho_{o 2}=0}-c I^{3 / 2}-\frac{1}{3} S_{\gamma} I^{3 / 2}-S_{\gamma}\left\{\frac { a } { b ^ { 3 } } \left[\frac{2}{9}\left(1+b I^{1 / 2}\right)^{3}\right.\right. \\
& \left.-\frac{1}{b^{2}} I+2\left(1+b I^{1 / 2}\right)-\frac{2}{3} \ln \left(1+b I^{1 / 2}\right)-\frac{11}{9}\right] \\
& \left.+\frac{a}{3} I^{3 / 2} \ln \left(1+b I^{1 / 2}\right)+\beta \alpha^{2} I^{2} \exp \left(-\alpha I^{1 / 2}\right)\right\} \\
\ln \gamma_{2}= & \ln \left(\frac{\rho}{\rho^{0}}\right)-\frac{1}{v_{2}}\left\{\left(\rho_{o 1}-\rho_{o 1}^{0}\right) \Delta F_{12}+\rho_{o 1} \Delta F_{22}\right\} \\
- & \frac{1}{v_{2}}\left\{\frac{1}{2}\left(\rho_{o 1}^{2}-\rho_{o 1}^{02}\right) \Delta \Phi_{112}+\rho_{o 1} \rho_{o 2} \Delta \Phi_{122}+\rho_{o 2}^{2} \Delta \Phi_{222}\right\}-\frac{\omega}{v_{2}} S_{\gamma} I^{1 / 2} \\
- & \frac{\omega}{v_{2}} S_{\gamma}\left\{a I^{1 / 2} \ln \left(1+b I^{1 / 2}\right)+2 \beta\left[1-\exp \left(-\alpha I^{1 / 2}\right)\left(1+\alpha I^{1 / 2}-\alpha^{2} / 2 I\right)\right]\right\}
\end{aligned}
$$

where $I$ is the molar ionic strength and the Limiting Law Property, $S_{\gamma}$ is,

$$
S_{\gamma}=\left[\frac{2 \pi e^{6} N_{A}}{(\varepsilon k T)^{3}}\right]^{\frac{1}{2}}
$$

The parameters are $\Delta F_{11}, \Delta F_{12}, \Delta F_{22}, \Delta \Phi_{111}, \Delta \Phi_{112}, \Delta \Phi_{122}$, and $\Delta \Phi_{222}$. It was found (O'Connell, $\mathrm{Hu}$, and Marshall 1999) that, except for $\Delta F_{22}$ and $\Delta \Phi_{222}$, these are ionically additive or follow simple combining rules. Using salt-specific parameters for $\Delta F_{22}$ and $\Delta \Phi_{222}$ gave excellent 
agreement in densities and activity coefficients for fifteen 1-1, 1-2, and 2-1 salts over the entire range of data available. Figure 9.11 shows mean ionic activity coefficients and densities for the systems $\mathrm{NaNO}_{3}$ and $\mathrm{CaCl}_{2}$. The sources of experimental information are given in Table 9.1. The agreement is quite good up to high salt concentrations.

[Insert Figure 9.11 and Table 9.1]

Work has not continued on this approach because of the complexity of the expressions and the lack of ionic additivity, combined with only limited improvement in accuracy compared to other models with the same number of parameters. However, the tabulations of salt DCFI from evaluated data (Hu 1997) can provide tests for such other models.

\subsection{Analysis of Equation of State Mixing and Combining Rules Using FST}

The simplest fundamental connection between equations of state, expressed as Helmholtz functions of $T, v$, and $\{x\}$, and correlation function integrals is via the second composition derivative of the residual Helmholtz energy and DCFI,

$$
1-C_{i j}=N\left[\frac{\partial^{2} \beta A^{r}}{\partial N_{i} \partial N_{j}}\right]_{T, V, N_{k}}
$$

As usual, the TCFI expressions are more complex because they involve matrix inverses of the second derivatives. Many applications use an EOS model that is cubic in molar volume, such as the generalized van der Waals form, with pure component parameters that depend upon composition according to mixing rules that employ combining rules with unlike interaction parameters of the solution components. An example is the original van der Waals EOS, 


$$
p=\frac{R T}{v-b(\{x\})}-\frac{a(\{x\})}{v^{2}}
$$

The Helmholtz energy, when written in the form for taking the derivatives of Equation 9.68 is,

$$
\frac{A^{r}(T, V,\{N\})}{R T}=N \ln \left(\frac{N}{V-N b(\{N\})}\right)^{2}-\frac{N^{2} a(\{N\})}{R T V}
$$

The derivatives can be taken for any set of mixing and combining rules. The well-known 1-fluid mixing rules are,

$$
\begin{aligned}
& N^{2} a(\{N\})=\sum_{i=1}^{n_{c}} \sum_{j=1}^{n_{c}} N_{i} N_{j} a_{i j} \\
& N b(\{N\})=\frac{\sum_{i=1}^{n_{c}} \sum_{j=1}^{n_{c}} N_{i} N_{j} b_{i j}}{\sum_{i=1}^{n_{c}} N_{i}}
\end{aligned}
$$

and, among the combining rule options, a common choice is,

$$
\begin{aligned}
& a_{i j}=\left(a_{i i} a_{j j}\right)^{\frac{1}{2}}\left(1-k_{i j}\right) \\
& b_{i j}=\frac{1}{2}\left(b_{i i}+b_{j j}\right)\left(1-l_{i j}\right)
\end{aligned}
$$

where $k_{i j}$ and $l_{i j}$ are binary parameters which are zero for pure components $(i=j)$. For these choices, Equation 9.68 becomes,

$$
1-C_{i i}=\left(\frac{v}{v-b_{i i}}\right)^{2}-\frac{2 a_{i i}}{k_{B} T v}
$$

and,

$$
1-C_{i j}=1+\frac{\left(b_{i i}+b_{j j}\right)\left(1-l_{j j}\right)}{v-b(\{x\})}+\frac{b_{i i} b_{j j}}{[v-b(\{x\})]^{2}}-\frac{2\left(a_{i i} a_{j j}\right)^{\frac{1}{2}}\left(1-k_{i j}\right)}{k_{B} T v}
$$

Equation 9.74, and expressions from other EOS models can be used to test the accuracy of 
mixing and combining rules by comparisons with experimental DCFI values. The EOS studied here is the Peng-Robinson (Peng and Robinson 1976) model,

$$
\frac{p^{r e s}}{R T}=\frac{N b(\{x\})}{V-N b(\{x\})}-\frac{N^{2} a(T,\{x\}) / R T}{V^{2}+2 N b(\{x\}) V+[N b(\{x\})]^{2}}
$$

An initial effort in this direction was presented in by O'Connell and Clairmont (O'connell and Clairmont 2010). The data bank of binary DCFI and TCFI values for a variety of subcritical systems given by Wooley and O'Connell (Wooley and O'Connell 1991) was used for DCFI comparisons as well as for composition variations of excess volume. The EOS models were the cubic original van der Waals and Peng-Robinson models, and the quintic DeSantis model, with mixing rules of the original van der Waals, Huron and Vidal, and Wong - Sandler forms (Poling, Praunitz, and O'Connell 2000). The last two rules use excess Gibbs energy results, usually from fitting VLE data, to establish mixture parameters that are more accurate for the composition dependence of liquid solutions. Figures 9.12 and 9.13 show DCFIs and $V^{E}$ from this analysis for the binary $\mathrm{CCl}_{4}(1)$ and methanol. The questions posed and conclusions were:

1. Do the EoS and mixing rules follow the composition variations for $1-C_{11}$ and $1-C_{22}$ from pure component to infinite dilution? The answer is sometimes, but not reliably.

2. Can binary parameters be found to describe the composition variations of $1-C_{12}$ and $V^{E}$ ? The answer is generally yes, but not always.

3. Is there a difference in results for the van der Waals \& $G^{E}$ mixing rules? The answer is yes, but there is no preponderance of accuracy in one form or another. The van der Waals mixing rules, with 2 binary parameters, is quite satisfactory for nonassociating, nonsolvating systems. But no mixing rule is adequate for components with hydrogen 
bonds in dilute solution. The accuracy of the descriptions of excess volume was uneven, with no apparent pattern of success or failure.

4. If experimental liquid volumes were used in the EOS to compute total pressures, the results were generally poor. The sensitivity of $p$ to density is too great to obtain accurate values from the EOS.

[Insert Figure 9.12 and 9.13]

This work is far from complete because only a few of the systems in the data base were tested and no contemporary EOS models, such as SAFT (Muller and Gubbins 2001; Economou 2002), PC-SAFT (Gross and Sadowski 2001) and CPA (Kontogeorgis et al. 1996), which have been reviewed by Kontogeorgis and Folas (Kontogeorgis et al. 2006a, 2006b) and by Polishuk and Mulero (Polishuk and Mulero 2011), were examined.

\subsection{Summary and Conclusions}

It has been shown that models for DCFIs can lead to successful models for solution properties and phase equilibria, especially for strongly nonideal systems such as dilute solutions of gases and solids. Because FST formulations are for composition derivatives of pressure and chemical potential or fugacity, the evaluation can appear complex and requires property values at certain reference states. This may be the reason such models have not been implemented into process simulators. However, the reliability and accuracy of models based on perturbations from hard spheres, such as Equation 9.4, is quite good for very many systems, and the results can at least be used to generate local parameterizations and to validate EOS models. Ultimately, results from 
molecular simulations, as described in Chapter 6, may lead to new relations for the thermodynamic models for use in process simulators. 
Table 9.1 Sources of Data for Figure 9.11.

\begin{tabular}{|c|c|c|}
\hline Salt & Property & Reference \\
\hline \multirow{2}{*}{$\mathrm{NaNO}_{3}$} & Density & Janz, et al.1970 \\
& Activity & Hamer and Wu 1972 \\
\hline & Coefficient & \\
\hline $\mathrm{CaCl}_{2}$ & Activity & Romankiw and Chou 1983 \\
& Coefficient & Staples and Nuttall 1977 \\
\hline
\end{tabular}


Figure 9.1 Scaled DCFI from Equation 9.3.

Figure 9.2 Density versus pressure for the $\mathrm{IL}\left[\mathrm{C}_{1} \mathrm{C}_{2} \mathrm{Im}\right][\mathrm{TfN}]$. Data (घ) from Gardas et al. (Gardas et al. 2007) and (\$) from Jacquemin, et al. (Jacquemin et al. 2007). Calculations of $p$ using Equation 9.6 with $p^{0}, \rho^{0}$, and $\rho$ from Jacquemin, et al. (Jacquemin et al. 2007) (-) and from Gardas, et al. (Gardas et al. 2007) (- -). The arrows identify the data associated with the lines. (Modified from J. Abildskov, M. D. Ellegaard, and J. P. O'Connell. 2010. Densities and isothermal compressibilities of ionic liquids - Modeling and application. Fluid Phase Equilibria. 295, 215.)

Figure 9.3 Variations of Krichevskii function, $A_{K r}$, for various small solutes in water; (a) for high solvent densities, (b) for lower densities. Symbols for data, lines for Equation 9.25. (Reprinted with permission from J. P. O'Connell, A. V. Sharygin, and R. H. Wood. 1996. Infinite dilution partial molar volumes of aqueous solutes over wide ranges of conditions. Industrial \& Engineering Chemistry Research. 35, 2808.)

Figure 9.4. Pressure versus liquid mole fraction for isotherms of methane with m-cresol. Symbols for data of Simnick, et al., (Simnick et al. 1979a) (-) regression of temperature dependence of Henry's Constant in Equation 9.26, (---) prediction using Equation 9.34 with Henry's Constant for methane in quinoline fitted to data of of Simnick, et al. (Simnick et al. 1979b). Arrows indicate prediction at $T=462 \mathrm{~K}$ is not accurate. 
Figure 9.5. Pressure versus liquid mole fraction of hydrogen (1) in the IL [hmim][NTf2] calculated using Henry's Constant of Equation 9.26 fitted to data of Kumelan, et al. (Kumelan et al. 2006). $\square T=293.2 \mathrm{~K} ;-\longrightarrow \bullet T=333.2 \mathrm{~K} ;-\cdots \Delta T=373.2 \mathrm{~K} ; \cdots \bullet T=$ 413.2K. (Modified with permission from J. Abildskov, M. D. Ellegaard, and J. P. O'Connell. 2009. Correlation of phase equilibria and liquid densities for gases with ionic liquids. Fluid Phase Equilibria. 286, 95.)

Figure 9.6. Log ratio of fugacity to liquid mole fraction of hydrogen (1) in the IL [hmim][NTf2] calculated using Henry's Constant of Equation 9.26 fitted to data of Kumelan, et al. (Kumelan et al. 2006). $\square \square T=293.2 \mathrm{~K} ;-\square-T=333.2 \mathrm{~K} ;-\cdots \Delta T=373.2 \mathrm{~K} ; \cdots \cdots T=$ 413.2K. (Reprinted with permission from J. Abildskov, M. D. Ellegaard, and J. P. O'Connell. 2009. Correlation of phase equilibria and liquid densities for gases with ionic liquids. Fluid Phase Equilibria. 286, 95.)

Figure 9.7 Henry's Constants $\left(H_{21}\right)$ for Hydrogen sulfide (2) in water (1) from Equations 9.37 to 9.41. (Reprinted with permission from A. Plyasunov, J. O'Connell, R. Wood, and E. Shock. 2000. Infinite dilution partial molar properties of aqueous solutions of nonelectrolytes. II. Equations for the standard thermodynamic functions of hydration of volatile nonelectrolytes over wide ranges of conditions including subcritical temperatures. Geochimica Et Cosmochimica Acta. 64, 2779.) 
Figure 9.8 (Left) Infinite dilution partial molar volume of aqueous $\mathrm{NaCl}$ vs. water density at $p=$ $38 \mathrm{MPa}$ over $600<T<725 \mathrm{~K}$. (-) from Equation 9.42. (O) Extrapolations by Sedlbauer et al. (Sedlbauer, Yezdimer, and Wood 1998) of data of Majer et al. (Majer et al. 1991). (Right) Infinite dilution heat capacity of aqueous $\mathrm{NaCl}$ at $p=28 \mathrm{MPa}$ over $640<T<680 \mathrm{~K}$. (-) from Equations 9.37 to 9.40 and 9.42 to 9.44. (O) Data of Carter (Carter 1992). (Reprinted with permission from J. Sedlbauer, J. O'Connell, and R. Wood. 2000. A new equation of state for correlation and prediction of standard molal thermodynamic properties of aqueous species at high temperatures and pressures. Chemical Geology. 163, 43.)

Figure 9.9 Excess Henry's Constants of Equation 9.46 for ethylene (2) in aqueous methanol and aqueous acetone solutions at 298.15 K. Data of Zeck and Knapp (Zeck and Knapp 1985), calculations with Equation 9.46 using experimental densities (-), zero excess volumes (- - -) and with an excess Gibbs energy rule (•.•) (O’Connell and Prausnitz 1964).

Figure 9.10 Estimated and experimental excess solubilities, $x_{2}^{E x}$, of solid solutes in mixed solvents: Left: naphthalene (2) / water (1) / acetone (3), Data of J. M. Lepree, et al. (Lepree, Mulski, and Connors 1994). Right: $\beta$-carotene (2) / acetone (1) / n-hexane (3), $\boldsymbol{\Delta}$ Data of Treszczanowicz, et al. (Treszczanowicz et al. 2001); — Calculated. 
Figure 9.11 Densities and mean ionic activity coefficients for $\mathrm{NaNO}_{3}(\downarrow)$ and $\mathrm{CaCl}_{2}(\bullet)$ at 298.15 K. Data sources given in Table 9.1. Calculations (-) and (---) from Equations 9.65 to 9.67.

Figure 9.12 DCFIs for the $\mathrm{CCl}_{4}-$ Methanol system at $T=298.15 \mathrm{~K}$ using Equation 9.74 with different mixing rules. EOS calculations from Peng-Robinson model, Equation 9.75, with the 2parameter, 1-fluid, van der Waals mixing rule (- - ), Equation 9.74, and Wong-Sandler (Wong and Sandler 1992) $G_{m}{ }^{E}$ mixing rule (-- -). Data (-) from tabulations of Wooley and O'Connell (Wooley and O’Connell 1991).

Figure 9.13 $V_{m}{ }^{E}$ for the $\mathrm{CCl}_{4}-$ Methanol system at $T=298.15 \mathrm{~K}$ computed with different mixing rules. EOS calculations from Peng-Robinson model, Equation 9.75, with the 2parameter, 1-fluid, van der Waals mixing rule (---) and Wong-Sandler (Wong and Sandler 1992) $G^{E}$ mixing rule (---). Data (-) from tabulations of Wooley and O'Connell (Wooley and O’Connell 1991). 


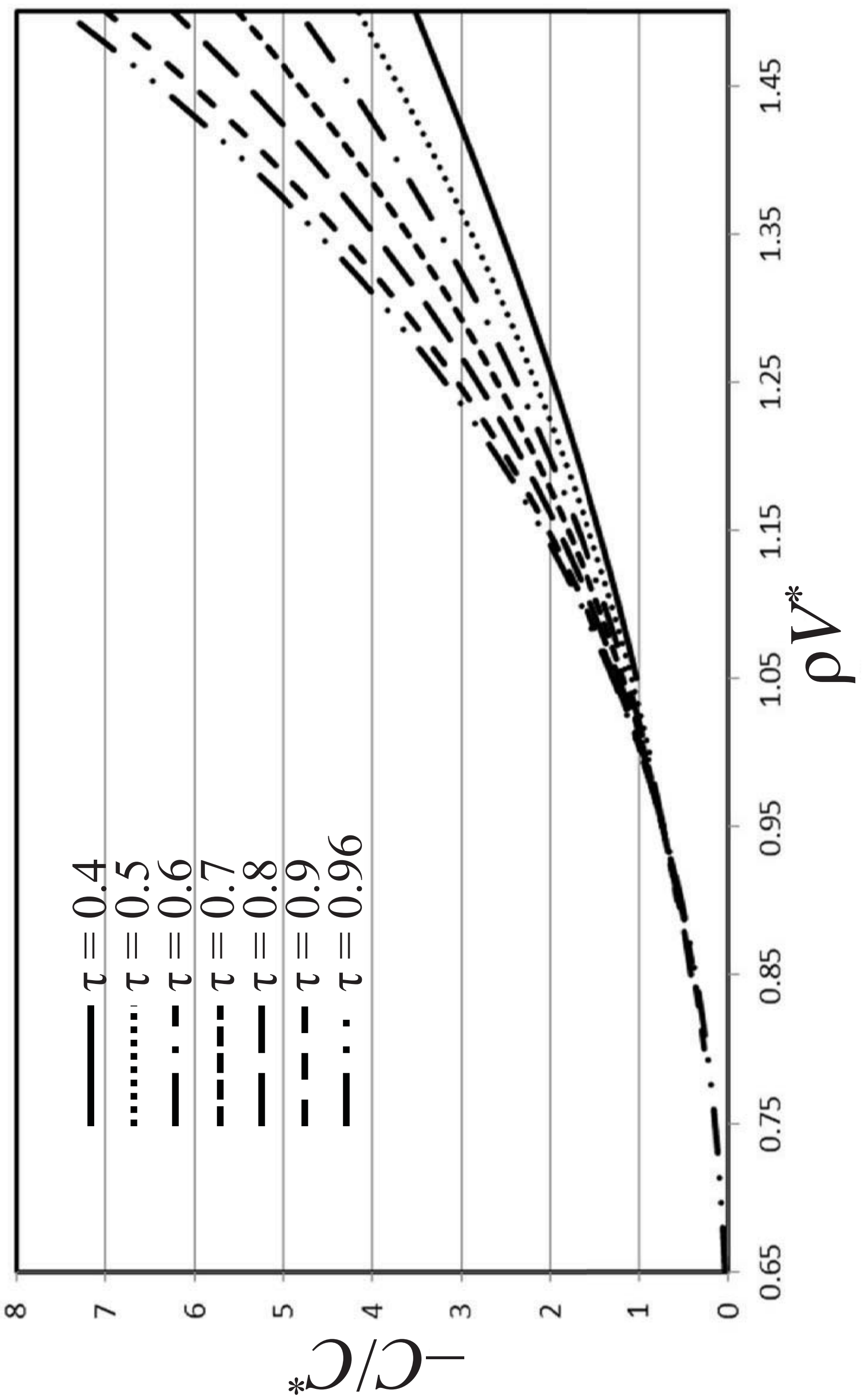




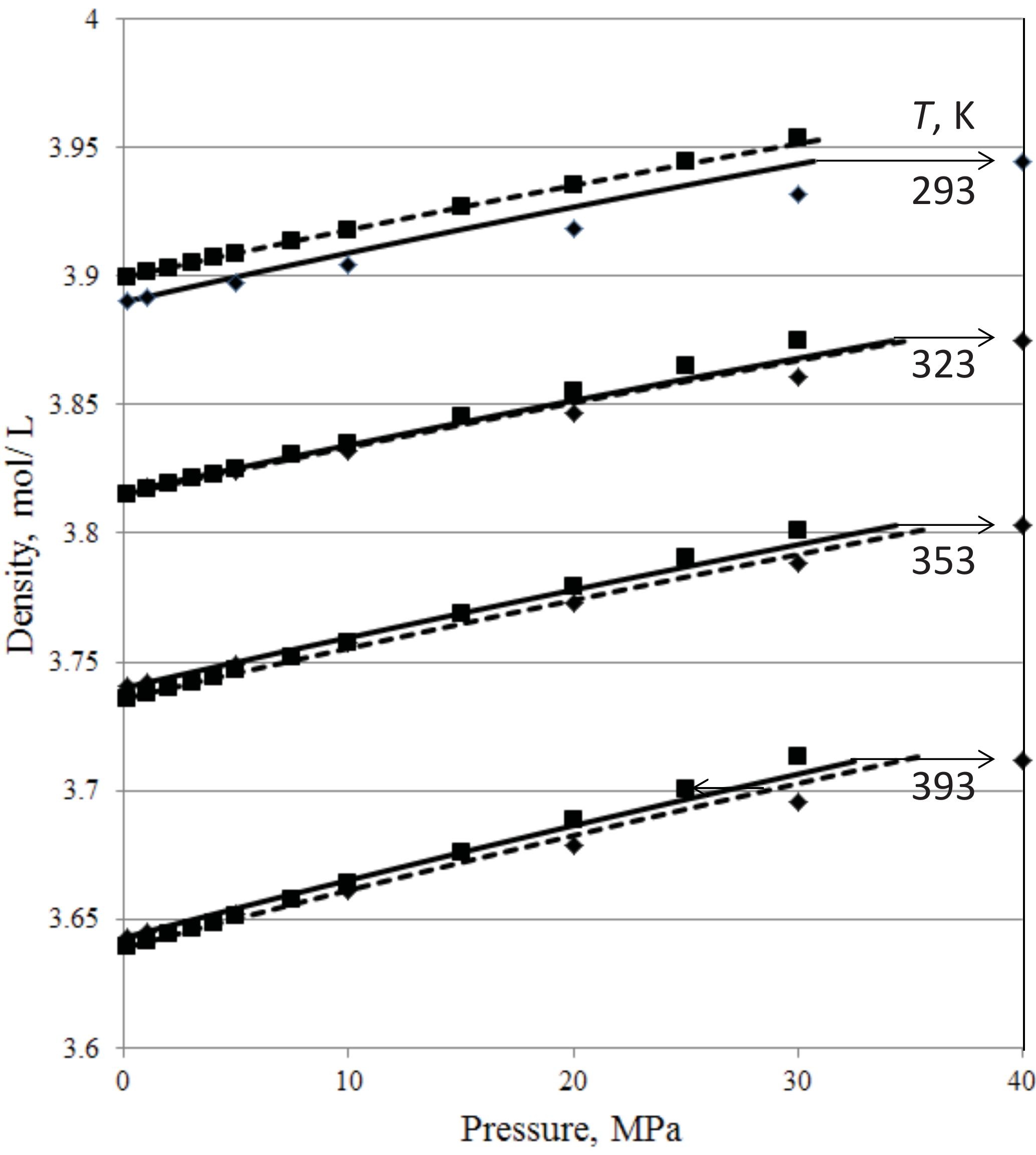



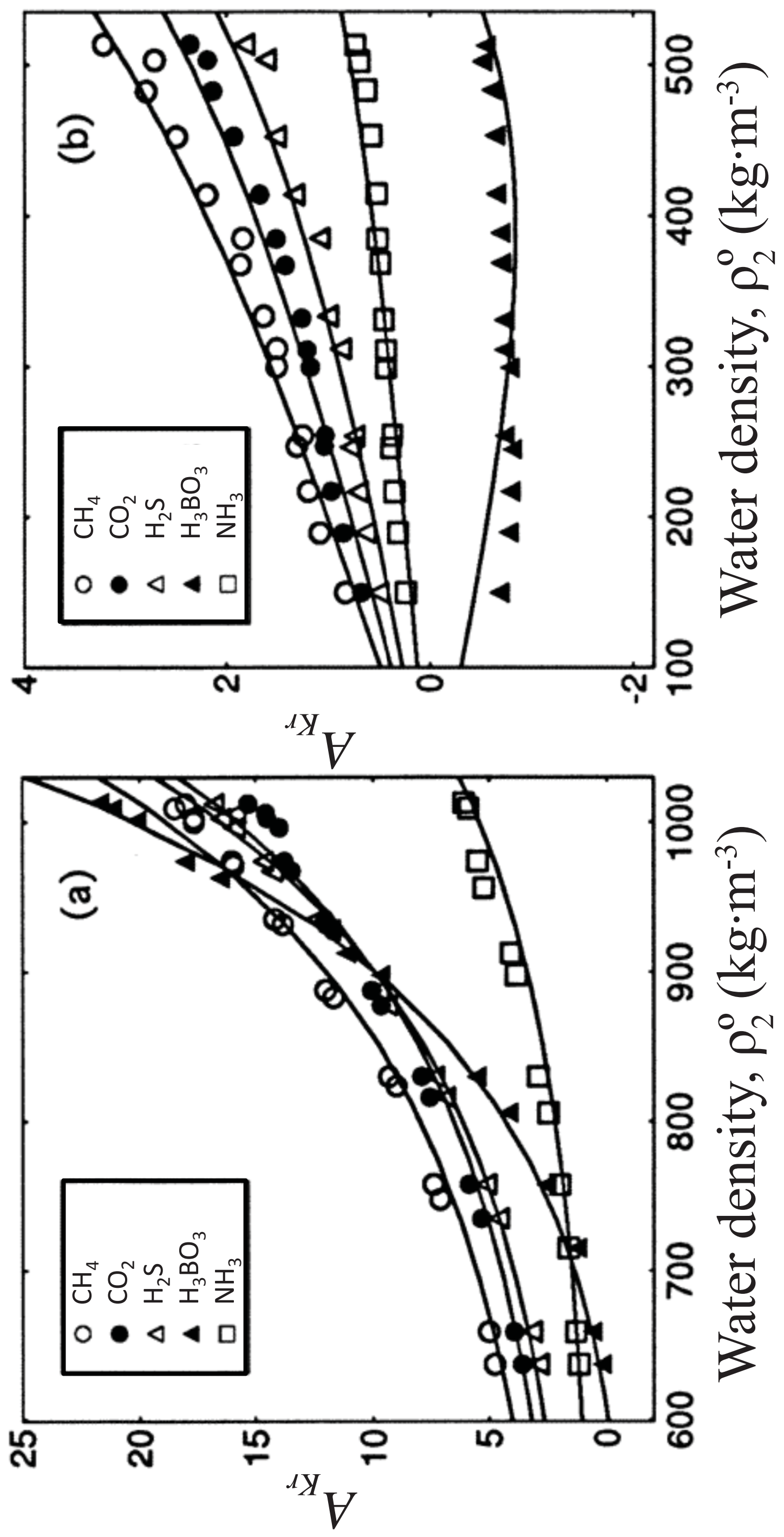


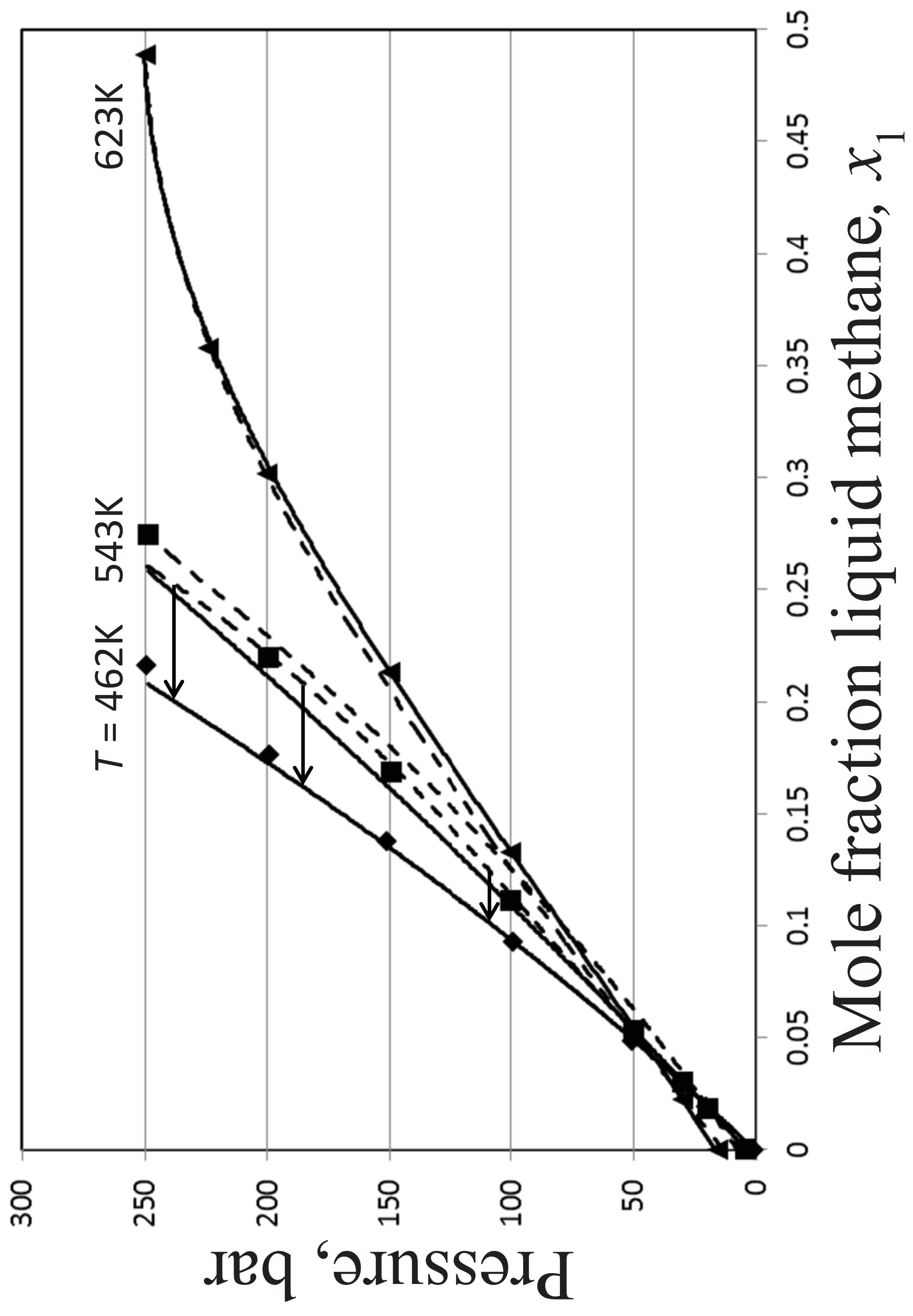














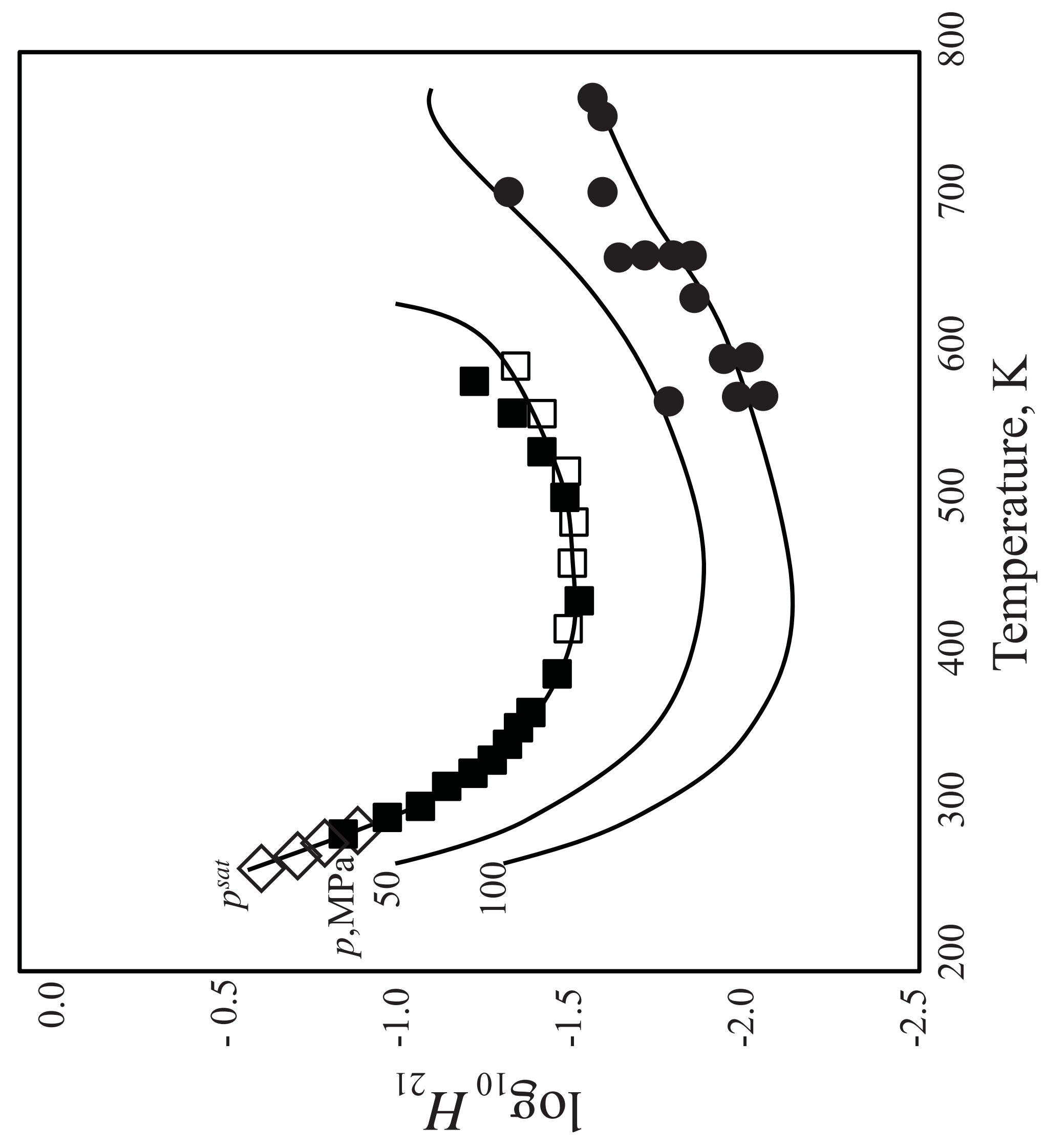




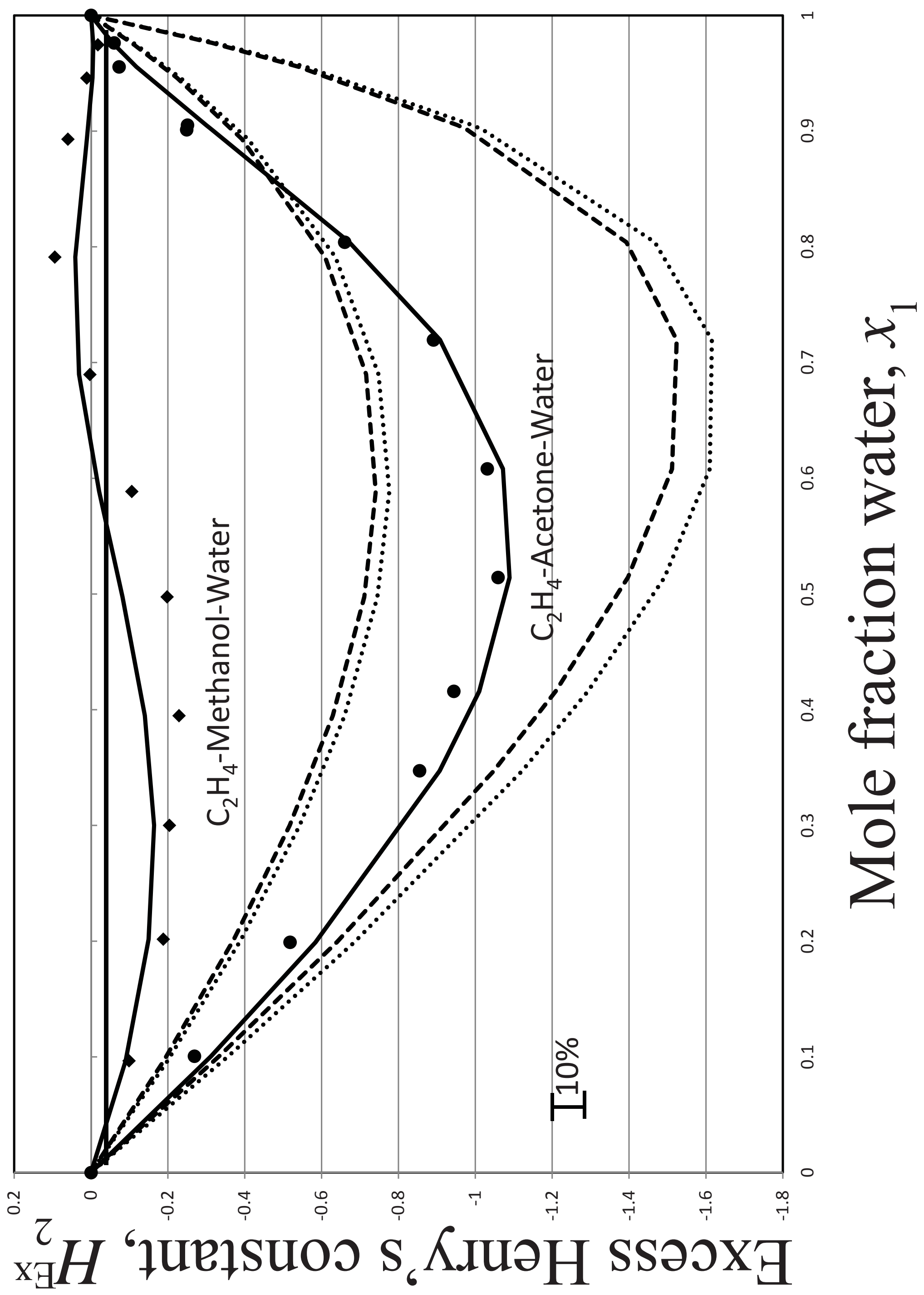




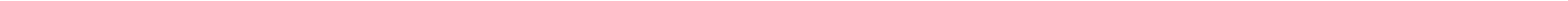



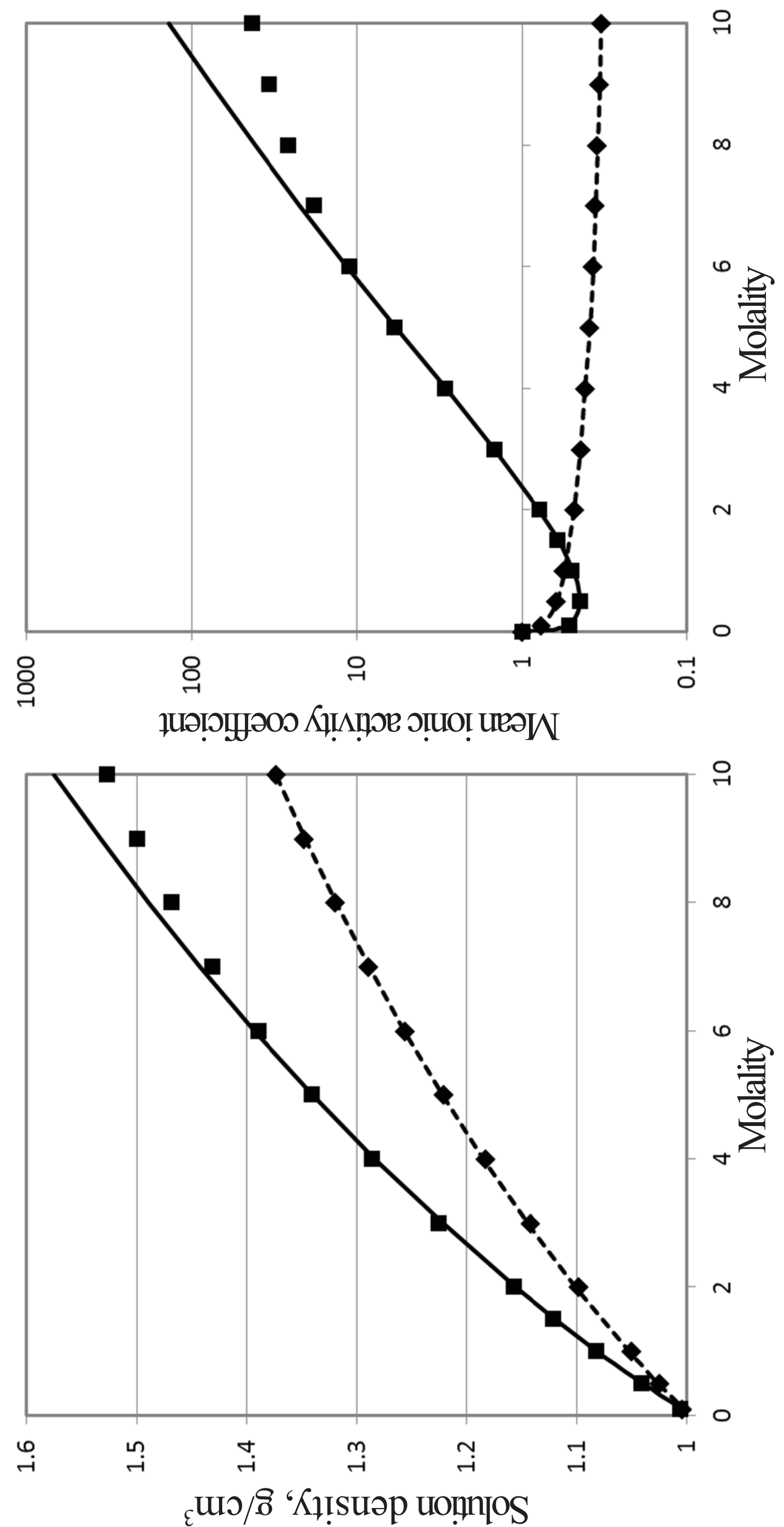


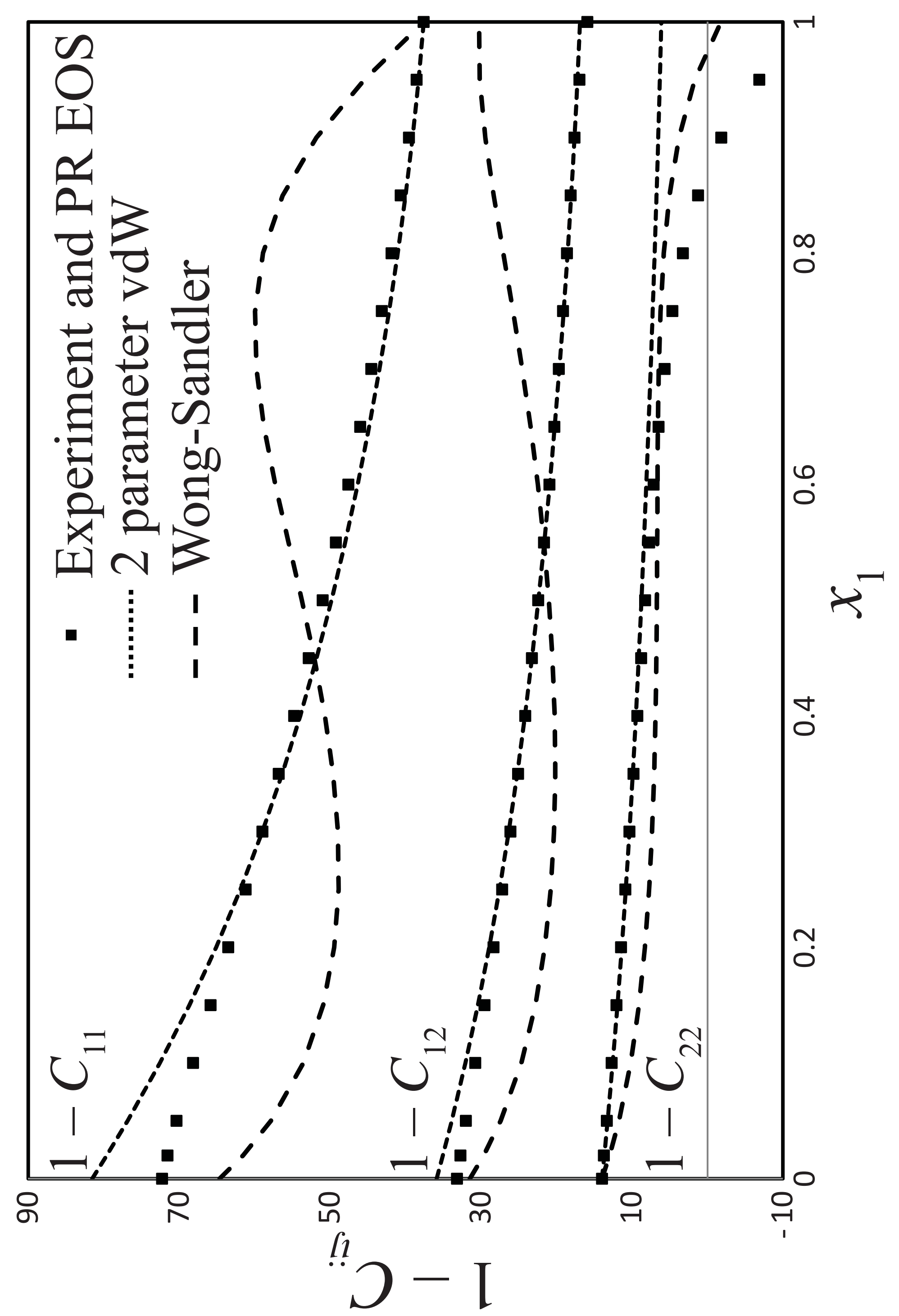




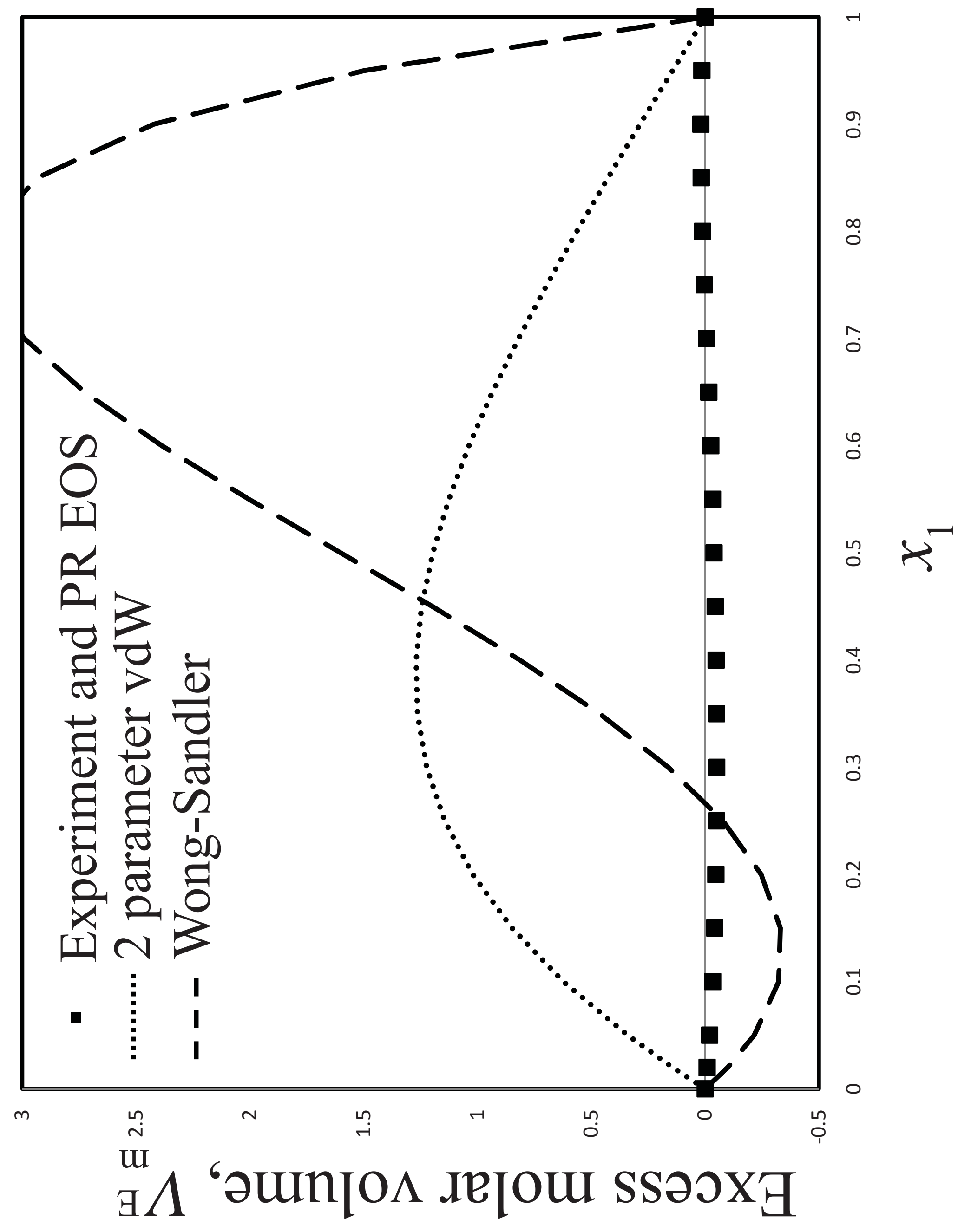




\section{Symbol Description}

\section{$\underline{\text { Greek }}$}

$\alpha_{p}$

Isobaric thermal expansion coefficient (Equation 1.6)

$\Gamma_{23}$

$\gamma_{ \pm}$

Preferential binding parameter (Equation 1.86)

$\gamma_{i}$

Mean ion molal activity coefficient (Equation 1.92)

$\gamma_{i}^{c}$

Lewis-Randall/rational/mole fraction activity coefficient (Equation 1.19)

Molar activity coefficient

$\gamma_{i}^{m} \quad$ Molal activity coefficient

$\Delta \quad$ Isothermal-isobaric partition function (Equation 1.28)

$\Delta G_{i j} \quad G_{i i}+G_{j j}-2 G_{i j}$ (Equation 1.93)

$\zeta_{2}$

$1+c_{i} G_{i i}+c_{j} G_{j j}+c_{i} c_{j}\left(G_{i i} G_{j j}-G_{i j}^{2}\right)$ (Equation 1.66)

$\eta_{12} \quad c_{i}+c_{j}+c_{i} c_{j}\left(G_{i i}+G_{j j}-2 G_{i j}\right)$ (Equation 1.66)

$\kappa_{T} \quad$ Isothermal compressibility (Equation 1.5)

$\Lambda_{i}$

Thermal de Broglie wavelength of specie $i$

$\lambda_{i}$

Absolute activity of $i$

$\mu_{i}$

Chemical potential of component $i$

$\mu_{i j}$

Chemical potential derivative (Equation 1.1)

$v \quad$ Number of cations/anions, $v=v_{+}+v_{-}$

$\Xi \quad$ Grand canonical partition function (Equation 1.28)

$\pi \quad$ Osmotic pressure

$\rho \quad$ Mass or total number density

$\rho_{\mathrm{i}} \quad$ Number density of $i,=N_{i} / V$, see also $c_{i}$

$\phi_{i} \quad$ Volume fraction of $i,=\rho_{i} \bar{V}_{i}$

$\varphi_{i} \quad$ Fugacity coefficient of $i$ (Equation 1.23)

$\Omega \quad$ Microcanonical partition function (Equation 1.28)

Mathematical

$<>$

$\{X\}$

1

$|\mathbf{A}|$

$\mathbf{A}^{\mathrm{ij}}$

A

I

$\delta_{i j}$

$\delta X_{i}$

$\left\langle(\delta X)^{2}>\right.$
Ensemble or time average

Set notation, $\left\{X_{1}, X_{2}, \ldots\right\}$

Unit matrix

Determinant of matrix A

Cofactor of matrix $\mathbf{A}$

Matrix with elements $A_{i j}$

Identity matrix

Kronecker delta

Instantaneous fluctuation, $X_{i}-\left\langle X_{i}\right\rangle$

Mean square fluctuation of a property $X$ 
$\underline{\text { Latin }}$

\begin{tabular}{|c|c|}
\hline+ & Cation \\
\hline - & Anion \\
\hline o & Pure \\
\hline$\infty$ & Infinitely dilute (limiting) \\
\hline 1 & Solvent \\
\hline $1 / k_{\mathrm{B}} T$ & $\beta$ \\
\hline 2 & Solute \\
\hline 3 & Cosolvent/cosolute/additive \\
\hline$\Delta_{\mathrm{r}} G$ & Reaction Gibbs energy (function) \\
\hline$\Delta_{\mathrm{r}} H$ & Reaction enthalpy \\
\hline$\Delta_{\mathrm{r}} S$ & Reaction entropy \\
\hline$\delta x_{j i}$ & Preferential solvation parameter ( $j$ surrounding $i$ ) \\
\hline$\delta x_{j i}^{\prime}$ & Corrected referential solvation parameter \\
\hline$\mu V T$ & Grand canonical ensemble \\
\hline$\hat{X}$ & Fourier transformed $X$ \\
\hline $\bar{X}_{i}$ & Partial molar property of $X$ \\
\hline$a_{ \pm}$ & Mean activity of electrolyte in solution \\
\hline$A$ & Helmholtz energy (function) \\
\hline $\mathrm{A}_{i}$ & Aggregate/Multimer of $i$ monomers \\
\hline$a_{i}$ & Activity of $i$ \\
\hline $\mathrm{aq}$ & Aqueous solution \\
\hline$c_{i}$ & Molarity of $i$, see also number density, $\rho_{i}$ \\
\hline$C_{i j}$ & $\rho \int c_{i j}(r) d r$, DCFI, elements of the $\boldsymbol{C}$ matrix (Equation 1.39) \\
\hline$c_{i j}(r)$ & Direct correlation function \\
\hline$C_{p}$ & Constant pressure heat capacity (Equation 1.7) \\
\hline$D$ & Activity derivative, concentration fluctuation term (Equation 1.73) \\
\hline$f_{i}$ & Fugacity of a substance $i$ in a gaseous mixture (Equation 1.21) \\
\hline$G$ & Gibbs energy (function) \\
\hline$g_{i j}$ & Radial (pair) distribution function, $\mathrm{RDF}$ \\
\hline$G_{i j}$ & Kirkwood-Buff integral, KBI \\
\hline$H$ & Enthalpy \\
\hline$h$ & Planck's constant \\
\hline$H_{i j}$ & $\rho \int h_{i j}(r) d r=\rho G_{i j}$, TCFI (see below Equation 1.38), or Henry's law constant \\
\hline$h_{i j}(r)$ & Total correlation function, TCF, $g_{i j}(r)-1$ \\
\hline & Ideal (mole fraction scale) \\
\hline$K$ & Equilibrium constant \\
\hline$k$ & Rate constant \\
\hline$k_{\mathrm{B}}$ & Boltzmann constant \\
\hline
\end{tabular}


$k_{\mathrm{H}}$

M

m

$m_{i}=c_{i} / c_{1}$

mix

$\mathrm{n}$

$n_{c}$

$N_{A}$

$N_{i}$

$N_{i j}$

NpT

NVE

NVT

$p$

$Q$

$r$

$R$

$R_{\text {cor }}$

$S$

$T$

$T_{\mathrm{m}}$

trs

U

V

$V_{\text {cor }}$

$X^{*}$

$X_{\mathrm{c}}$

$X^{\mathrm{E}}$

$X^{\mathrm{r}}$

$x_{i}$

$X_{\mathrm{m}}$

$y_{i}$

$z_{+/-}$

Acronyms

$\mathrm{COM}$

DCF

DCFI

EOS

FF
Henry's law constant, see also $H_{i j}$

Monomer

$m$-value for protein denaturation (see Equation 1.99)

(Dimensionless) molality

Mixing process

Number of monomers in an aggregate

Number of components in the system

Avogadro's number

Number of entities (usually molecules, atoms, or ions)

Excess coordination number

Isothermal-isobaric (Gibbs) ensemble

Microcanonical ensemble

Canonical ensemble

Pressure

Canonical partition function (Equation 1.28)

$\left|\boldsymbol{r}_{1}-\boldsymbol{r}_{2}\right|$, distance between COM of molecules

Gas constant

Correlation radius (see $V_{\text {cor }}$ )

Entropy

Temperature (thermodynamic)

Melting temperature

Transfer between two phases

Internal energy

Volume

Correlation volume (see Equation 1.81)

Reduced or characteristic quantity $X$

Critical $X$ ( $X$ is pressure or temperature)

Excess of $X$

Residual of quantity $X$

Liquid phase mole fraction composition

Molar quantity

Gas phase mole fraction composition, or solute solubility

Charge of cation/anion

Center of mass

Direct correlation function

Direct correlation function integral

Equation of state

Force Field 


\begin{tabular}{ll} 
FST & Fluctuation solution theory \\
FT & Fluctuation theory \\
GD & Gibbs-Duhem \\
IG & Ideal gas \\
KB & Kirkwood-Buff \\
KBFF & Kirkwood-Buff Force Field \\
KBI & Kirkwood-Buff integral \\
LJ & Lennard-Jones \\
MC & Monte Carlo \\
MD & Molecular Dynamics \\
MDF & Molecular Distribution Function \\
MM & McMillan-Mayer \\
MW & Molecular Weight \\
NRTL & Non-Random Two Liquid \\
OSA & Osmotic stress analysis \\
OZ & Ornstein-Zernike \\
PF & Partition function \\
PI & Preferential Interaction \\
PMF & Potential of mean force \\
PS & Preferential Solvation \\
PY & Percus-Yevick \\
RDF & Radial distribution function \\
RK & Redlich-Kister \\
RISM & Reference interaction-site model \\
SAFT & Statistical associated-fluid theory \\
SANS & Small-angle neutron scattering \\
SAXS & Small-angle X-ray scattering \\
SI & Symmetric ideal \\
SPT & Scaled particle theory \\
TCF & Total correlation function \\
TCFI & Total correlation function integral \\
UNIFAC & UNIversal Functional Activity Coefficient \\
UNIQUAC & UNIversal QUAsiChemical \\
VDW & van der Waals \\
\hline
\end{tabular}


Abernethy, G. M., and M. J. Gillan. 1980. New method of solving the HNC equation for ionic liquids. Molecular Physics. 39, 839.

Abildskov, J., M. D. Ellegaard, and J. P. O'Connell. 2009. Correlation of phase equilibria and liquid densities for gases with ionic liquids. Fluid Phase Equilibria. 286, 95.

Abildskov, J., M. D. Ellegaard, and J. P. O'Connell. 2010a. Densities and isothermal compressibilities of ionic liquids-modeling and application. Fluid Phase Equilibria. 295, 215.

Abildskov, J., M. D. Ellegaard, and J. P. O'Connell. 2010b. Phase behavior of mixtures of ionic liquids and organic solvents. Journal of Supercritical Fluids. 55, 833.

Abramowitz, M., and I. A. Stegun. 1970. Handbook of Mathematical Functions. New York: Dover Publications, Inc.

Acree Jr., W. E. 1984. Thermodynamic Properties of Nonelectrolyte Solutions. Orlando: Academic Press, Inc.

Adschiri, T., Y. W. Lee, M. Goto, and S. Takami. 2011. Green materials synthesis with supercritical water. Green Chemistry. 13, 1380.

Allison, J. R., M. Bergeler, N. Hansen, and W. F. van Gunsteren. 2011. Current computer modeling cannot explain why two highly similar sequences fold into different structures. Biochemistry. 50, 10965.

Allison, S. K., J. P. Fox, R. Hargreaves, and S. P. Bates. 2005. Clustering and microimmiscibility in alcohol-water mixtures: Evidence from molecular-dynamics simulations. Physical Review B. 71, 024201.

Almasy, L., G. Jancso, and L. Cser. 2002. Application of SANS to the determination of Kirkwood-Buff integrals in liquid mixtures. Applied Physics A-Materials Science and Processing. 74, S1376.

Alves, W. A., and P. S. Santos. 2007. Using Raman spectroscopy to investigate donor-acceptor reactions in the formamide/dimethylsulfoxide/acetonitrile system. Journal of Raman Spectroscopy. 38, 1332.

Andersen, H. C., and D. Chandler. 1972. Optimized cluster expansions for classical fluids. I. General theory and variational formulation of the mean spherical model and hard sphere Percus-Yevick equations. Journal of Chemical Physics. 57, 1918.

Anderson, C. F., E. S. Courtenay, and M. T. Record. 2002. Thermodynamic expressions relating different types of preferential interaction coefficients in solutions containing two solute components. Journal of Physical Chemistry B. 106, 418.

Anfinsen, C. B. 1973. Principles that govern the folding of protein chains. Science. 181, 223.

Aparicio, S., R. Alcalde, B. Garcia, and J. M. Leal. 2008. Structure-composition relationships in ternary solvents containing methylbenzoate. Journal of Physical Chemistry B. 112, 3420.

Aparicio, S., R. Alcalde, J. M. Leal, and B. García. 2005. Characterization and preferential solvation of the hexane/hexan-1-ol/methylbenzoate ternary solvent. Journal of Physical Chemistry B. 109, 6375.

Arakawa, T., R. Bhat, and S. N. Timasheff. 1990. Preferential interactions determine protein solubility in 3-component solutions - the $\mathrm{MgCl}_{2}$ system. Biochemistry. 29, 1914.

Arakawa, T., and S. N. Timasheff. 1982. Preferential interactions of proteins with salts in concentrated solutions. Biochemistry. 21, 6545.

Arakawa, T., and S. N. Timasheff. 1984. Mechanism of protein salting in and salting out by divalent-cation salts - Balance between hydration and salt binding. Biochemistry. 23, 5912. 
Arakawa, T., and S. N. Timasheff. 1985a. The stabilization of proteins by osmolytes. Biophysical Journal. 47, 411.

Arakawa, T., and S. N. Timasheff. 1985b. Theory of protein solubility. Methods in Enzymology. $114,49$.

Arakawa, T., and S. N. Timasheff. 1987. Abnormal solubility behavior of $\beta$-lactoglobulin salting-in by glycine and $\mathrm{NaCl}$. Biochemistry. 26, 5147.

Archer, A. J., and N. B. Wilding. 2007. Phase behavior of a fluid with competing attractive and repulsive interactions. Physical Review E. 76, 031501.

Attard, P. 1990. Integral-equations and closure relations for the bridge function and for the triplet correlation-function. Journal of Chemical Physics. 93, 7301.

Attard, P., D. R. Berard, C. P. Ursenbach, and G. N. Patey. 1991. Interaction free-energy between planar walls in dense fluids - An Ornstein-Zernike approach with results for hard-sphere, Lennard-Jones, and dipolar systems. Physical Review A. 44, 8224.

Auton, M., and D. W. Bolen. 2004. Additive transfer free energies of the peptide backbone unit that are independent of the model compound and the choice of concentration scale. Biochemistry. 43, 1329.

Auton, M., and D. W. Bolen. 2005. Predicting the energetics of osmolyte-induced protein folding/unfolding. Proceedings of the National Academy of Sciences of the United States of America. 102, 15065.

Auton, M., and D. W. Bolen. 2007. Application of the transfer model to understand how naturally occurring osmolytes affect protein stability. Methods in Enzymology. 428, 397.

Auton, M., D. W. Bolen, and J. Rösgen. 2008. Structural thermodynamics of protein preferential solvation: Osmolyte solvation of proteins, aminoacids, and peptides. Proteins: Structure, Function, and Bioinformatics. 73, 802.

Auton, M., L. M. F. Holthauzen, and D. W. Bolen. 2007. Anatomy of energetic changes accompanying urea-induced protein denaturation. Proceedings of the National Academy of Sciences of the United States of America. 104, 15317.

Auton, M., J. Rösgen, M. Sinev, L. M. F. Holthauzen, and D. W. Bolen. 2011. Osmolyte effects on protein stability and solubility: A balancing act between backbone and side-chains. Biophysical Chemistry. 159, 90.

Baldwin, R. L. 1996. How Hofmeister ion interactions affect protein stability. Biophysical Journal. 71, 2056.

Ball, P. 2008. Water - An enduring mystery. Nature. 452, 291.

Baynes, B. M., and B. L. Trout. 2003. Proteins in mixed solvents: A molecular-level perspective. Journal of Physical Chemistry B. 107, 14058.

Behera, R. 1998. On the calculation of thermodynamic properties of electrolyte solutions from Kirkwood-Buff theory. Journal of Chemical Physics. 108, 3373.

Ben-Naim, A. 1975. Solute and solvent effects on chemical-equilibria. Journal of Chemical Physics. 63, 2064.

Ben-Naim, A. 1977. Inversion of Kirkwood-Buff theory of solutions - Application to waterethanol system. Journal of Chemical Physics. 67, 4884.

Ben-Naim, A. 1987. Solvation Thermodynamics. New York: Plenum Press.

Ben-Naim, A. 1988. Theory of preferential solvation of nonelectrolytes. Cell Biophysics. 12, 255.

Ben-Naim, A. 1989. Preferential solvation in 2-component systems. Journal of Physical Chemistry. 93, 3809. 
Ben-Naim, A. 1990a. Inversion of Kirkwood-Buff theory of solutions and its applications. In Fluctuation Theory of Mixtures, Edited by E. Matteoli and G. A. Mansoori. New York: Taylor and Francis.

Ben-Naim, A. 1990b. Preferential solvation in 2-component and in 3-component systems. Pure and Applied Chemistry. 62, 25.

Ben-Naim, A. 1992. Statistical Thermodynamics for Chemists and Biochemists. New York: Plenum Press.

Ben-Naim, A. 2006. Molecular Theory of Solutions. New York: Oxford University Press.

Ben-Naim, A. 2007a. A critique of some recent suggestions to correct the Kirkwood-Buff integrals. Journal of Physical Chemistry B. 111, 2896.

Ben-Naim, A. 2007b. Reply to "Comment on 'A critique of some recent suggestions to correct the Kirkwood-Buff integrals"'. Journal of Physical Chemistry B. 111, 3072.

Ben-Naim, A. 2008. Comment on "The Kirkwood-Buff theory of solutions and the local composition of liquid mixtures". Journal of Physical Chemistry B. 112, 5874.

Ben-Naim, A. 2009. Molecular Theory of Water and Aqueous Solutions. Part 1: Understanding Water. Singapore: World Scientific Publishing Co.

Ben-Naim, A. 2011. Molecular Theory of Water and Aqueous Solutions. Part 2: The Role of Water in Protein Folding, Self-Assembly and Molecular Recognition. Singapore: World Scientific Publishing Co.

Ben-Naim, A., and A. Santos. 2009. Local and global properties of mixtures in one-dimensional systems. II. Exact results for the Kirkwood-Buff integrals. Journal of Chemical Physics. $131,164512$.

Bennion, B. J., and V. Daggett. 2003. The molecular basis for the chemical denaturation of proteins by urea. Proceedings of the National Academy of Sciences of the United States of America. 100, 5142.

Bentenitis, N., N. R. Cox, and P. E. Smith. 2009. A Kirkwood-Buff derived force field for thiols, sulfides, and disulfides. Journal of Physical Chemistry B. 113, 12306.

Berendsen, H. J. C., J. R. Grigera, and T. P. Straatsma. 1987. The missing term in effective pair potentials. Journal of Physical Chemistry. 91, 6269.

Berendsen, H. J. C., J. P. M. Postma, W. F. van Gunsteren, and J. Hermans. 1981. Interaction models for water in relation to protein hydration. In Intermolecular Forces, Edited by B. Pullman. Dordrecht: D. Reidel.

Beutler, T. C., A. E. Mark, R. C. van Schaik, P. R. Gerber, and W. F. van Gunsteren. 1994. Avoiding singularities and numerical instabilities in free-energy calculations based on molecular simulations. Chemical Physics Letters. 222, 529.

Biben, T., and J. P. Hansen. 1991. Phase-separation of asymmetric binary hard-sphere fluids. Physical Review Letters. 66, 2215.

Bjelkmar, P., P. Larsson, M. A. Cuendet, B. Hess, and E. Lindahl. 2010. Implementation of the CHARMM force field in GROMACS: Analysis of protein stability effects from correction maps, virtual interaction sites, and water models. Journal of Chemical Theory and Computation. 6, 459.

Blanco, M. A., E. Sahin, Y. Li, and C. J. Roberts. 2011. Reexamining protein-protein and protein-solvent interactions from Kirkwood-Buff analysis of light scattering in multicomponent solutions. Journal of Chemical Physics. 134, 225103.

Blum, L., and A. J. Torruella. 1972. Invariant expansion for 2-body correlations Thermodynamic functions, scattering, and Ornstein-Zernike equation. Journal of 
Chemical Physics. 56, 303.

Bolen, D. W. 2004. Effects of naturally occurring osmolytes on protein stability and solubility: Issues important in protein crystallization. Methods. 34, 312.

Bolen, D. W., and I. V. Baskakov. 2001. The osmophobic effect: Natural selection of a thermodynamic force in protein folding. Journal of Molecular Biology. 310, 955.

Bolen, D. W., and G. D. Rose. 2008. Structure and energetics of the hydrogen-bonded backbone in protein folding. Annual Review of Biochemistry. 77, 339.

Bondi, A. 1964. van der Waals volumes and radii. Journal of Physical Chemistry. 68, 441.

Bonnet, P., and R. A. Bryce. 2004. Molecular dynamics and free energy analysis of neuraminidase-ligand interactions. Protein Science. 13, 946.

Bouillot, B., S. Teychene, and B. Biscans. 2011. An evaluation of thermodynamic models for the prediction of drug and drug-like molecule solubility in organic solvents. Fluid Phase Equilibria. 309, 36.

Bowman, G. R., V. A. Voelz, and V. S. Pande. 2011. Taming the complexity of protein folding. Current Opinion in Structural Biology. 21, 4.

Branco, R. J. F., M. Graber, V. Denis, and J. Pleiss. 2009. Molecular mechanism of the hydration of Candida antarctica lipase B in the gas phase: Water adsorption isotherms and molecular dynamics simulations. ChemBioChem. 10, 2913.

Brelvi, S. W., and J. P. O'Connell. 1972. Corresponding states correlations for liquid compressibility and partial molal volumes of gases at infinite dilution in liquids. American Institute of Chemical Engineers Journal. 18, 1239.

Brelvi, S. W., and J. P. O'Connell. 1975a. Generalized isothermal equation of state for dense liquids. American Institute of Chemical Engineers Journal. 21, 171.

Brelvi, S. W., and J. P. O'Connell. 1975b. Generalized prediction of isothermal compressibilities and an isothermal equation of state for liquid-mixtures. American Institute of Chemical Engineers Journal. 21, 1024.

Brelvi, S. W., and J. P. O'Connell. 1975c. Prediction of unsymmetric convention liquid-phase activity-coefficients of hydrogen and methane. American Institute of Chemical Engineers Journal. 21, 157.

Brennecke, J. F. 1993. Spectroscopic investigation of reactions in supercritical fluids. A review. In Supercritical Fluid Engineering Science. Fundamentals and Applications, Edited by E. Kiran and J. F. Brennecke. Washington, DC: American Chemical Society.

Brennecke, J. F., P. G. Debenedetti, C. A. Eckert, and K. P. Johnston. 1990. Letter to the editor. American Institute of Chemical Engineers Journal. 36, 1927.

Brennecke, J. F., and C. A. Eckert. 1989. Phase-equilibria for supercritical fluid process design. American Institute of Chemical Engineers Journal. 35, 1409.

Brinkman, H. C., and J. J. Hermans. 1949. The effect of non-homogeneity of molecular weight on the scattering of light by high polymer solutions. Journal of Chemical Physics. 17, 574.

Broccio, M., D. Costa, Y. Liu, and S. H. Chen. 2006. The structural properties of a two-Yukawa fluid: Simulation and analytical results. Journal of Chemical Physics. 124, 084501.

Brooks, C. L., M. Karplus, and B. M. Pettitt. 1988. Proteins: A Theoretical Perspective of Dynamics, Structure and Thermodynamics. Volume 71, Advances in Chemical Physics: Wiley.

Brunner, G. 1983. Selectivity of supercritical compounds and entrainers with respect to model substances. Fluid Phase Equilibria. 10, 289. 
Brunner, G. 2005. Supercritical fluids: Technology and application to food processing. Journal of Food Engineering. 67, 21.

Brunner, G., Ed. 2004. Supercritical Fluids as Solvents and Reaction Media. Amsterdam: Elsevier B.V.

Bruno, T. J., and J. F. Ely. 1991. Supercritical Fluid Technology Reviews in Modern Theory Application. Boca Raton: CRC Press.

Bryngelson, J. D., J. N. Onuchic, N. D. Socci, and P. G. Wolynes. 1995. Funnels, pathways, and the energy landscape of protein folding: A synthesis. Proteins: Structure, Function, and Bioinformatics. 21, 167.

Buff, F. P., and R. Brout. 1955. Molecular formulation of thermodynamic functions encountered in solution theory. Journal of Chemical Physics. 23, 458.

Buff, F. P., and F. M. Schindler. 1958. Small perturbations in solution theory. Journal of Chemical Physics. 29, 1075.

Bustamante, C., and P. Bustamante. 1996. Nonlinear enthalpy-entropy compensation for the solubility of phenacetin in dioxane-water solvent mixtures. Journal of Pharmaceutical Sciences. 85, 1109.

Bustamante, P., B. Escalera, A. Martin, and E. Selles. 1993. A modification of the extended Hildebrand approach to predict the solubility of structurally related drugs in solvent mixtures. Journal of Pharmacy and Pharmacology. 45, 253.

Cabezas, H., and J. P. O'Connell. 1986. A fluctuation theory model of strong electrolytes. Fluid Phase Equilibria. 30, 213.

Cabezas, H., and J. P. O'Connell. 1993. Some uses and misuses of thermodynamic models for dilute liquid solutions. Industrial and Engineering Chemistry Research. 32, 2892.

Cagin, T., and B. M. Pettitt. 1991. Molecular-dynamics with a variable number of molecules. Molecular Physics. 72, 169.

Callen, H. B. 1962. Thermodynamics: An Introduction to the Physical Theories of Equilibrium Thermostatics and Irreversible Thermodynamics. New York: Wiley.

Campanella, E. A., P. M. Mathias, and J. P. O'Connell. 1987. Equilibrium properties of liquids containing supercritical substances. American Institute of Chemical Engineers Journal. 33, 2057.

Canchi, D. R., and A. E. Garcia. 2011. Backbone and side-chain contributions in protein denaturation by urea. Biophysical Journal. 100, 1526.

Carter, R. W. 1992. Ph.D. Thesis, University of Delaware.

Casassa, E. F., and H. Eisenberg. 1964. Thermodynamic analysis of multicomponent solutions. Advances in Protein Chemistry. 19, 287.

Case, F. H., J. Brennan, A. Chaka, K. D. Dobbs, D. G. Friend, D. Frurip, P. A. Gordon, J. Moore, R. D. Mountain, J. Olson, R. B. Ross, M. Schiller, and V. K. Shen. 2007. The third industrial fluid properties simulation challenge. Fluid Phase Equilibria. 260, 153.

Celinski, S. A., and J. M. Scholtz. 2002. Osmolyte effects on helix formation in peptides and the stability of coiled-coils. Protein Science. 11, 2048.

Ceperley, D. M., and G. V. Chester. 1977. Perturbation approach to classical one-component plasma. Physical Review A. 15, 756.

Chaikin, P. M., and T. C. Lubensky. 2000. Principles of Condensed Matter Physics. Cambridge, UK: Cambridge University Press.

Chalikian, T. V. 2003. Volumetric properties of proteins. Annual Review of Biophysics and Biomolecular Structure. 32, 207. 
Chalikian, T. V. 2011. Volumetric measurements in binary solvents: Theory to experiment. Biophysical Chemistry. 156, 3.

Chalikian, T. V., and R. Filfil. 2003. How large are the volume changes accompanying protein transitions and binding? Biophysical Chemistry. 104, 489.

Chandler, D. 2005. Interfaces and the driving force of hydrophobic assembly. Nature. 437, 640.

Chapman, D. L. 1913. Li. A contribution to the theory of electrocapillarity. Philisophical Magazine Series 6. 25, 475.

Cheatham, T. E., and B. R. Brooks. 1998. Recent advances in molecular dynamics simulation towards the realistic representation of biomolecules in solution. Theoretical Chemistry Accounts. 99, 279.

Chialvo, A. A. 1990a. An alternative approach to modeling excess Gibbs free energy in terms of Kirkwood-Buff integrals. In Fluctuation Theory of Mixtures, Edited by E. Matteoli and G. A. Mansoori. New York: Taylor and Francis.

Chialvo, A. A. 1990b. Determination of excess Gibbs free-energy from computer-simulation via the single charging-integral approach. I. Theory. Journal of Chemical Physics. 92, 673.

Chialvo, A. A. 1991. Excess properties of liquid-mixtures from computer-simulation - A coupling-parameter approach to the determination of their dependence on molecular asymmetry. Molecular Physics. 73, 127.

Chialvo, A. A. 1993a. Accurate calculation of excess thermal, infinite dilution, and related properties of liquid mixtures via molecular-based simulation. Fluid Phase Equilibria. 83, 23.

Chialvo, A. A. 1993b. Solute-solute and solute-solvent correlations in dilute near-critical ternary mixtures: Mixed-solute and entrainer effects. Journal of Physical Chemistry. 97, 2740.

Chialvo, A. A., S. Chialvo, J. M. Simonson, and Y. V. Kalyuzhnyi. 2008. Solvation phenomena in dilute multicomponent solutions. I. Formal results and molecular outlook. Journal of Chemical Physics. 128, 214512.

Chialvo, A. A., and P. T. Cummings. 1994. Solute-induced effects on the structure and the thermodynamics of infinitely dilute mixtures. American Institute of Chemical Engineers Journal. 40, 1558.

Chialvo, A. A., and P. T. Cummings. 1995. Comment on "Near critical phase behavior of dilute mixtures". Molecular Physics. 84, 41.

Chialvo, A. A., and P. T. Cummings. 1999. Molecular-based modeling of water and aqueous solutions at supercritical conditions. In Advances in Chemical Physics, Edited by S. A. Rice. New York: Wiley and Sons.

Chialvo, A. A., P. T. Cummings, and Y. V. Kalyuzhnyi. 1998. Solvation effect on kinetic rate constant of reactions in supercritical solvents. American Institute of Chemical Engineers Journal. 44, 667.

Chialvo, A. A., P. T. Cummings, J. M. Simonson, and R. E. Mesmer. 1999. Solvation in hightemperature electrolyte solutions. II. Some formal results. Journal of Chemical Physics. $110,1075$.

Chialvo, A. A., P. T. Cummings, J. M. Simonson, and R. E. Mesmer. 2000a. Solvation in hightemperature aqueous electrolyte solutions. Journal of Molecular Liquids. 87, 233.

Chialvo, A. A., and P. G. Debenedetti. 1992. Molecular dynamics study of solute-solute microstructure in attractive and repulsive supercritical mixtures. Industrial and Engineering Chemistry Research. 31, 1391.

Chialvo, A. A., Y. V. Kalyuzhnyi, and P. T. Cummings. 1996. Solvation thermodynamics of gas 
solubility at sub- and near-critical conditions. American Institute of Chemical Engineers Journal. 42, 571.

Chialvo, A. A., P. G. Kusalik, P. T. Cummings, and J. M. Simonson. 2001. Solvation in hightemperature electrolyte solutions. III. Integral equation calculations and interpretation of experimental data. Journal of Chemical Physics. 114, 3575.

Chialvo, A. A., P. G. Kusalik, P. T. Cummings, J. M. Simonson, and R. E. Mesmer. 2000b. Molecular approach to high-temperature solvation. Formal, integral equations, and experimental results. Journal of Physics-Condensed Matter. 12, 3585.

Chialvo, A. A., P. G. Kusalik, Y. V. Kalyuzhnyi, and P. T. Cummings. 2000c. Applications of integral equations calculations to high-temperature solvation phenomena. Journal of Statistical Physics. 100, 167.

Chiti, F., and C. M. Dobson. 2006. Protein misfolding, functional amyloid, and human disease. Annual Review of Biochemistry. 75, 333.

Chitra, R., and P. E. Smith. 2000. Molecular dynamics simulations of the properties of cosolvent solutions. Journal of Physical Chemistry B. 104, 5854.

Chitra, R., and P. E. Smith. 2001a. A comparison of the properties of 2,2,2-trifluoroethanol and 2,2,2-trifluoroethanol/water mixtures using different force fields. Journal of Chemical Physics. 115, 5521.

Chitra, R., and P. E. Smith. 2001b. Preferential interactions of cosolvents with hydrophobic solutes. Journal of Physical Chemistry B. 105, 11513.

Chitra, R., and P. E. Smith. 2001c. Properties of 2,2,2-trifluoroethanol and water mixtures. Journal of Chemical Physics. 114, 426.

Chitra, R., and P. E. Smith. 2002. Molecular association in solution: A Kirkwood-Buff analysis of sodium chloride, ammonium sulfate, guanidinium chloride, urea, and 2,2,2trifluoroethanol in water. Journal of Physical Chemistry B. 106, 1491.

Cho, S. S., Y. Levy, and P. G. Wolynes. 2009. Quantitative criteria for native energetic heterogeneity influences in the prediction of protein folding kinetics. 106, 434.

Choudhury, N. 2006. A molecular dynamics simulation study of buckyballs in water: Atomistic versus coarse-grained models of $\mathrm{C}_{60}$. Journal of Chemical Physics. 125, 034502.

Choudhury, N., and B. M. Pettitt. 2005a. Local density profiles are coupled to solute size and attractive potential for nanoscopic hydrophobic solutes. Molecular Simulation. 31, 457.

Choudhury, N., and B. M. Pettitt. 2005b. On the mechanism of hydrophobic association of nanoscopic solutes. Journal of the American Chemical Society. 127, 3556.

Choudhury, N., and B. M. Pettitt. 2006a. Enthalpy-entropy contributions to the potential of mean force of nanoscopic hydrophobic solutes. Journal of Physical Chemistry B. 110, 8459.

Choudhury, N., and B. M. Pettitt. 2006b. The role of attractive forces on the dewetting of large hydrophobic solutes. In Modelling Molecular Structure and Reactivity in Biological Systems, Edited by K. J. Naidoo. Cambridge, UK: Royal Society of Chemistry.

Choudhury, N., and B. M. Pettitt. 2007. The dewetting transition and the hydrophobic effect. Journal of the American Chemical Society. 129, 4847.

Christensen, S., G. H. Peters, F. Y. Hansen, and J. Abildskov. 2007a. Thermodynamic models from fluctuation solution theory analysis of molecular simulations. Fluid Phase Equilibria. 261, 185.

Christensen, S., G. H. Peters, F. Y. Hansen, J. P. O’Connell, and J. Abildskov. 2007b. Generation of thermodynamic data for organic liquid mixtures from molecular simulations. Molecular Simulation. 33, 449. 
Christensen, S., G. H. Peters, F. Y. Hansen, J. P. O'Connell, and J. Abildskov. 2007c. State conditions transferability of vapor-liquid equilibria via fluctuation solution theory with correlation function integrals from molecular dynamics simulation. Fluid Phase Equilibria. 260, 169.

Ciach, A., and W. T. Gozdz. 2001. Nonelectrolyte solutions exhibiting structure on the nanoscale. Annual Reports on the Progress of Chemistry, Section "C" (Physical Chemistry). 97, 269.

Clifford, A. A. 1999. Fundamentals of Supercritical Fluids. New York: Oxford University Press.

Clifford, A. A., K. Pople, W. J. Gaskill, K. D. Bartle, and C. M. Rayner. 1998. Potential tuning and reaction control in the Diels-Alder reaction between cyclopentadiene and methyl acrylate in supercritical carbon dioxide. Journal of the Chemical Society, Faraday Transactions. 94, 1451.

Cochran, H. D., L. L. Lee, and D. M. Pfund. 1990. Structure and properties of supercritical fluid mixtures from Kirkwood-Buff fluctuation theory and integral equation methods. In Fluctuation Theory of Mixtures, Edited by E. Matteoli and G. A. Mansoori. New York: Taylor and Francis.

Cohn, E. J., and J. T. Edsall. 1943. Proteins, amino acids and peptides as ions and dipolar ions. New York: Reinhold Publishing Corporation.

Conti, G., P. Gianni, L. Lepori, and E. Matteoli. 2003. Volumetric study of (2-methoxyethanol + tetrahydrofuran + cyclohexane) at 298.15 K. Journal of Chemical Thermodynamics. 35, 503.

Cooney, W. R., and J. P. O'Connell. 1987. Correlation of partial molar volumes at infinite dilution of salts in water. Chemical Engineering Communications. 56, 341.

Cornell, W. D., P. Cieplak, C. I. Bayly, I. R. Gould, K. M. Merz, D. M. Ferguson, D. C. Spellmeyer, T. Fox, J. W. Caldwell, and P. A. Kollman. 1995. A 2nd generation forcefield for the simulation of proteins, nucleic-acids, and organic-molecules. Journal of the American Chemical Society. 117, 5179.

Courtenay, E. S., M. W. Capp, C. F. Anderson, and M. T. Record. 2000. Vapor pressure osmometry studies of osmolyte-protein interactions: Implications for the action of osmoprotectants in vivo and for the interpretation of "osmotic stress" experiments in vitro. Biochemistry. 39, 4455.

Courtenay, E. S., M. W. Capp, and M. T. Record. 2001. Thermodynamics of interactions of urea and guanidinium salts with protein surface: Relationship between solute effects on protein processes and changes in water-accessible surface area. Protein Science. 10, 2485.

Coussaert, T., and M. Baus. 1997. Virial approach to hard-sphere demixing. Physical Review Letters. 79, 1881.

Curtiss, C. F., and R. B. Bird. 1999. Multicomponent diffusion. Industrial and Engineering Chemistry Research. 38, 2515.

D'Arrigo, G., R. Giordano, and J. Teixeira. 2009. Temperature and concentration dependence of SANS spectra of aqueous solutions of short-chain amphiphiles. European Physical Journal E. 29, 37.

Dai, S., S. Weerasinghe, and P. E. Smith. 2012. A Kirkwood-Buff derived force field for amines and carboxylic acids. In preparation.

Davidson, N. R. 1962. Statistical Mechanics. New York: McGraw-Hill.

Davis-Searles, P. R., A. J. Saunders, D. A. Erie, D. J. Winzor, and G. J. Pielak. 2001. 
Interpreting the effects of small uncharged solutes on protein-folding equilibria. Annual Review of Biophysics and Biomolecular Structure. 30, 271.

Davis, M. I. 1993. Thermodynamic and related studies of amphiphile plus water-systems. Chemical Society Reviews. 22, 127.

Day, R., D. Paschek, and A. E. Garcia. 2010. Microsecond simulations of the folding/unfolding thermodynamics of the Trp-cage miniprotein. Proteins: Structure, Function, and Bioinformatics. 78, 1889.

de Boer, J. 1940. Contribution to the theory of compressed gases. Ph.D. Thesis, University of Amsterdam, Amsterdam.

de Boer, J. 1949. Molecular distribution and equation of state of gases. Reports on Progress in Physics. 12, 305.

de Gennes, P. G. 1977. Microscopic Structure and Dynamics of Liquids. New York: Plenum Press.

Debenedetti, P. G. 1988. Fluctuation-based computer calculation of partial molar properties. 2. A numerically accurate method for the determination of partial molar energies and enthalpies. Journal of Chemical Physics. 88, 2681.

Debenedetti, P. G., and A. A. Chialvo. 1992. Solute-solute correlations in infinitely dilute supercritical mixtures. Journal of Chemical Physics. 97, 504.

Debenedetti, P. G., and S. K. Kumar. 1986. Infinite dilution fugacity coefficients and the general behavior of dilute binary systems. American Institute of Chemical Engineers Journal. 32, 1253.

Debenedetti, P. G., and S. K. Kumar. 1988. The molecular basis of temperature effects in supercritical extraction. American Institute of Chemical Engineers Journal. 34, 645.

Debenedetti, P. G., and R. S. Mohamed. 1989. Attractive, weakly attractive and repulsive nearcritical systems. Journal of Chemical Physics. 90, 4528.

Derr, E. L., and C. H. Deal, Jr. 1969. Analytical solutions of groups. Correlation of activity coefficients through structural group parameters. Paper read at Proceedings of the International Symposium on Distillation.

Dickhut, R. M., A. W. Andren, and D. E. Armstrong. 1989. Naphthalene solubility in selected organic solvent-water mixtures. Journal of Chemical and Engineering Data. 34, 438.

Diedrichs, A., and J. Gmehling. 2011. Solubility calculation of active pharmaceutical ingredients in alkanes, alcohols, water and their mixtures using various activity coefficient models. Industrial and Engineering Chemistry Research. 50, 1757.

Dill, K. A. 1990. Dominant forces in protein folding. Biochemistry. 29, 7133.

Dill, K. A., K. Ghosh, and J. D. Schmit. 2011. Physical limits of cells and proteomes. Proceedings of the National Academy of Sciences of the United States of America. 108, 17876.

Dixit, S., J. Crain, W. C. K. Poon, J. L. Finney, and A. K. Soper. 2002. Molecular segregation observed in a concentrated alcohol-water solution. Nature. 416, 829.

Dixon, M., and P. Hutchinson. 1977. Method for extrapolation of pair distribution functions. Molecular Physics. 33, 1663.

Dougan, L., S. P. Bates, R. Hargreaves, J. P. Fox, J. Crain, J. L. Finney, V. Reat, and A. K. Soper. 2004. Methanol-water solutions: A bi-percolating liquid mixture. Journal of Chemical Physics. 121, 6456.

Dyson, H. J., and P. E. Wright. 2002. Coupling of folding and binding for unstructured proteins. Current Opinion in Structural Biology. 12, 54. 
Dyson, H. J., and P. E. Wright. 2005. Intrinsically unstructured proteins and their functions. Nature Reviews Molecular Cell Biology. 6, 197.

Economou, I. G. 2002. Statistical Associating Fluid Theory: A successful model for the calculation of thermodynamic and phase equilibrium properties of complex fluid mixtures. Industrial and Engineering Chemistry Research. 41, 953.

Economou, I. G., and M. D. Donohue. 1990. Mean field calculation of thermodynamic properties of supercritical fluids. American Institute of Chemical Engineers Journal. 36, 1920.

Einstein, A. 1910. Theorie der opaleszenz von homogenen flüssigkeiten und flüssigkeitsgemischen in der nähe des kritischen zustandes. Annalen der Physik. 33, 1275 .

Eisenberg, H. 1976. Biological Macromolecules and Polyelectrolytes in Solution. Oxford: Clarendon Press.

Ellegaard, M. D. 2011. Molecular thermodynamics using fluctuation solution theory. Ph.D. Thesis, Department of Chemical and Biochemical Engineering, Technical University of Denmark.

Ellegaard, M. D., J. Abildskov, and J. P. O'Connell. 2010. Molecular thermodynamic modeling of mixed solvent solubility. Industrial and Engineering Chemistry Research. 49, 11620.

Ellegaard, M. D., J. Abildskov, and J. P. O'Connell. 2011. Solubilities of gases in ionic liquids using a corresponding-states approach to Kirkwood-Buff solution theory. Fluid Phase Equilibria. 302, 93.

Ellegaard, M. E., J. Abildskov, and J. P. O'Connell. 2009. Method for predicting solubilities of solids in mixed solvents. American Institute of Chemical Engineers Journal. 55, 1256.

Ellington, J. B., K. M. Park, and J. F. Brennecke. 1994. Effect of local composition enhancements on the esterification of phtalic-anhydride with methanol in supercritical carbon-dioxide. Industrial and Engineering Chemistry Research. 33, 965.

Enciso, E. 1985. Numerical-solution of the SSOZ equation by extension of Gillan method to nonhomonuclear molecular fluids. Molecular Physics. 56, 129.

Felitsky, D. J., and M. T. Record. 2004. Application of the local-bulk partitioning and competitive binding models to interpret preferential interactions of glycine betaine and urea with protein surface. Biochemistry. 43, 9276.

Feng, J. W. A., J. Kao, and G. R. Marshall. 2009. A second look at mini-protein stability: Analysis of FSD-1 using circular dichroism, differential scanning calorimetry, and simulations. Biophysical Journal. 97, 2803.

Ferrario, M., M. Haughney, I. R. McDonald, and M. L. Klein. 1990. Molecular-dynamics simulation of aqueous mixtures - Methanol, acetone, and ammonia. Journal of Chemical Physics. 93, 5156.

Fisher, M. E. 1964. Correlation functions + critical region of simple fluids. Journal of Mathematical Physics. 5, 944.

Foffi, G., C. de Michele, F. Sciortino, and P. Tartaglia. 2005. Arrested phase separation in a short-ranged attractive colloidal system: A numerical study. Journal of Chemical Physics. $122,224903$.

Foiles, S. M., N. W. Ashcroft, and L. Reatto. 1984. Structure factor and direct correlationfunction of a fluid from finite-range simulation data. Journal of Chemical Physics. 81, 6140.

Forsythe, E. L., R. A. Judge, and M. L. Pusey. 1999. Tetragonal chicken egg white lysozyme solubility in sodium chloride solutions. Journal of Chemical and Engineering Data. 44, 
637.

Fowler, R. H., and E. A. Guggenheim. 1939. Statistical Thermodynamics: A Version of Statistical Mechanics for Students of Physics and Chemistry. Cambridge, England: The University Press.

Frank, H. S., and F. Franks. 1968. Structural approach to solvent power of water for hydrocarbons - Urea as a structure breaker. Journal of Chemical Physics. 48, 4746.

Franks, F., and D. J. G. Ives. 1966. The structural properties of alcohol-water mixtures. Quarterly Reviews, Chemical Society. 20, 1.

Freddolino, P. L., C. B. Harrison, Y. X. Liu, and K. Schulten. 2010. Challenges in proteinfolding simulations. Nature Physics. 6, 751.

Fredenslund, A., J. Gmehling, and P. Rasmussen. 1977. Vapor-Liquid Equilibria Using UNIFAC: A Group-Contribution Method. Amsterdam: Elsevier.

Fredenslund, A., R. L. Jones, and J. M. Prausnitz. 1975. Group-contribution estimation of activity-coefficients in nonideal liquid-mixtures. American Institute of Chemical Engineers Journal. 21, 1086.

French, H. T. 1987. Vapour pressures and activity coefficients of (acetonitrile + water) at 308.15 K. Journal of Chemical Thermodynamics. 19, 1155.

Friedman, H. L. 1962. Ionic Solution Theory: Based on Cluster Expansion Methods, Monographs in Statistical Physics and Thermodynamics. New York: Interscience Publishers.

Friedman, H. L. 1986. Methods to determine structure in water and aqueous solutions. In Methods in Enzymology, Edited by P. Lester: Academic Press.

Friedman, H. L., and P. S. Ramanathan. 1970. Theory of mixed electrolyte solutions and application to a model for aqueous lithium chloride-cesium chloride. Journal of Physical Chemistry. 74, 3756.

Fries, P. H., and G. N. Patey. 1985. The solution of the hypernetted-chain approximation for fluids of nonspherical particles - A general-method with application to dipolar hardspheres. Journal of Chemical Physics. 82, 429.

Frisch, H. L., and J. L. Lebowitz. 1964. The Equilibrium Theory of Classical Fluids: A Lecture Note and Reprint Volume. Edited by H. L. Frisch and J. L. Lebowitz. New York: W. A. Benjamin.

Galam, S., and J. P. Hansen. 1976. Statistical-mechanics of dense ionized matter. 6. Electron screening corrections to thermodynamic properties of one-component plasma. Physical Review A. 14, 816.

García, B., S. Aparicio, R. Alcalde, and J. M. Leal. 2003. Preferential solvation in ternary solutions containing methylbenzoate. A Kirkwood-Buff fluctuation theory study. Journal of Physical Chemistry B. 107, 13478.

Gardas, R. L., M. G. Freire, P. J. Carvalho, I. M. Marrucho, I. M. A. Fonseca, A. G. M. Ferreira, and J. A. P. Coutinho. 2007. P $\rho$ T measurements of imidazolium-based ionic liquids. Journal of Chemical and Engineering Data. 52, 1881.

Gee, M. B. 2010. Computer simulation and theory of amino acid interactions in solution, Chemistry, Kansas State University, Manhattan, Kansas.

Gee, M. B., N. R. Cox, Y. Jiao, N. Bentenitis, S. Weerasinghe, and P. E. Smith. 2011. A Kirkwood-Buff derived force field for aqueous alkali halides. Journal of Chemical Theory and Computation. 7, 1369.

Gee, M. B., and P. E. Smith. 2009. Kirkwood-Buff theory of molecular and protein association, 
aggregation, and cellular crowding. Journal of Chemical Physics. 131, 165101.

Gee, M. B., and P. E. Smith. 2012. A Kirkwood-Buff derived force field for amine salts and carboxylates. In preparation.

Gekko, K., and S. N. Timasheff. 1981. Thermodynamic and kinetic examination of protein stabilization by glycerol. Biochemistry. 20, 4677.

Gianni, P., L. Lepori, and E. Matteoli. 2010. Excess Gibbs energies and volumes of the ternary system chloroform + tetrahydrofuran + cyclohexane at 298.15 K. Fluid Phase Equilibria. 297, 52.

Gibbs, J. W. 1902. Elementary Principles in Statistical Mechanics: Developed with Special Reference to the Rational Foundation of Thermodynamics. New York: Charles Scribner's Sons.

Gibbs, J. W. 1948. Elementary principles in statistical mechanics. In The Collected Works of J. Willard Gibbs. New Haven: Yale University Press.

Gillan, M. J. 1979. New method of solving the liquid structure integral-equations. Molecular Physics. 38, 1781.

Girardeau, M. D., and R. M. Mazo. 1973. Variational methods in statistical mechanics. In Advances in Chemical Physics, Edited by I. Prigogine and S. Rice: John Wiley and Sons, Inc.

Gmehling, J. 1995. From UNIFAC to modified UNIFAC to PSRK with the help of DDB. Fluid Phase Equilibria. 107, 1.

Gouy, M. 1910. Sur la constitution de la charge électrique à la surface d'un électrolyte. Journal de Physique Théorique et Appliquée. 9, 457.

Gray, C. G., and K. E. Gubbins. 1984. Theory of Molecular Fluids. Volume 1: Fundamentals. New York: Oxford University Press.

Greene, R. F., and C. N. Pace. 1974. Urea and guanidine-hydrochloride denaturation of ribonuclease, lysozyme, $\alpha$-chymotrypsin, and $\beta$-lactoglobulin. Journal of Biological Chemistry. 249, 5388.

Gross, J., and G. Sadowski. 2001. Perturbed-chain SAFT: An equation of state based on a perturbation theory for chain molecules. Industrial and Engineering Chemistry Research. 40, 1244.

Gross, J., and J. Vrabec. 2006. An equation-of-state contribution for polar components: Dipolar molecules. American Institute of Chemical Engineers Journal. 52, 1194.

Gruszkiewicz, M. S., and R. H. Wood. 1997. Conductance of dilute $\mathrm{LiCl}, \mathrm{NaCl}, \mathrm{NaBr}$, and $\mathrm{CsBr}$ solutions in supercritical water using a flow conductance cell. Journal of Physical Chemistry B. 101, 6549.

Gubbins, K. E., and J. P. O'Connell. 1974. Isothermal compressibility and partial molal volume for polyatomic liquids. Journal of Chemical Physics. 60, 3449.

Guo, B., S. Kao, H. McDonald, A. Asanov, L. L. Combs, and W. W. Wilson. 1999. Correlation of second virial coefficients and solubilities useful in protein crystal growth. Journal of Crystal Growth. 196, 424.

Guo, J. H., Y. Luo, A. Augustsson, S. Kashtanov, J. E. Rubensson, D. K. Shuh, H. Agren, and J. Nordgren. 2003. Molecular structure of alcohol-water mixtures. Physical Review Letters. $91,157401$.

Hall, D. G. 1971. Kirkwood-Buff theory of solutions - Alternative derivation of part of it and some applications. Transactions of the Faraday Society. 67, 2516.

Hall, D. G. 1983. Thermodynamics of micellar solutions. In Aggregation Processes in Solution, 
Edited by J. Gormally and E. Wyn-Jones. Amsterdam: Elsevier Scientific Publishing Co. Hamer, W. J., and Y.-C. Wu. 1972. Osmotic coefficients and mean activity coefficients of uniunivalent electrolytes in water at 25 degrees. Journal of Physical Chemistry Reference Data. 1, 1047.

Handa, Y. P., and G. C. Benson. 1979. Volume changes on mixing 2 liquids - Review of the experimental-techniques and the literature data. Fluid Phase Equilibria. 3, 185.

Hansen, J. P., and I. R. McDonald. 1986. Theory of Simple Liquids. 2nd. Ed. New York: Academic Press.

Hansen, J. P., and I. R. McDonald. 2006. Theory of Simple Liquids. 3rd. Ed. Amsterdam: Academic Press.

Henderson, D. 1974. Theory of simple mixtures. Annual Review of Physical Chemistry. 25, 461.

Henry, W. 1803. Experiments on the quantity of gases absorbed by water, at different temperatures, and under different pressures. Philosophical Transactions of the Royal Society of London. 93, 29.

Herczenik, E., and M. F. B. G. Gebbink. 2008. Molecular and cellular aspects of protein misfolding diseases. The FASEB Journal. 22, 2115.

Hess, B., C. Kutzner, D. van der Spoel, and E. Lindahl. 2008. GROMACS 4: Algorithms for highly efficient, load-balanced, and scalable molecular simulation. Journal of Chemical Theory and Computation. 4, 435.

Hess, B., and N. F. A. van der Vegt. 2009. Cation specific binding with protein surface charges. Proceedings of the National Academy of Sciences of the United States of America. 106, 13296.

Hildebrand, J. H. 1924. Solubility. New York: Chemical Catalog Company.

Hill, T. L. 1956. Statistical Mechanics: Principles and Selected Applications. New York: McGraw-Hill.

Hill, T. L. 1957. Theory of solutions. I. Journal of the American Chemical Society. 79, 4885.

Hill, T. L. 1959. Theory of solutions. II. Osmotic pressure virial expansion and light scattering in two component solutions. Journal of Chemical Physics. 30, 93.

Hnědkovský, L., V. Majer, and R. H. Wood. 1995. Volumes and heat-capacities of $\mathrm{H}_{3} \mathrm{BO}_{3}(a q)$ at temperatures from $298.15 \mathrm{~K}$ to $705 \mathrm{~K}$ and at pressures to $35 \mathrm{MPa}$. Journal of Chemical Thermodynamics. 27, 801.

Hnědkovský, L., R. H. Wood, and V. Majer. 1996. Volumes of aqueous solutions of $\mathrm{CH}_{4}, \mathrm{CO}_{2}$, $\mathrm{H}_{2} \mathrm{~S}$, and $\mathrm{NH}_{3}$ at temperatures from $298.15 \mathrm{~K}$ to $705 \mathrm{~K}$ and pressures to $35 \mathrm{MPa}$. Journal of Chemical Thermodynamics. 28, 125.

Horinek, D., and R. R. Netz. 2011. Can simulations quantitatively predict peptide transfer free energies to urea solutions? Thermodynamic concepts and force field limitations. Journal of Physical Chemistry A. 115, 6125.

Hornak, V., R. Abel, A. Okur, B. Strockbine, A. Roitberg, and C. Simmerling. 2006. Comparison of multiple Amber force fields and development of improved protein backbone parameters. Proteins: Structure, Function, and Bioinformatics. 65, 712.

Horta, B. A. C., P. F. J. Fuchs, W. F. van Gunsteren, and P. H. Hünenberger. 2011. New interaction parameters for oxygen compounds in the GROMOS force field: Improved pure-liquid and solvation properties for alcohols, ethers, aldehydes, ketones, carboxylic acids, and esters. Journal of Chemical Theory and Computation. 7, 1016.

Hu, C. Y., H. Kokubo, G. C. Lynch, D. W. Bolen, and B. M. Pettitt. 2010a. Backbone additivity in the transfer model of protein solvation. Protein Science. 19, 1011. 
Hu, C. Y., G. C. Lynch, H. Kokubo, and B. M. Pettitt. 2010b. Trimethylamine N-oxide influence on the backbone of proteins: An oligoglycine model. Proteins: Structure, Function, and Bioinformatics. 78, 695.

Hu, C. Y., B. M. Pettitt, and J. Rösgen. 2009. Osmolyte solutions and protein folding. F1000 Biology Reports. 1, 1.

Hu, Y. 1997. Fluctuation solution theory for strong electrolyte solutions. Ph.D. Thesis, University of Virginia.

Hua, L., R. Zhou, D. Thirumalai, and B. J. Berne. 2008. Urea denaturation by stronger dispersion interactions with proteins than water implies a 2-stage unfolding. Proceedings of the National Academy of Sciences of the United States of America. 105, 16928.

Huang, Y. H., and J. P. O'Connell. 1987. Corresponding states correlation for the volumetric properties of compressed liquids and liquid-mixtures. Fluid Phase Equilibria. 37, 75.

Hutchenson, K. W., A. M. Scurto, and B. Subramaniam, Eds. 2009. Gas-Expanded Liquids and Near-Critical Media: Green Chemistry and Engineering. Volume 1006, ACS symposium series.

Hynes, J. T. 1985. The theory of reactions in solution. In Theory of Chemical Reaction Dynamics, Edited by M. Baer. Boca Raton: CRC Press.

Jacquemin, J., P. Husson, V. Mayer, and I. Cibulka. 2007. High-pressure volumetric properties of imidazolium-based ionic liquids: Effect of the anion. Journal of Chemical and Engineering Data. 52, 2204.

Jagla, E. A. 1999. Core-softened potentials and the anomalous properties of water. Journal of Chemical Physics. 111, 8980.

Jakob, A., H. Grensemann, J. Lohmann, and J. Gmehling. 2006. Further development of modified UNIFAC (Dortmund): Revision and extension 5. Industrial and Engineering Chemistry Research. 45, 7924.

Janz, G. J., B. G. Oliver, G. R. Lakshmin, and G. E. Mayer. 1970. Electrical conductance, diffusion, viscosity, and density of sodium nitrate, sodium perchlorate, and sodium thiocyanate in concentrated aqueous solutions. Journal of Physical Chemistry. 74, 1285.

Jha, A. K., A. Colubri, M. H. Zaman, S. Koide, T. R. Sosnick, and K. F. Freed. 2005. Helix, sheet, and polyproline II frequencies and strong nearest neighbor effects in a restricted coil library. Biochemistry. 44, 9691.

Jiang, W., M. Hodoscek, and B. Roux. 2009. Computation of absolute hydration and binding free energy with free energy perturbation distributed replica-exchange molecular dynamics (FEP/REMD). Journal of Chemical Theory and Computation. 5, 2583.

Jiao, Y., F. Chen, S. Weerasinghe, and P. E. Smith. 2012. A Kirkwood-Buff derived force field for alchohols in water. In preparation.

Jiao, Y., and P. E. Smith. 2011. Fluctuation theory of molecular association and conformational equilibria. Journal of Chemical Physics. 135, 014502.

Jolly, D. L., and R. J. Bearman. 1980. Molecular-dynamics simulation of the mutual and selfdiffusion coefficients in Lennard-Jones liquid-mixtures. Molecular Physics. 41, 137.

Jolly, D. L., B. C. Freasier, and R. J. Bearman. 1976. Extension of simulation radial-distribution functions to an arbitrary range by Baxter's factorization technique. Chemical Physics. 15, 237.

Jonah, D. A. 1983. Investigation of binary-liquid mixtures via the study of infinitely dilutesolutions. Advances in Chemistry Series. 395.

Jonah, D. A. 1986. On a method of numerical differentiation and its application to the evaluation 
of limiting activity-coefficients and their 1st derivatives. Chemical Engineering Science. 41, 2261.

Jonah, D. A., and H. D. Cochran. 1994. Chemical-potentials in dilute, multicomponent solutions. Fluid Phase Equilibria. 92, 107.

Jorgensen, W. L., J. Chandrasekhar, J. D. Madura, R. W. Impey, and M. L. Klein. 1983. Comparison of simple potential functions for simulating liquid water. Journal of Chemical Physics. 79, 926.

Jorgensen, W. L., and J. Tirado-Rives. 2005. Potential energy functions for atomic-level simulations of water and organic and biomolecular systems. Proceedings of the National Academy of Sciences of the United States of America. 102, 6665.

Jorgensen, W. L., and J. Tirado-Rives. 1988. The OPLS potential functions for proteins - energy minimizations for crystals of cyclic-peptides and crambin. Journal of the American Chemical Society. 110, 1657.

Joung, I. S., and T. E. Cheatham, III. 2008. Determination of alkali and halide monovalent ion parameters for use in explicitly solvated biomolecular simulations. Journal of Physical Chemistry B. 112, 9020.

Joung, I. S., and T. E. Cheatham, III. 2009. Molecular dynamics simulations of the dynamic and energetic properties of alkali and halide ions using water-model-specific ion parameters. Journal of Physical Chemistry B. 113, 13279.

Jouyban-Gharamaleki, A., L. Valaee, M. Barzegar-Jalali, B. J. Clark, and W. E. Acree. 1999. Comparison of various cosolvency models for calculating solute solubility in watercosolvent mixtures. International Journal of Pharmaceutics. 177, 93.

Jouyban, A., S. Romero, H. K. Chan, B. J. Clark, and P. Bustamante. 2002. A cosolvency model to predict solubility of drugs at several temperatures from a limited number of solubility measurements. Chemical and Pharmaceutical Bulletin. 50, 594.

Juraszek, J., and P. G. Bolhuis. 2008. Rate constant and reaction coordinate of Trp-cage folding in explicit water. Biophysical Journal. 95, 4246.

Kaminski, G. A., R. A. Friesner, J. Tirado-Rives, and W. L. Jorgensen. 2001. Evaluation and reparametrization of the OPLS-AA force field for proteins via comparison with accurate quantum chemical calculations on peptides. Journal of Physical Chemistry B. 105, 6474.

Kan, A. T., and M. B. Tomson. 1996. UNIFAC prediction of aqueous and nonaqueous solubilities of chemicals with environmental interest. Environmental Science and Technology. 30, 1369.

Kang, M., and P. E. Smith. 2006. A Kirkwood-Buff derived force field for amides. Journal of Computational Chemistry. 27, 1477.

Kang, M., and P. E. Smith. 2007. Preferential interaction parameters in biological systems by Kirkwood-Buff theory and computer simulation. Fluid Phase Equilibria. 256, 14.

Kang, M., and P. E. Smith. 2008. Kirkwood-Buff theory of four and higher component mixtures. Journal of Chemical Physics. 128, 244511.

Karunaweera, S., M. B. Gee, S. Weerasinghe, and P. E. Smith. 2012. Theory and simulation of multicomponent osmotic systems. Journal of Chemical Theory and Computation. in press.

Kauzmann, W. 1959. Some factors in the interpretation of protein denaturation. In Advances in Protein Chemistry, Edited by C. B. Anfinsen, M. L. Anson, K. Bailey and J. T. Edsall. San Diego: Academic Press Inc.

Kežić, B., and A. Perera. 2011. Towards a more accurate reference interaction site model integral 
equation theory for molecular liquids. Journal of Chemical Physics. 135, 234104.

Kim, J. I. 1978. A critical study of the $\mathrm{Ph}_{4} \mathrm{AsPh}_{4} \mathrm{~B}$ assumption for single ion thermodynamics in amphiprotic and dipolar-aprotic solvents; evaluation of physical parameters relevant to theoretical consideration. Zeitschrift für Physikalische Chemie. 113, 129.

Kimura, Y., and Y. Yoshimura. 1992. Chemical-equilibrium in fluids from the gaseous to liquid states: Solvent density dependence of the dimerization equilibrium of 2-methyl-2nitrosopropane in carbon dioxide, chlorotrifluoromethane, and trifluoromethane. Journal of Chemical Physics. 96, 3085.

Kiran, E., P. G. Debenedetti, and C. J. Peters, Eds. 2000. Supercritical fluids. Fundamentals and applications. Volume E366, Nato asi. Dordrecht: Klüwer Academic Publishers.

Kiran, E., and J. M. H. Levelt Sengers. 1994. Supercritical fluids. Fundamentals for applications. Volume E273, Nato asi. Dordrecht: Klüwer Academic Publishers.

Kirkwood, J. G. 1934. Theory of solutions of molecules containing widely separated charges with special application to zwitterions. Journal of Chemical Physics. 2, 351.

Kirkwood, J. G. 1935. Statistical mechanics of fluid mixtures. Journal of Chemical Physics. 3, 300.

Kirkwood, J. G. 1936. Statistical mechanics of liquid solutions. Chemical Reviews. 19, 275.

Kirkwood, J. G. Privately circulated. Selected topics in statistical mechanics based on a series of lectures. Lectures delivered at Princeton University, Spring term of 1947. Notes by J. H. Irving.

Kirkwood, J. G., and F. P. Buff. 1951. The statistical mechanical theory of solutions. 1. Journal of Chemical Physics. 19, 774.

Kirkwood, J. G., and R. J. Goldberg. 1950. Light scattering arising from composition fluctuations in multi-component systems. Journal of Chemical Physics. 18, 54.

Klein-Seetharaman, J., M. Oikawa, S. B. Grimshaw, J. Wirmer, E. Duchardt, T. Ueda, T. Imoto, L. J. Smith, C. M. Dobson, and H. Schwalbe. 2002. Long-range interactions within a nonnative protein. Science. 295, 1719.

Knez, E. 2009. Enzymatic reactions in dense gases. Journal of Supercritical Fluids. 47, 357.

Koga, Y. 2007. Solution Thermodynamics and its Application to Aqueous Solutions Amsterdam: Elsevier.

Kojima, K., and K. Tochigi. 1979. Prediction of Vapor-Liquid Equilibria by the ASOG Method. Tokyo: Elsevier Scientific Publishing Company.

Kojima, K., S. J. Zhang, and T. Hiaki. 1997. Measuring methods of infinite dilution activity coefficients and a database for systems including water. Fluid Phase Equilibria. 131, 145.

Kokubo, H., C. Y. Hu, and B. M. Pettitt. 2011. Peptide conformational preferences in osmolyte solutions: Transfer free energies of decaalanine. Journal of the American Chemical Society. 133, 1849.

Kokubo, H., and B. Pettitt. 2007. Preferential solvation in urea solutions at different concentrations: Properties from simulation studies. Journal of Physical Chemistry B. 111, 5233.

Kokubo, H., J. Rösgen, D. W. Bolen, and B. M. Pettitt. 2007a. Physicochemical basis of nonideality in urea solutions by chemical potential calculations. Biophysical Journal. 642A.

Kokubo, H., J. Rösgen, D. W. Bolen, and B. M. Pettitt. 2007b. Molecular basis of the apparent near ideality of urea solutions. Biophysical Journal. 93, 3392.

Kontogeorgis, G. M., M. L. Michelsen, G. K. Folas, S. Derawi, N. von Solms, and E. H. Stenby. 
2006a. Ten years with the applications of cubic-plus-association EOS to pure organic compounds and self-associating system (cubic-plus-association) equation of state. Part 1. Pure compounds and self-associating systems. Industrial and Engineering Chemistry Research. 45, 4855.

Kontogeorgis, G. M., M. L. Michelsen, G. K. Folas, S. Derawi, N. von Solms, and E. H. Stenby. 2006b. Ten years with the CPA (cubic-plus-association) equation of state. Part 2. Crossassociating and multicomponent systems. Industrial and Engineering Chemistry Research. 45, 4869.

Kontogeorgis, G. M., E. C. Voutsas, I. V. Yakoumis, and D. P. Tassios. 1996. An equation of state for associating fluids. Industrial and Engineering Chemistry Research. 35, 4310.

Kornblatt, J. A., and M. J. Kornblatt. 2002. The effects of osmotic and hydrostatic pressures on macromolecular systems. Biochimica Et Biophysica Acta-Protein Structure and Molecular Enzymology. 1595, 30.

Krichevskii, I. R. 1937. Thermodynamics of an infinitely dilute solution in mixed solvents. I. The Henry coefficient in a mixed solvent behaving as an ideal solvent. Zhurnal Fizicheskoi Khimii. 9, 41.

Kruse, A., and E. Dinjus. 2007. Hot compressed water as reaction medium and reactant properties and synthesis reactions. Journal of Supercritical Fluids. 39, 362.

Kulkarni, A. M., and C. F. Zukoski. 2002. Nanoparticle crystal nucleation: Influence of solution conditions. Langmuir. 18, 3090.

Kumar, S. K., and K. P. Johnston. 1988. Modelling the solubility of solids in supercritical fluids with density as the independent variable. Journal of Supercritical Fluids. 1, 15.

Kumelan, J., A. P. S. Kamps, D. Tuma, and G. Maurer. 2006. Solubility of $\mathrm{H}_{2}$ in the ionic liquid [bmim] $\left[\mathrm{PF}_{6}\right]$. Journal of Chemical and Engineering Data. 51, 11.

Kuntz Jr., I. D., and W. Kauzmann. 1974. Hydration of proteins and polypeptides. Advances in Protein Chemistry. 28, 239.

Kurnik, R. T., and R. C. Reid. 1982. Solubility of solid mixtures in supercritical fluids. Fluid Phase Equilibria. 8, 93.

Kusalik, P. G., and G. N. Patey. 1987. The thermodynamic properties of electrolyte-solutions some formal results. Journal of Chemical Physics. 86, 5110.

Kusalik, P. G., and G. N. Patey. 1988. On the molecular theory of aqueous-electrolyte solutions .1. The solution of the RHNC approximation for models at finite concentration. Journal of Chemical Physics. 88, 7715.

Kwiatkowski, J., Z. Lisicki, and W. Majewski. 1984. An experimental-method for measuring solubilities of solids in supercritical fluids. Berichte der Bunsen-Gesellschaft-Physical Chemistry Chemical Physics. 88, 865.

Lado, F. 1964. Perturbation correction to radial distribution function. Physical Review A-General Physics. 135, 1013.

Lazaridis, T. 2002. Binding affinity and specificity from computational studies. Current Organic Chemistry. 6, 1319.

Lazaridis, T., A. Masunov, and F. Gandolfo. 2002. Contributions to the binding free energy of ligands to avidin and streptavidin. Proteins: Structure, Function, and Genetics. 47, 194.

Lebowitz, J. L., and J. K. Percus. 1961. Long-range correlations in a closed system with applications to nonuniform fluids. Physical Review. 122, 1675.

Lebowitz, J. L., and J. K. Percus. 1963. Asymptotic behavior of radial distribution function. Journal of Mathematical Physics. 4, 248. 
Lee, J. C., and S. N. Timasheff. 1981. The stabilization of proteins by sucrose. Journal of Biological Chemistry. 256, 7193.

Lee, M. E., and N. F. A. van der Vegt. 2005. A new force field for atomistic simulations of aqueous tertiary butanol solutions. Journal of Chemical Physics. 122, 114509.

Lepori, L., and E. Matteoli. 1997. Excess Gibbs energies of the ternary system ethanol + tetrahydrofuran + cyclohexane at 298.15 k. Fluid Phase Equilibria. 134, 113.

Lepori, L., and E. Matteoli. 1998. Excess volumes of the ternary system ethanol + tetrahydrofuran + cyclohexane at $298.15 \mathrm{k}$. Fluid Phase Equilibria. 145, 69.

Lepori, L., E. Matteoli, G. Conti, and P. Gianni. 1998. Excess Gibbs energies of the ternary system ethanol + N,N-dimethylformamide + cyclohexane at $298.15 \mathrm{k}$. Fluid Phase Equilibria. 153, 293.

Lepree, J. M., M. J. Mulski, and K. A. Connors. 1994. Solvent effects on chemical processes .6. The phenomenological model applied to the solubility of naphthalene and 4-nitroaniline in binary aqueous-organic solvent mixtures. Journal of the Chemical Society-Perkin Transactions 2, 1491.

Levelt Sengers, J. M. H. 1991. Solubility near the solvent's critical point. Journal of Supercritical Fluids. 4, 215.

Lewis, G. N. 1900a. A new conception of thermal pressure and a theory of solutions. Proceedings of the American Academy of Arts and Sciences. 36, 145.

Lewis, G. N. 1900b. A new view of the thermal pressure and theory of solutions. Zeitschrift für Physikalische Chemie. 35, 343.

Lewis, G. N. 1901. The law of physico-chemical change. Proceedings of the American Academy of Arts and Sciences. 37, 49.

Li, A., W. J. Doucette, and A. W. Andren. 1994. Estimation of aqueous solubility, octanol/water partition-coefficient, and Henry's law constant for polychlorinated-biphenyls using UNIFAC. Chemosphere. 29, 657.

Li, T. W., E. H. Chimowitz, and F. Munoz. 1995. First-order corrections to infinite dilution fugacity coefficients using computer-simulation. American Institute of Chemical Engineers Journal. 41, 2300.

Licence, P., and M. Poliakoff. 2008. An introduction to supercritical fluids: From bench scale to commercial plant. In New methodologies and techniques for a sustainable organic chemistry, Edited by A. Mordini and F. Faigl.

Lim, W. K., J. Rösgen, and S. W. Englander. 2009. Urea, but not guanidinium, destabilizes proteins by forming hydrogen bonds to the peptide group. Proceedings of the National Academy of Sciences of the United States of America. 106, 2595.

Lin, C.-L., and R. H. Wood. 1996. Prediction of the free energy of dilute aqueous methane, ethane, and propane at temperatures from 600 to 1200 degrees $\mathrm{C}$ and densities from 0 to $1 \mathrm{~g} \mathrm{~cm}^{-3}$ using molecular dynamics simulations. Journal of Physical Chemistry. 100, 16399.

Lin, T.-Y., and S. N. Timasheff. 1994. Why do some organisms use a urea-methylamine mixture as osmolyte? Thermodynamic compensation of urea and trimethylamine n-oxide interactions with protein. Biochemistry. 33, 12695.

Liu, H., and J. P. O'Connell. 1998. On the measurement of solute partial molar volumes in nearcritical fluids with supercritical fluid chromatography. Industrial and Engineering Chemistry Research. 37, 3323.

Liu, Y., and D. Bolen. 1995. The peptide backbone plays a dominant role in protein stabilization 
by naturally occurring osmolytes. Biochemistry. 34, 12884.

Longuet-Higgins, H. C. 1951. The statistical thermodynamics of multicomponent systems. Proceedings of the Royal Society of London. Series A. Mathematical and Physical Sciences. 205, 247.

Lupis, C. H. P. 1983. Chemical Thermodynamics of Materials. New York: North-Holland. Mackerell, A. D. 2004. Empirical force fields for biological macromolecules: Overview and issues. Journal of Computational Chemistry. 25, 1584.

Mackerell, A. D., D. Bashford, M. Bellott, R. L. Dunbrack, J. D. Evanseck, M. J. Field, S. Fischer, J. Gao, H. Guo, S. Ha, D. J. McCarthy, L. Kuchnir, K. Kuczera, F. T. K. Lau, C. Mattos, S. Michnick, T. Ngo, D. T. Nguyen, B. Prodhom, W. E. Reiher, B. Roux, M. Schlenkrich, J. C. Smith, R. Stote, J. Straub, M. Watanabe, J. Wiorkiewicz-Kuczera, D. Yin, and M. Karplus. 1998. All-atom empirical potential for molecular modeling and dynamics studies of proteins. Journal of Physical Chemistry B. 102, 3586.

Mackerell, A. D., M. Feig, and C. L. Brooks. 2004. Extending the treatment of backbone energetics in protein force fields: Limitations of gas-phase quantum mechanics in reproducing protein conformational distributions in molecular dynamics simulations. Journal of Computational Chemistry. 25, 1400.

Maerzke, K. A., N. E. Schultz, R. B. Ross, and J. I. Siepmann. 2009. TraPPE-UA force field for acrylates and monte carlo simulations for their mixtures with alkanes and alcohols. Journal of Physical Chemistry B. 113, 6415.

Majer, V., L. Hui, R. Crovetto, and R. H. Wood. 1991. Volumetric properties of aqueous 1-1 electrolyte-solutions near and above the critical-temperature of water. 1. Densities and apparent molar volumes of $\mathrm{NaCl}(a q)$ from $0.0025 \mathrm{~mol} \cdot \mathrm{kg}^{-1}$ to $3.1 \mathrm{~mol} \cdot \mathrm{kg}^{-1}, 604.4-\mathrm{K}$ to 725.5-K, and 18.5-MPa to 38.0-MPa. Journal of Chemical Thermodynamics. 23, 213.

Majer, V., J. Sedlbauer, and G. Bergin. 2008. Henry's law constant and related coefficients for aqueous hydrocarbons, $\mathrm{CO}_{2}$ and $\mathrm{H}_{2} \mathrm{~S}$ over a wide range of temperature and pressure. Fluid Phase Equilibria. 272, 65.

Mansoori, G. A., and J. F. Ely. 1985. Statistical mechanical theory of local compositions. Fluid Phase Equilibria. 22, 253.

Marcus, Y. 1983. A quasi-lattice quasi-chemical theory of preferential solvation of ions in mixed solvents. Australian Journal of Chemistry. 36, 1719.

Marcus, Y. 1989. Preferential solvation. Part 3. Binary solvent mixtures. Journal of the Chemical Society, Faraday Transactions 1: Physical Chemistry in Condensed Phases. 85, 381.

Marcus, Y. 1990. Preferential solvation in mixed solvents. Part 5. Binary mixtures of water and organic solvents. Journal of the Chemical Society, Faraday Transactions. 86, 2215.

Marcus, Y. 1991. Preferential solvation in mixed solvents. Part 6. Binary mixtures containing methanol, ethanol, acetone or triethylamine and another organic solvent. Journal of the Chemical Society, Faraday Transactions. 87, 1843.

Marcus, Y. 1995. Preferential solvation in mixed solvents. Part 7. Binary mixtures of water and alkanolamines. Journal of the Chemical Society, Faraday Transactions. 91, 427.

Marcus, Y. 1999. Preferential solvation in mixed solvents. Part 8. Aqueous methanol from subambient to elevated temperatures. Physical Chemistry Chemical Physics. 1, 2975.

Marcus, Y. 2001. Preferential solvation in mixed solvents. Part 10. Completely miscible aqueous co-solvent binary mixtures at 298.15 K. Monatshefte für Chemie. 132, 1387.

Marcus, Y. 2002a. Preferential solvation in mixed solvents. Part 11. Eight additional completely miscible aqueous co-solvent binary mixtures and the relationship between the volume- 
corrected preferential solvation parameters and the structures of the co-solvents. Physical Chemistry Chemical Physics. 4, 4462.

Marcus, Y. 2002b. Solvent Mixtures: Properties and selective Solvation. New York: Marcel Dekker, Inc.

Marcus, Y. 2003. Preferential solvation in mixed solvents. Part 12. Aqueous glycols. Journal of Molecular Liquids. 107, 109.

Marcus, Y. 2006a. Preferential solvation in mixed solvents. Part 13. Mixtures of tetrahydrofuran with organic solvents: Kirkwood-Buff. Journal of Solution Chemistry. 35, 251.

Marcus, Y. 2006b. Preferential solvation in mixed solvents. Part 14. Mixtures of 1,4-dioxane with organic solvents: Kirkwood-Buff integrals and volume-corrected preferential solvation parameters. Journal of Molecular Liquids. 128, 115.

Marcus, Y. 2008. Clustering in liquid mixtures of water and acetonitrile. In Solution Chemistry Research Progress, Edited by D. V. Bostrelli. New York: Nova Science Publishers, Inc.

Marcus, Y. 2011. Water structure enhancement in water-rich binary solvent mixtures. Journal of Molecular Liquids. 158, 23.

Marcus, Y. 2012. Water structure enhancement in water-rich binary solvent mixtures. Part 2. The excess partial molar heat capacity of the water. Journal of Molecular Liquids. 166, 62.

Marcus, Y., and Y. Migron. 1991. Polarity, hydrogen bonding, and structure of mixtures of water and cyanomethane. Journal of Physical Chemistry. 95, 400.

Marlow, G. E., and B. M. Pettitt. 1994. Studies of salt-peptide solutions: Theoretical and experimental approaches. In Advances in Computational Biology, Edited by H. O. Villar: Elsevier Science.

Martin, W., J. Baross, D. Kelley, and M. J. Russell. 2008. Hydrothermal vents and the origin of life. Nature Reviews Microbiology. 6, 805.

Mathias, P. M., and J. P. O'Connell. 1979. A predictive method for PVT and phase behavior of liquids containing supercritical components. In Equations of state in engineering and research: American Chemical Society.

Mathias, P. M., and J. P. O'Connell. 1981. Molecular thermodynamics of liquids containing supercritical compounds. Chemical Engineering Science. 36, 1123.

Matteoli, E. 1997. A study on Kirkwood-Buff integrals and preferential solvation in mixtures with small deviations from ideality and/or with size mismatch of components. Importance of a proper reference system. Journal of Physical Chemistry B. 101, 9800.

Matteoli, E., P. Gianni, and L. Lepori. 2010. Excess Gibbs energies of the ternary system 2methoxyethanol + tetrahydrofuran + cyclohexane and other relevant binaries at $298.15 \mathrm{~K}$. Journal of Chemical and Engineering Data. 55, 5441.

Matteoli, E., and L. Lepori. 1984. Solute solute interactions in water. 2. An analysis through the Kirkwood-Buff integrals for 14 organic solutes. Journal of Chemical Physics. 80, 2856.

Matteoli, E., and L. Lepori. 1990. The ternary system water + 1-propanol + urea at $298.15 \mathrm{~K}$. Activity coefficients, partial molal volumes and Kirkwood-Buff integrals. Journal of Molecular Liquids. 47, 89.

Matteoli, E., and L. Lepori. 1995. Kirkwood-Buff integrals and preferential solvation in ternary non-electrolyte mixtures. Journal of the Chemical Society, Faraday Transactions. 91, 431; Corrigendum: 91, 1885.

Matteoli, E., and L. Lepori. 2007. Comment on "A critique of some recent suggestions to correct the Kirkwood-Buff integrals". Journal of Physical Chemistry B. 111, 3069.

Matteoli, E., and L. Lepori. 2008. Reply to "Comment on 'The Kirkwood-Buff theory of 
solutions and the local composition of liquid mixtures'". Journal of Physical Chemistry B. $112,5878$.

Matteoli, E., and G. A. Mansoori. 1995. A simple expression for radial-distribution functions of pure fluids and mixtures. Journal of Chemical Physics. 103, 4672.

Matteoli, E., and G. A. Mansoori, Eds. 1990. Fluctuation Theory of Mixtures. Edited by G. A. Mansoori, Advances in Thermodynamics. New York: Taylor and Francis.

Mazo, R. M. 1958. Statistical mechanical theory of solutions. Journal of Chemical Physics. 29, 1122.

Mazo, R. M. 2006. A fluctuation theory analysis of the salting-out effect. Journal of Physical Chemistry B. 110, 24077.

Mazo, R. M. 2007. Salting out near the critical point. Journal of Physical Chemistry B. 111, 7288.

McGuigan, D. B., and P. A. Monson. 1990. Analysis of infinite dilution partial molar volumes using distribution function theory. Fluid Phase Equilibria. 57, 227.

McMillan, W. G., and J. E. Mayer. 1945. The statistical thermodynamics of multicomponent systems. Journal of Chemical Physics. 13, 276.

McNaught, A. D., and A. Wilkinson. 1997. IUPAC Compendium of Chemical Terminology: The Gold Book, $2^{\text {nd }}$ Ed.. Oxford: Blackwell Scienctific Publications.

Mecke, M., A. Muller, J. Winkelmann, J. Vrabec, J. Fischer, R. Span, and W. Wagner. 1996. An accurate van der Waals-type equation of state for the Lennard-Jones fluid. International Journal of Thermophysics. 17, 391.

Miyawaki, O. 2009. Thermodynamic analysis of protein unfolding in aqueous solutions as a multisite reaction of protein with water and solute molecules. Biophysical Chemistry. $144,46$.

Modell, M., and R. C. Reid. 1983. Thermodynamics and its Applications. 2nd Ed. Englewood Cliffs (New Jersey): Prentice Hall.

Morris, J. W., P. J. Mulvey, M. M. Abbott, and H. C. van Ness. 1975. Excess thermodynamic functions for ternary systems. I. Acetone-chloroform-methanol at 50 degrees. Journal of Chemical and Engineering Data. 20, 403.

Morris, K. R. 1988. Solubility of aromatic compounds in mixed solvents. Ph.D. Thesis, Pharmaceutical Sciences Graduate College, The University of Arizona.

Mota, F. L., A. J. Queimada, A. E. Andreatta, S. P. Pinho, and E. A. Macedo. 2012. Calculation of drug-like molecules solubility using predictive activity coefficient models. Fluid Phase Equilibria. 322, 48.

Mu, Y. G., D. S. Kosov, and G. Stock. 2003. Conformational dynamics of trialanine in water. 2. Comparison of Amber, CHARMM, GROMOS, and OPLS force fields to NMR and infrared experiments. Journal of Physical Chemistry B. 107, 5064.

Mukherji, D., N. F. A. van der Vegt, K. Kremer, and L. Delle Site. 2012. Kirkwood-Buff analysis of liquid mixtures in an open boundary simulation. Journal of Chemical Theory and Computation. 8, 375.

Muller, E. A., and K. E. Gubbins. 2001. Molecular-based equations of state for associating fluids: A review of saft and related approaches. Industrial and Engineering Chemistry Research. 40, 2193.

Munoz, F., and E. H. Chimowitz. 1993. Critical phenomena in mixtures. 2. Synergistic and other effects near mixture critical-points. Journal of Chemical Physics. 99, 5450.

Munoz, F., T. W. Li, and E. H. Chimowitz. 1995. Henry's law and synergism in dilute near- 
critical solutions - theory and simulation. American Institute of Chemical Engineers Journal. 41, 389.

Münster, A. 1969. Statistical Thermodynamics. Berlin: Springer-Verlag.

Münster, A. 1970. Classical Thermodynamics. London: Wiley-Interscience.

Myers, D. B., and R. L. Scott. 1963. Thermodynamic functions for nonelectrolyte solutions. Industrial and Engineering Chemistry. 55, 43.

Myers, J. K., C. N. Pace, and J. M. Scholtz. 1995. Denaturant $m$-values and heat-capacity changes - relation to changes in accessible surface-areas of protein unfolding. Protein Science. 4, 2138.

Nagata, I., and K. Miyazaki. 1992. Excess enthalpies of (aniline + propan-2-ol) and of (aniline + propan-2-ol + benzene) at the temperature $298.15 \mathrm{~K}$. Journal of Chemical Thermodynamics. 24, 1175.

Newman, K. E. 1994. Kirkwood-Buff solution theory - derivation and applications. Chemical Society Reviews. 23, 31.

Nichols, J. W., S. G. Moore, and D. R. Wheeler. 2009. Improved implementation of KirkwoodBuff solution theory in periodic molecular simulations. Physical Review E. 80, 051203.

Nikolova, P. V., S. J. B. Duff, P. Westh, et al. 2000. A thermodynamic study of aqueous acetonitrile: Excess chemical potentials, partial molar enthalpies, entropies and volumes, and fluctuations. Canadian Journal of Chemistry. 78, 1553.

Novák, J. P., J. Matouš, and J. Pick. 1987. Liquid-Liquid Equilibria. Amsterdam: Elsevier.

Nozaki, Y., and C. Tanford. 1963. The solubility of amino acids and related compounds in aqueous urea solutions. Journal of Biological Chemistry. 238, 4074.

Nymeyer, H. 2009. Energy landscape of the Trpzip2 peptide. Journal of Physical Chemistry B. $113,8288$.

O'Brien, E. P., G. Ziv, G. Haran, B. R. Brooks, and D. Thirumalai. 2008. Effects of denaturants and osmolytes on proteins are accurately predicted by the molecular transfer model. Proceedings of the National Academy of Sciences of the United States of America. 105, 13403.

O’Connell, J. P. 1971a. Molecular thermodynamics of gases in mixed solvents. American Institute of Chemical Engineers Journal. 17, 658.

O'Connell, J. P. 1971b. Thermodynamic properties of solutions based on correlation functions. Molecular Physics. 20, 27.

O'Connell, J. P. 1981. Thermodynamic properties of solutions and the theory of fluctuations. Fluid Phase Equilibria. 6, 21.

O'Connell, J. P. 1990. Thermodynamic properties of mixtures from fluctuation solution theory. In Fluctuation Theory of Mixtures, Edited by E. Matteoli and G. A. Mansoori. New York: Taylor and Francis.

O'Connell, J. P. 1993. Application of fluctuation solution theory to strong electrolyte-solutions. Fluid Phase Equilibria. 83, 233.

O'Connell, J. P. 1994. Thermodynamics and fluctuation solution theory with some applications to systems at near or supercritical conditions. In Part II: Fluctuations, crossover effects, transport properties. In Supercritical fluids: Fundamentals for Application, Edited by E. Kiran and J. M. H. Levelt Sengers. Dordrecht, The Netherlands: Klüwer Academic Publishers.

O'Connell, J. P. 1995. Application of fluctuation solution theory to thermodynamic properties of solutions. Fluid Phase Equilibria. 104, 21. 
O’Connell, J. P., and J. M. Haile. 2005. Thermodynamics: Fundamentals for Applications. New York: Cambridge University Press.

O’Connell, J. P., Y. Q. Hu, and K. A. Marshall. 1999. Aqueous strong electrolyte solution activity coefficients and densities from fluctuation solution theory. Fluid Phase Equilibria. 158, 583.

O'Connell, J. P., and H. Q. Liu. 1998. Thermodynamic modelling of near-critical solutions. Fluid Phase Equilibria. 144, 1.

O'Connell, J. P., and J. M. Prausnitz. 1964. Thermodynamics of gas solubility in mixed solvents. Industrial and Engineering Chemistry Fundamentals. 3, 347.

O'Connell, J. P., A. V. Sharygin, and R. H. Wood. 1996. Infinite dilution partial molar volumes of aqueous solutes over wide ranges of conditions. Industrial and Engineering Chemistry Research. 35, 2808.

O'Connell, J. P., and H. Q. Liu. 1998. Thermodynamic modelling of near-critical solutions. Fluid Phase Equilibria. 144, 1.

O'Connell, J. P., and R. Clairmont. 2010. Evaluation of equation of state combining and mixing rules with properties from fluctuation solution theory. Poster presented at the 12th international conference on properties and phase equilibria for product and process design. Suzhou, Jiangsu, China.

Oostenbrink, C., A. Villa, A. E. Mark, and W. F. van Gunsteren. 2004. A biomolecular force field based on the free enthalpy of hydration and solvation: The GROMOS force-field parameter sets 53a5 and 53a6. Journal of Computational Chemistry. 25, 1656.

Pace, C. N. 1986. Determination and analysis of urea and guanidine hydrochloride denaturation curves. In Methods in Enzymology. Enzyme Structure Part L, Edited by C. H. W. Hirs and S. N. Timasheff: Academic Press, Inc.

Pace, C. N., S. Trevino, E. Prabhakaran, and J. M. Scholtz. 2004. Protein structure, stability and solubility in water and other solvents. Philosophical Transactions of the Royal Society of London Series B-Biological Sciences. 359, 1225.

Paduszynski, K., and U. Domanska. 2012. A new group contribution method for prediction of density of pure ionic liquids over a wide range of temperature and pressure. Industrial and Engineering Chemistry Research. 51, 591.

Pappenberger, G., C. Saudan, M. Becker, A. E. Merbach, and T. Kiefhaber. 2000. Denaturantinduced movement of the transition state of protein folding revealed by high-pressure stopped-flow measurements. Proceedings of the National Academy of Sciences of the United States of America. 97, 17.

Parsegian, V. A., R. P. Rand, and D. C. Rau. 1995. Macromolecules and water: Probing with osmotic stress. Energetics of Biological Macromolecules. 259, 43.

Parsegian, V. A., R. P. Rand, and D. C. Rau. 2000. Osmotic stress, crowding, preferential hydration, and binding: A comparison of perspectives. Proceedings of the National Academy of Sciences of the United States of America. 97, 3987.

Paschek, D., R. Day, and A. E. Garcia. 2011. Influence of water-protein hydrogen bonding on the stability of Trp-cage miniprotein. A comparison between the TIP3P and TIP4P-Ew water models. Physical Chemistry Chemical Physics. 13, 19840.

Paschek, D., S. Hempel, and A. E. Garcia. 2008. Computing the stability diagram of the Trpcage miniprotein. Proceedings of the National Academy of Sciences of the United States of America. 105, 17754.

Paul, S., and G. Patey. 2007. Structure and interaction in aqueous urea-trimethylamine-N-oxide 
solutions. Journal of the American Chemical Society. 129, 4476.

Pauling, L., R. B. Corey, and H. R. Branson. 1951. The structure of proteins: Two hydrogenbonded helical configurations of the polypeptide chain. Proceedings of the National Academy of Sciences of the United States of America. 37, 205.

Pearson, F. J., and G. S. Rushbrooke. 1957. XX. On the theory of binary fluid mixtures. Proceedings of the Royal Society of Edinburgh, Section: A Mathematics. 64, 305.

Peng, D.-Y., and D. B. Robinson. 1976. A new two-constant equation of state. Industrial and Engineering Chemistry Fundamentals. 15, 59.

Perera, A. 2009. Bridge function and fundamental measure theory: A test in dimension one. Molecular Physics. 107, 2251.

Perera, A. 2011. On the microscopic structure of liquid water. Molecular Physics. 109, 2433.

Perera, A., B. Kežić, F. Sokolić, and L. Zoranić. 2012. Micro-heterogeneity in complex liquids. In Molecular Dynamics - Studies of Synthetic and Biological Macromolecules, Edited by L. Wang. Rijeka, Croatia: InTech.

Perera, A., R. Mazighi, and B. Kežić. 2012. Fluctuations and micro-heterogeneity in aqueous mixtures. Journal of Chemical Physics. 136, 174516.

Perera, A., and G. N. Patey. 1988. The solution of the hypernetted-chain and Percus-Yevick approximations for fluids of hard spherocylinders. Journal of Chemical Physics. 89, 5861.

Perera, A., and F. Sokolic. 2004. Modeling nonionic aqueous solutions: The acetone-water mixture. Journal of Chemical Physics. 121, 11272.

Perera, A., F. Sokolić, L. Almasy, and Y. Koga. 2006. Kirkwood-Buff integrals of aqueous alcohol binary mixtures. Journal of Chemical Physics. 124, 124515.

Perera, A., F. Sokolić, L. Almasy, P. Westh, and Y. Koga. 2005. On the evaluation of the Kirkwood-Buff integrals of aqueous acetone mixtures. Journal of Chemical Physics. 123, 024503.

Perera, A., L. Zoranić, F. Sokolić, and R. Mazighi. 2011. A comparative molecular dynamics study of water-methanol and acetone-methanol mixtures. Journal of Molecular Liquids. $159,52$.

Perkyns, J. S., Y. Wang, and B. M. Pettitt. 1996. Salting in peptides: Conformationally dependent solubilities and phase behavior of a tripeptide zwitterion in electrolyte solution. Journal of the American Chemical Society. 118, 1164.

Perry, R. L., H. Cabezas, and J. P. O'Connell. 1988. Fluctuation thermodynamic properties of strong electrolyte-solutions. Molecular Physics. 63, 189.

Perry, R. L., and J. P. O'Connell. 1984. Fluctuation thermodynamic properties of reactive components from species correlation-function integrals. Molecular Physics. 52, 137.

Perry, R. L., J. C. Telotte, and J. P. O'Connell. 1981. Solution thermodynamics for reactive components. Fluid Phase Equilibria. 5, 245.

Pettitt, B. M., and P. J. Rossky. 1986. Alkali halides in water: Ion-solvent correlations and ionion potentials of mean force at infinite dilution. Journal of Chemical Physics. 84, 5836.

Pfund, D. M., and H. D. Cochran. 1993. Chemical potentials in ternary supercritical fluid mixtures. In Supercritical Engineering Science. Fundamentals Studies and Applications, Edited by E. Kiran and J. F. Brennecke. Washington, DC: American Chemical Society.

Pierce, V., M. Kang, M. Aburi, S. Weerasinghe, and P. E. Smith. 2008. Recent applications of Kirkwood-Buff theory to biological systems. Cell Biochemistry and Biophysics. 50, 1.

Pitzer, K. S. 1995. Thermodynamics. New York: McGraw-Hill. 
Ploetz, E. A., N. Bentenitis, and P. E. Smith. 2010a. Developing force fields from the microscopic structure of solutions. Fluid Phase Equilibria. 290, 43.

Ploetz, E. A., N. Bentenitis, and P. E. Smith. 2010b. Kirkwood-Buff integrals for ideal solutions. Journal of Chemical Physics. 132, 164501.

Ploetz, E. A., and P. E. Smith. 2011a. A Kirkwood-Buff force field for the aromatic amino acids. Physical Chemistry Chemical Physics. 13, 18154.

Ploetz, E. A., and P. E. Smith. 2011b. Local fluctuations in solution mixtures. Journal of Chemical Physics. 135, 044506.

Plyasunov, A. V. 2011. Thermodynamics of $\mathrm{B}(\mathrm{OH})_{3}$ in the vapor phase of water: Vapor-liquid and Henry's constants, fugacity and second cross virial coefficients. Fluid Phase Equilibria. 305, 212.

Plyasunov, A. V., J. P. O'Connell, and R. H. Wood. 2000. Infinite dilution partial molar properties of aqueous solutions of nonelectrolytes. I. Equations for partial molar volumes at infinite dilution and standard thermodynamic functions of hydration of volatile nonelectrolytes over wide ranges of conditions. Geochimica et Cosmochimica Acta. 64, 495.

Plyasunov, A. V., J. P. O’Connell, R. H. Wood, and E. L. Shock. 2000. Infinite dilution partial molar properties of aqueous solutions of nonelectrolytes. II. Equations for the standard thermodynamic functions of hydration of volatile nonelectrolytes over wide ranges of conditions including subcritical temperatures. Geochimica et Cosmochimica Acta. 64, 2779.

Plyasunov, A. V., J. P. O'Connell, R. H. Wood, and E. L. Shock. 2001. Semiempirical equation of state for the infinite dilution thermodynamic functions of hydration of nonelectrolytes over wide ranges of temperature and pressure. Fluid Phase Equilibria. 183, 133.

Plyasunov, A. V., E. L. Shock, and J. P. O'Connell. 2006. Corresponding-states correlations for estimating partial molar volumes of nonelectrolytes at infinite dilution in water over extended temperature and pressure ranges. Fluid Phase Equilibria. 247, 18.

Pohorille, A., and L. R. Pratt. 1990. Cavities in molecular liquids and the theory of hydrophobic solubilities. Journal of the American Chemical Society. 112, 5066.

Poland, D. C., and H. A. Scheraga. 1965. Hydrophobic bonding and micelle stability. Journal of Physical Chemistry. 69, 2431.

Poling, B. E., J. M. Praunitz, and J. P. O'Connell. 2000. The Properties of Gases and Liquids. 5th Ed. New York: McGraw-Hill. Errata at http://www.che.virginia.edu/PGL5/.

Polishuk, I., and A. Mulero. 2011. The numerical challenges of SAFT EoS models. Reviews in Chemical Engineering. 27, 241.

Pratt, L. R., and D. Chandler. 1977. Theory of the hydrophobic effect. Journal of Chemical Physics. 67, 3683.

Prausnitz, J. M., R. N. Lichtenthaler, and E. Gomes de Azevedo. 1986. Molecular Thermodynamics of Fluid Phase Equilibria. 2nd. Ed. Englewood Cliffs: Prentice-Hall.

Prausnitz, J. M., R. N. Lichtenthaler, and E. Gomes de Azevedo. 1999. Molecular Thermodynamics of Fluid-Phase Equilibria. 3rd Ed., Prentice Hall International Series in the Physical and Chemical Engineering Sciences. Upper Saddle River, N.J.: PrenticeHall.

Press, W. H., S. A. Teukolsky, W. T. Vetterling, and B. P. Flannery. 1992. Numerical Recipes in C: The Art of Scientific Computing. 2nd Ed. Cambridge: Cambridge University Press.

Prigogine, I. with contributions from A. Bellemans and V. Mathot. 1957. The Molecular Theory 
of Solutions. Amsterdam: North-Holland Publishing Co.

Prigogine, I., and R. Dufay. 1954. Chemical Thermodynamics, Treatise on Thermodynamics. London; New York: Longmans, Green.

Puliti, G., S. Paolucci, and M. Sen. 2011. Thermodynamic properties of gold-water nanolayer mixtures using molecular dynamics. Journal of Nanoparticle Research. 13, 4277.

Qu, Y. X., C. L. Bolen, and D. W. Bolen. 1998. Osmolyte-driven contraction of a random coil protein. Proceedings of the National Academy of Sciences of the United States of America. 95, 9268.

Ramirez, R., M. Mareschal, and D. Borgis. 2005. Direct correlation functions and the density functional theory of polar solvents. Chemical Physics. 319, 261.

Raoult, F.-M. 1878. Vapour-tension and solidifying point of saline solutions. Comptes Rendus Hebdomadaires des Seances de l'Academie des Sciences. 87, 167.

Raoult, F.-M. 1882. Law of freezing of solvents. Comptes Rendus Hebdomadaires des Seances de l'Academie des Sciences. 95, 1030.

Raoult, F.-M. 1887. General law of the vapor pressure of solvents. Comptes Rendus Hebdomadaires des Seances de l'Academie des Sciences. 104, 1430.

Raoult, F.-M. 1888. Vapour-tensions of ethereal solutions. Zeitschrift für Physikalische Chemie, Stöchiometrie und Verwandtschaftslehre. 2, 353.

Rasaiah, J. C., and H. L. Friedman. 1968. Integral equation methods in the computation of equilibrium properties of ionic solutions. Journal of Chemical Physics. 48, 2742.

Reaves, J. T., and C. B. Roberts. 1999. Subcritical solvent effects on a parallel Diels-Alder reaction network. Industrial and Engineering Chemistry Research. 38, 855.

Record, M. T., W. T. Zhang, and C. F. Anderson. 1998. Analysis of effects of salts and uncharged solutes on protein and nucleic acid equilibria and processes: A practical guide to recognizing and interpreting polyelectrolyte effects, Hofmeister effects, and osmotic effects of salts. Advances in Protein Chemistry. 51, 281.

Redlich, O., and A. T. Kister. 1948. Thermodynamics of nonelectrolyte solutions $-x-y-T$ relations in a binary system. Industrial and Engineering Chemistry. 40, 341.

Ren, P. Y., C. J. Wu, and J. W. Ponder. 2011. Polarizable atomic multipole-based molecular mechanics for organic molecules. Journal of Chemical Theory and Computation. 7, 3143.

Retailleau, P., A. Ducruix, and M. Ries-Kautt. 2002. Importance of the nature of anions in lysozyme crystallisation correlated with protein net charge variation. Acta Crystallographica Section D-Biological Crystallography. 58, 1576.

Retailleau, P., M. Ries-Kautt, and A. Ducruix. 1997. No salting-in of lysozyme chloride observed at low ionic strength over a large range of pH. Biophysical Journal. 73, 2156.

Richards, J. P. 2011. Magmatic to hydrothermal metal fluxes in convergent and collided margins. Ore Geology Reviews. 40, 1.

Ries-Kautt, M. M., and A. F. Ducruix. 1989. Relative effectiveness of various ions on the solubility and crystal-growth of lysozyme. Journal of Biological Chemistry. 264, 745.

Roberts, C. B., J. F. Brennecke, and J. E. Chateauneuf. 1995. Solvation effects on reactions of triplet benzophenone in supercritical fluids. American Institute of Chemical Engineers Journal. 41, 1306.

Roberts, C. B., J. W. Zhang, J. E. Chateauneuf, and J. F. Brennecke. 1995. Laser flash-photolysis and integral-equation theory to investigate reactions of dilute solutes with oxygen in supercritical fluids. Journal of the American Chemical Society. 117, 6553.

Robinson, C. R., S. G. Sligar, M. L. Johnson, and G. K. Ackers. 1995. Hydrostatic and osmotic 
pressure as tools to study macromolecular recognition. Energetics of Biological Macromolecules. 259, 395.

Romankiw, L. A., and I. M. Chou. 1983. Densities of aqueous $\mathrm{NaCl}, \mathrm{KCl}, \mathrm{MgCl}_{2}$, and $\mathrm{CaCl}_{2}$ binary-solutions in the concentration range $0.5-6.1-\mathrm{m}$ at 25-degrees-C, 30-degrees-C, 35degrees-C, 40-degrees-C, and 45-degrees-C. Journal of Chemical and Engineering Data. 28,300 .

Romero, S., A. Reillo, B. Escalera, and P. Bustamante. 1996. The behavior of paracetamol in mixtures of amphiprotic and amphiprotic-aprotic solvents. Relationship of solubility curves to specific and nonspecific interactions. Chemical and Pharmaceutical Bulletin. 44, 1061.

Rose, G., P. Fleming, J. Banavar, and A. Maritan. 2006. A backbone-based theory of protein folding. Proceedings of the National Academy of Sciences of the United States of America. 103, 16623.

Rosenberg, R. M., and W. L. Peticolas. 2004. Henry's law: A retrospective. Journal of Chemical Education. 81, 1647.

Rösgen, J., B. M. Pettitt, and D. W. Bolen. 2004. Uncovering the basis for nonideal behavior of biological molecules. Biochemistry. 43, 14472.

Rösgen, J., B. M. Pettitt, and D. W. Bolen. 2005. Protein folding, stability, and solvation structure in osmolyte solutions. Biophysical journal. 89, 2988.

Rösgen, J., B. M. Pettitt, J. Perkyns, and D. W. Bolen. 2004. Statistical thermodynamic approach to the chemical activities in two-component solutions. Journal of Physical Chemistry B. $108,2048$.

Rossky, P. J. 2008. Protein denaturation by urea: Slash and bond. Proceedings of the National Academy of Sciences of the United States of America. 105, 16825.

Rowlinson, J. S., and F. L. Swinton. 1982. Liquids and Liquid Mixtures. 3rd Ed. London: Butterworth Scientific.

Ruckenstein, E., and I. Shulgin. 2002a. The solubility of solids in mixtures composed of a supercritical fluid and an entrainer. Fluid Phase Equilibria. 200, 53.

Ruckenstein, E., and I. L. Shulgin. 2001a. Effect of a third component on the interactions in a binary mixture determined from the fluctuation theory of solutions. Fluid Phase Equilibria. 180, 281.

Ruckenstein, E., and I. L. Shulgin. 2001b. Entrainer effect in supercritical mixtures. Fluid Phase Equilibria. 180, 345.

Ruckenstein, E., and I. L. Shulgin. 2002b. Salting-out or -in by fluctuation theory. Industrial and Engineering Chemistry Research. 41, 4674.

Ruckenstein, E., and I. L. Shulgin. 2003a. Ideal multicomponent liquid solution as a mixed solvent. Industrial and Engineering Chemistry Research. 42, 4406.

Ruckenstein, E., and I. L. Shulgin. 2003b. Solubility of drugs in aqueous solutions. Part 1: Ideal mixed solvent approximation. International Journal of Pharmaceutics. 258, 193.

Ruckenstein, E., and I. L. Shulgin. 2003c. Solubility of drugs in aqueous solutions. Part 2: Binary nonideal mixed solvent. International Journal of Pharmaceutics. 260, 283.

Ruckenstein, E., and I. L. Shulgin. 2003d. Solubility of drugs in aqueous solutions. Part 3: Multicomponent mixed solvent. International Journal of Pharmaceutics. 267, 121.

Ruckenstein, E., and I. L. Shulgin. 2004. Solubility of drugs in aqueous solutions. Part 4: Drug solubility by the dilute approximation. International Journal of Pharmaceutics. 278, 221.

Ruckenstein, E., and I. L. Shulgin. 2005. Solubility of hydrophobic organic pollutants in binary 
and multicomponent aqueous solvents. Environmental Science and Technology. 39, 1623. Ruckenstein, E., and I. L. Shulgin. 2006. Effect of salts and organic additives on the solubility of proteins in aqueous solutions. Advances in Colloid and Interface Science. 123, 97.

Ruckenstein, E., and I. L. Shulgin, Eds. 2009. Thermodynamics of Solutions: From Gases to Pharmaceutics to Proteins. Dordrecht: Springer.

Salacuse, J. J., A. R. Denton, and P. A. Egelstaff. 1996. Finite-size effects in molecular dynamics simulations: Static structure factor and compressibility. 1. Theoretical method. Physical Review E. 53, 2382.

Sasahara, K., M. Sakurai, and K. Nitta. 2001. Pressure effect on denaturant-induced unfolding of hen egg white lysozyme. Proteins: Structure, Function, and Genetics. 44, 180.

Sasahara, K., N. Sakurai, and K. Nitta. 1999. The volume and compressibility changes of lysozyme associated with guanidinium chloride and pressure-assisted unfolding. Journal of Molecular Biology. 291, 693.

Savage, P. E., S. Golapan, T. I. Mizan, C. J. Martino, and E. E. Brock. 1995. Reactions at supercritical conditions: Applications and fundamentals. American Institute of Chemical Engineers Journal. 41, 1723.

Schachman, H. K., and M. A. Lauffer. 1949. The hydration, size and shape of tobacco mosaic virus. Journal of the American Chemical Society. 71, 536.

Schellman, J. A. 1987. Selective binding and solvent denaturation. Biopolymers. 26, 549.

Schmid, B., and J. Gmehling. 2012. Revised parameters and typical results of the VTPR group contribution equation of state. Fluid Phase Equilibria. 317, 110.

Schmid, N., A. P. Eichenberger, A. Choutko, S. Riniker, M. Winger, A. E. Mark, and W. F. van Gunsteren. 2011. Definition and testing of the GROMOS force-field versions 54A7 and 54B7. European Biophysics Journal with Biophysics Letters. 40, 843.

Schnell, S. K., X. Liu, J.-M. Simon, A. Bardow, D. Bedeaux, T. J. H. Vlugt, and S. Kjelstrup. 2011. Calculating thermodynamic properties from fluctuations at small scales. Journal of Physical Chemistry B. 115, 10911.

Schoen, M., and C. Hoheisel. 1984. The mutual diffusion coefficient- $D_{12}$ in binary-liquid model mixtures - molecular-dynamics calculations based on Lennard-Jones (12-6) potentials. 1. The method of determination. Molecular Physics. 52, 33.

Sedlbauer, J., J. P. O'Connell, and R. H. Wood. 2000. A new equation of state for correlation and prediction of standard molal thermodynamic properties of aqueous species at high temperatures and pressures. Chemical Geology. 163, 43.

Sedlbauer, J., E. M. Yezdimer, and R. H. Wood. 1998. Partial molar volumes at infinite dilution in aqueous solutions of $\mathrm{NaCl}, \mathrm{LiCl}, \mathrm{NaBr}$, and $\mathrm{CsBr}$ at temperatures from $550 \mathrm{~K}$ to 725 K. Journal of Chemical Thermodynamics. 30, 3.

Shimizu, S. 2004. Estimating hydration changes upon biomolecular reactions from osmotic stress, high pressure, and preferential hydration experiments. Proceedings of the National Academy of Sciences of the United States of America. 101, 1195.

Shimizu, S. 2011. Molecular origin of the cosolvent-induced changes in the thermal stability of proteins. Chemical Physics Letters. 514, 156.

Shimizu, S., and C. L. Boon. 2004. The Kirkwood-Buff theory and the effect of cosolvents on biochemical reactions. Journal of Chemical Physics. 121, 9147.

Shimizu, S., and N. Matubayasi. 2006. Preferential hydration of proteins: A Kirkwood-Buff approach. Chemical Physics Letters. 420, 518.

Shimizu, S., W. M. McLaren, and N. Matubayasi. 2006. The Hofmeister series and protein-salt 
interactions. Journal of Chemical Physics. 124, 234905.

Shukla, D., and B. L. Trout. 2011. Understanding the synergistic effect of arginine and glutamic acid mixtures on protein solubility. Journal of Physical Chemistry B. 115, 11831.

Shulgin, I., and E. Ruckenstein. 2002a. The solubility of binary mixed gases by the fluctuation theory. Industrial and Engineering Chemistry Research. 41, 6279.

Shulgin, I. L., and E. Ruckenstein. 2002b. Henry's constant in mixed solvents from binary data. Industrial and Engineering Chemistry Research. 41, 1689.

Shulgin, I. L., and E. Ruckenstein. 2003. Prediction of gas solubility in binary polymer plus solvent mixtures. Polymer. 44, 901.

Shulgin, I. L., and E. Ruckenstein. 2005a. A protein molecule in an aqueous mixed solvent: Fluctuation theory outlook. Journal of Chemical Physics. 123, 054909.

Shulgin, I. L., and E. Ruckenstein. 2005b. Relationship between preferential interaction of a protein in an aqueous mixed solvent and its solubility. Biophysical Chemistry. 118, 128.

Shulgin, I. L., and E. Ruckenstein. 2006a. The Kirkwood-Buff theory of solutions and the local composition of liquid mixtures. Journal of Physical Chemistry B. 110, 12707.

Shulgin, I. L., and E. Ruckenstein. 2006b. Preferential hydration and solubility of proteins in aqueous solutions of polyethylene glycol. Biophysical Chemistry. 120, 188.

Shulgin, I. L., and E. Ruckenstein. 2008a. Excess around a central molecule with application to binary mixtures. Physical Chemistry Chemical Physics. 10, 1097.

Shulgin, I. L., and E. Ruckenstein. 2008b. Reply to "Comment on 'The Kirkwood-Buff theory of solutions and the local composition of liquid mixtures"'. Journal of Physical Chemistry B. $112,5876$.

Simnick, J. J., H. M. Sebastian, H. M. Lin, and K. C. Chao. 1979a. Gas-liquid equilibrium in mixtures of methane+m-xylene, and methane-meta-cresol. Fluid Phase Equilibria. 3, 145.

Simnick, J. J., H. M. Sebastian, H. M. Lin, and K. C. Chao. 1979b. Vapor-liquid-equilibrium in methane + quinoline mixtures at elevated-temperatures and pressures. Journal of Chemical and Engineering Data. 24, 239.

Smit, B. 1992. Phase-diagrams of Lennard-Jones fluids. Journal of Chemical Physics. 96, 8639.

Smith, P. E. 2004. Cosolvent interactions with biomolecules: Relating computer simulation data to experimental thermodynamic data. Journal of Physical Chemistry B. 108, 18716.

Smith, P. E. 2006a. Chemical potential derivatives and preferential interaction parameters in biological systems from Kirkwood-Buff theory. Biophysical Journal. 91, 849.

Smith, P. E. 2006b. Equilibrium dialysis data and the relationships between preferential interaction parameters for biological systems in terms of Kirkwood-Buff integrals. Journal of Physical Chemistry B. 110, 2862.

Smith, P. E. 2008. On the Kirkwood-Buff inversion procedure. Journal of Chemical Physics. 129, 124509.

Smith, P. E., G. E. Marlow, and B. M. Pettitt. 1993. Peptides in ionic-solutions - A simulation study of a bis(penicillamine) enkephalin in sodium-acetate solution. Journal of the American Chemical Society. 115, 7493.

Smith, P. E., and R. M. Mazo. 2008. On the theory of solute solubility in mixed solvents. Journal of Physical Chemistry B. 112, 7875.

Smith, P. E., and B. M. Pettitt. 1991. Effects of salt on the structure and dynamics of the bis(penicillamine) enkephalin zwitterion - a simulation study. Journal of the American Chemical Society. 113, 6029. 
Smith, P. E., and B. M. Pettitt. 1992. Amino-acid side-chain populations in aqueous and saline solution: bis-penicillamine enkephalin. Biopolymers. 32, 1623.

Soper, A. K., L. Dougan, J. Crain, and J. L. Finney. 2006. Excess entropy in alcohol-water solutions: A simple clustering explanation. Journal of Physical Chemistry B. 110, 3472.

Staples, B. R., and R. L. Nuttall. 1977. Activity and osmotic coefficients of aqueous calciumchloride at 298.15-K. Journal of Physical and Chemical Reference Data. 6, 385.

Steinfeld, J. I., J. S. Francisco, and W. L. Hase. 1989. Chemical Kinetics and Dynamics. Englewood Cliffs: Prentice Hall.

Stell, G., G. N. Patey, and J. S. Høye. 1981. Dielectric constants of fluid models: Statistical mechanical theory and its quantitative implementation. Advances in Chemical Physics. $48,183$.

Stockmayer, W. H. 1950. Light scattering in multi-component systems. Journal of Chemical Physics. 18, 58.

Stradner, A., H. Sedgwick, F. Cardinaux, W. C. K. Poon, S. U. Egelhaaf, and P. Schurtenberger. 2004. Equilibrium cluster formation in concentrated protein solutions and colloids. Nature. 432, 492.

Tanford, C. 1964. Isothermal unfolding of globular proteins in aqueous urea solutions. Journal of American Chemical Society. 86, 2050.

Tanford, C. 1974. Thermodynamics of micelle formation: Prediction of micelle size and size distribution. Proceedings of the National Academy of Sciences. 71, 1811.

Tanford, C. 1997. How protein chemists learned about the hydrophobic factor. Protein Science. 6, 1358.

Teubner, M., and R. Strey. 1987. Origin of the scattering peak in microemulsions. Journal of Chemical Physics. 87, 3195.

Teufel, D. P., C. M. Johnson, J. K. Lum, and H. Neuweiler. 2011. Backbone-driven collapse in unfolded protein chains. Journal of Molecular Biology. 409, 250.

Theodorou, D. N., and U. W. Suter. 1985. Geometrical considerations in model systems with periodic boundaries. Journal of Chemical Physics. 82, 955.

Timasheff, S. N. 1992. A physicochemical basis for the selection of osmolytes by nature. In Water and Life: Comparative Analysis of Water Relationships at the Organismic, Cellular, and Molecular Levels Edited by G. N. Somero, C. B. Osmond and C. L. Bolis. Berlin: Springer-Verlag.

Timasheff, S. N. 1993. The control of protein stability and association by weak-interactions with water - how do solvents affect these processes? Annual Review of Biophysics and Biomolecular Structure. 22, 67.

Timasheff, S. N. 1998a. Control of protein stability and reactions by weakly interacting cosolvents: The simplicity of the complicated. Advances in Protein Chemistry. 51, 355.

Timasheff, S. N. 1998b. In disperse solution, "osmotic stress" is a restricted case of preferential interactions. Proceedings of the National Academy of Sciences of the United States of America. 95, 7363.

Timasheff, S. N. 2002a. Protein-solvent preferential interactions, protein hydration, and the modulation of biochemical reactions by solvent components. Proceedings of the National Academy of Sciences of the United States of America. 99, 9721.

Timasheff, S. N. 2002b. Protein hydration, thermodynamic binding, and preferential hydration. Biochemistry. 41, 13473.

Timasheff, S. N., and T. Arakawa. 1988. Mechanism of protein precipitation and stabilization by 
co-solvents. Journal of Crystal Growth. 90, 39.

Timasheff, S. N., and T. Arakawa. 1989. Stabilization of protein structure by solvents. In Protein Structure: A Practical Approach, Edited by T. E. Creighton. Oxford: IRL Press at Oxford University Press.

Timasheff, S. N., and G. F. Xie. 2003. Preferential interactions of urea with lysozyme and their linkage to protein denaturation. Biophysical Chemistry. 105, 421.

Tokunaga, J. 1975. Solubilities of oxygen, nitrogen, and carbon-dioxide in aqueous alcohol solutions. Journal of Chemical and Engineering Data. 20, 41.

Tolmachev, V. V. 1960. Relationship between the statistic variation principle and the method of forming partial sums for diagrams in the thermodynamic perturbation theory for a modified statement of the problem of bose-einstein non-ideal system. Doklady Akademii Nauk USSR. 134, 1324.

Tran, H. T., A. Mao, and R. V. Pappu. 2008. Role of backbone-solvent interactions in determining conformational equilibria of intrinsically disordered proteins. Journal of the American Chemical Society. 130, 7380.

Treece, J. M., R. S. Sheinson, and T. L. McMeekin. 1964. Solubilities of $\beta$-lactoglobulins A, B, and AB. Archives of Biochemistry and Biophysics. 108, 99.

Treiner, C., P. Tzias, M. Chemla, and G. M. Poltoratskii. 1976. Solvation of tetrabutylammonium bromide in water + acetonitrile mixtures at $298.15 \mathrm{~K}$ from vapour pressure measurements of dilute solutions. Journal of the Chemical Society, Faraday Transactions 1: Physical Chemistry in Condensed Phases. 72, 2007.

Treszczanowicz, T., A. J. Treszczanowicz, T. Kasprzycka-Guttman, and A. Kulesza. 2001. Solubility of $\beta$-carotene in binary solvents formed by some hydrocarbons with ketones. Journal of Chemical and Engineering Data. 46, 792.

Uversky, V. N., C. J. Oldfield, and A. K. Dunker. 2005. Showing your ID: Intrinsic disorder as an ID for recognition, regulation and cell signaling. Journal of Molecular Recognition. $18,343$.

Valdeavella, C. V., J. S. Perkyns, and B. M. Pettitt. 1994. Investigations into the common ion effect. Journal of Chemical Physics. 101, 5093.

van't Hoff, J. H. 1887. Die rolle des osmotischen druckes in der analogie zwischen lösungen und gasen. Zeitschrift für Physikalische Chemie, Stöchiometrie und Verwandtschaftslehre. 1, 481.

van't Hoff, J. H. 1894. How the theory of solutions arose. Berichte der Deutschen Chemischen Gesellschaft. 27, 6.

van Alsten, J. G., and C. A. Eckert. 1993. Effect of entrainers and of solute size and polarity in supercritical-fluid solutions. Journal of Chemical and Engineering Data. 38, 605.

van Ness, H. C. 1995. Thermodynamics in the treatment of vapor/liquid equilibrium (vle) data. Pure and Applied Chemistry. 67, 859.

van Ness, H. C., and M. M. Abbott. 1982. Classical Thermodynamics of Nonelectrolyte Solutions: With Applications to Phase Equilibria. New York: McGraw Hill.

Vergara, A., L. Paduano, F. Capuano, and R. Sartorio. 2002. Kirkwood-Buff integrals for polymer-solvent mixtures. Preferential solvation and volumetric analysis in aqueous peg solutions. Physical Chemistry Chemical Physics. 4, 4716.

Verlet, L. 1968. Computer experiments on classical fluids. 2. Equilibrium correlation functions. Physical Review. 165, 201.

Vlcek, L., A. A. Chialvo, and D. R. Cole. 2011. Optimized unlike-pair interactions for water- 
carbon dioxide mixtures described by the SPC/E and EPM2 models. Journal of Physical Chemistry B. 115, 8775.

Wallas, S. M. 1985. Phase Equilibria in Chemical Engineering. Boston: ButterworthHeinemann.

Wang, J. M., P. Cieplak, and P. A. Kollman. 2000. How well does a restrained electrostatic potential (RESP) model perform in calculating conformational energies of organic and biological molecules? Journal of Computational Chemistry. 21, 1049.

Wang, S. S., C. G. Gray, P. A. Egelstaff, and K. E. Gubbins. 1973. Monte-Carlo study of pair correlation-function for a liquid with non-central forces. Chemical Physics Letters. 21, 123.

Wang, W., O. Donini, C. M. Reyes, and P. A. Kollman. 2001. Biomolecular simulations: Recent developments in force fields, simulations of enzyme catalysis, protein-ligand, proteinprotein, and protein-nucleic acid noncovalent interactions. Annual Review of Biophysics and Biomolecular Structure. 30, 211.

Wedberg, N. H. R. I. 2011. Molecular modeling of enzyme dynamics towards understanding solvent effects. Ph.D. Thesis, DTU Chemical Engineering, Technical University of Denmark, Kongens Lyngby.

Wedberg, R., J. Abildskov, and G. H. Peters. 2012. Protein dynamics in organic media at varying water activity studied by molecular dynamics simulation. Journal of Physical Chemistry B. 116, 2575.

Wedberg, R., J. P. O’Connell, G. H. Peters, and J. Abildskov. 2010. Accurate Kirkwood-Buff integrals from molecular simulations. Molecular Simulation. 36, 1243.

Wedberg, R., J. P. O'Connell, G. H. Peters, and J. Abildskov. 2011a. Pair correlation function integrals: Computation and use. Journal of Chemical Physics. 135, 084113.

Wedberg, R., J. P. O'Connell, G. H. Peters, and J. Abildskov. 2011b. Total and direct correlation function integrals from molecular simulation of binary systems. Fluid Phase Equilibria. $302,32$.

Wedberg, R., G. H. Peters, and J. Abildskov. 2008. Total correlation function integrals and isothermal compressibilities from molecular simulations. Fluid Phase Equilibria. 273, 1.

Weerasinghe, S., M. B. Gee, M. Kang, N. Bentenitis, and P. E. Smith. 2010. Developing force fields from the microscopic structure of solutions: The Kirkwood-Buff approach. In Modeling solvent environments: Wiley-VCH Verlag GmbH and Co. KGaA.

Weerasinghe, S., and B. M. Pettitt. 1994. Ideal chemical-potential contribution in moleculardynamics simulations of the grand-canonical ensemble. Molecular Physics. 82, 897.

Weerasinghe, S., and P. E. Smith. 2003a. Cavity formation and preferential interactions in urea solutions: Dependence on urea aggregation. Journal of Chemical Physics. 118, 5901.

Weerasinghe, S., and P. E. Smith. 2003b. Kirkwood-Buff derived force field for mixtures of acetone and water. Journal of Chemical Physics. 118, 10663.

Weerasinghe, S., and P. E. Smith. 2003c. A Kirkwood-Buff derived force field for mixtures of urea and water. Journal of Physical Chemistry B. 107, 3891.

Weerasinghe, S., and P. E. Smith. 2003d. A Kirkwood-Buff derived force field for sodium chloride in water. Journal of Chemical Physics. 119, 11342.

Weerasinghe, S., and P. E. Smith. 2004. A Kirkwood-Buff derived force field for the simulation of aqueous guanidinium chloride solutions. Journal of Chemical Physics. 121, 2180.

Weerasinghe, S., and P. E. Smith. 2005. A Kirkwood-Buff derived force field for methanol and aqueous methanol solutions. Journal of Physical Chemistry B. 109, 15080. 
Weinreb, P. H., W. Zhen, A. Poon, K. A. Conway, and P. T. Lansbury. 1996. NACP, a protein implicated in Alzheimer's disease and learning, is natively unfolded. Biochemistry. 35, 13709.

Weinstein, R. D., A. R. Renslo, R. L. Danheiser, J. G. Harris, and J. W. Tester. 1996. Kinetic correlation of Diels-Alder reactions in supercritical carbon dioxide. Journal of Physical Chemistry. 100, 12337.

Wen, X.-G. 2004. Quantum Field Theory of Many-Body Systems: From the Origin of Sound to an Origin of Light and Electrons. Oxford: Oxford University Press.

Wheeler, D. R., and J. Newman. 2004a. Molecular dynamics simulations of multicomponent diffusion. 1. Equilibrium method. Journal of Physical Chemistry B. 108, 18353.

Wheeler, D. R., and J. Newman. 2004b. Molecular dynamics simulations of multicomponent diffusion. 2. Nonequilibrium method. Journal of Physical Chemistry B. 108, 18362.

Widom, B. 1963. Some topics in the theory of fluids. Journal of Chemical Physics. 39, 2808.

Wienke, G., and J. Gmehling. 1998. Prediction of octanol-water partition coefficients, Henry coefficients, and water solubilities using UNIFAC. Toxicological and Environmental Chemistry. 65, 57.

Wiggins, P. 2008. Life depends upon two kinds of water. PLoS One. 3, e1406.

Wilczek-Vera, G., and J. H. Vera. 2011. The activity of individual ions. A conceptual discussion of the relation between the theory and the experimentally measured values. Fluid Phase Equilibria. 312, 79.

Wilhelm, E., R. Battino, and R. J. Wilcock. 1977. Low-pressure solubility of gases in liquid water. Chemical Reviews. 77, 219.

Williams, J. R., and A. A. Clifford, Eds. 2000. Supercritical fluid methods and protocols. Edited by J. M. Waker, Methods in Biotechnology. Totowa, New Jersey, USA: Humana Press Inc.

Wilson, G. M. 1964. Vapor-liquid equilibrium. XI. A new expression for the excess free energy of mixing. Journal of the American Chemical Society. 86, 127.

Wong, D. S. H., and S. I. Sandler. 1992. A theoretically correct mixing rule for cubic equations of state. American Institute of Chemical Engineers Journal. 38, 671.

Wooley, R. J., and J. P. O'Connell. 1991. A database of fluctuation thermodynamic properties and molecular correlation-function integrals for a variety of binary liquids. Fluid Phase Equilibria. 66, 233.

Wrabl, J., and D. Shortle. 1999. A model of the changes in denatured state structure underlying m value effects in staphylococcal nuclease. Nature Structural Biology. 6, 876.

Wright, P. E., and H. J. Dyson. 1999 Intrinsically unstructured proteins: Re-assessing the protein structure-function paradigm. Journal of Molecular Biology. 293, 321.

Wyman, J. 1964. Linked functions and reciprocal effects in hemoglobin - A 2nd look. Advances in Protein Chemistry. 19, 223.

Yalkowsky, S. H., and T. J. Roseman. 1981. Solubilization of drugs by cosolvents. In Techniques of Solubilization of Drugs, Edited by S. H. Yalkowsky. New York: Marcel Dekker.

Yancey, P., M. Clark, S. Hand, R. Bowlus, and G. Somero. 1982. Living with water stress: Evolution of osmolyte systems. Science. 217, 1214.

Yesodharan, S. 2002. Supercritical water oxidation: An environmentally safe method for the disposal of organic wastes. Current Science. 82, 1112.

Zeck, S., and H. Knapp. 1985. Solubilities of ethylene, ethane, and carbon-dioxide in mixed- 
solvents consisting of methanol, acetone, and water. International Journal of Thermophysics. 6, 643.

Zhang, C., and J. P. Ma. 2010. Enhanced sampling and applications in protein folding in explicit solvent. Journal of Chemical Physics. 132, 16.

Zhang, W. T., M. W. Capp, J. P. Bond, C. F. Anderson, and M. T. Record. 1996.

Thermodynamic characterization of interactions of native bovine serum albumin with highly excluded (glycine betaine) and moderately accumulated (urea) solutes by a novel application of vapor pressure osmometry. Biochemistry. 35, 10506.

Zhong, Y., and S. Patel. 2010. Nonadditive empirical force fields for short-chain linear alcohols: Methanol to butanol. Hydration free energetics and Kirkwood-Buff analysis using charge equilibration models. Journal of Physical Chemistry B. 114, 11076.

Zhu, X., P. E. M. Lopes, and A. D. Mackerell, Jr. 2012. Recent developments and applications of the CHARMM force fields. Wiley Interdisciplinary Reviews-Computational Molecular Science. 2, 167.

Zielkiewicz, J. 1995a. Kirkwood-Buff integrals in the binary and ternary mixtures containing heptane and aliphatic alcohol. Journal of Physical Chemistry. 99, 3357.

Zielkiewicz, J. 1995b. Solvation of DMF in the $N, N$-dimethylformamide + alcohol + water mixtures investigated by means of the Kirkwood-Buff integrals. Journal of Physical Chemistry. 99, 4787.

Zoranić, L., R. Mazighi, F. Sokolić, and A. Perera. 2009. Concentration fluctuations and microheterogeneity in aqueous amide mixtures. Journal of Chemical Physics. 130, 124315.

Zou, Q., B. J. Bennion, V. Daggett, and K. P. Murphy. 2002. The molecular mechanism of stabilization of proteins by TMAO and its ability to counteract the effects of urea. Journal of the American Chemical Society. 124, 1192. 